\title{
MASTER
}

$U C-20 D$

\section{PERFORMANCE ANALYSES OF ELMO BUMPY TORUS PLASMAS AND PLASMA SUPPORT SYSTEMS}

\author{
MAX E, FENSTERMACHER \\ UNIVERSITY OF MICHIGAN \\ NUCLEAR ENGINEERING DEPARTMENT
}

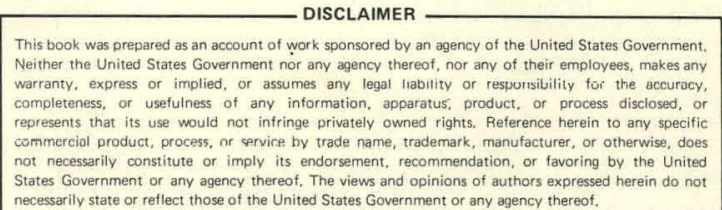

COOPERATIVE GRADUATE EDUCATION PROGRAM IN FUSION TECHNOLOGY

ADMINISTERED FOR THE U.S. DEPARTMENT OF ENERGY

BY THE WESTINGHOUSE ELECTRIC CORPORATION

CONTRACT EG-77-C-02-4231-A000 


\section{DISCLAIMER}

This report was prepared as an account of work sponsored by an agency of the United States Government. Neither the United States Government nor any agency Thereof, nor any of their employees, makes any warranty, express or implied, or assumes any legal liability or responsibility for the accuracy, completeness, or usefulness of any information, apparatus, product, or process disclosed, or represents that its use would not infringe privately owned rights. Reference herein to any specific commercial product, process, or service by trade name, trademark, manufacturer, or otherwise does not necessarily constitute or imply its endorsement, recommendation, or favoring by the United States Government or any agency thereof. The views and opinions of authors expressed herein do not necessarily state or reflect those of the United States Government or any agency thereof. 


\section{DISCLAIMER}

Portions of this document may be illegible in electronic image products. Images are produced from the best available original document. 


\section{ACKNOWLEDGEMENT}

This work was performed for the U.S. Department of Energy, under Contract EG-77-C-02-4231-A000, Cooperative Graduate Education Program in Fusion Technology. Reproduction, translation, publication, use and disposal, in whole or in part, by or for the United States Government is permitted.

The author would like to thank the Westinghouse Fusion Power Systems personnel, especially Dr. D. Klein, for the opportunity to participate in this program. Special thanks to G. Gibson, D. Sink, and E. Iwinski for their assistance and guidance during the project and their helpful comments during the preparation of this report. Much thanks also to fellow graduate students Mark Griffis, Carol Johnson, and Dave McDaniel for their support and understanding during this work. In addition, thanks to Professor T. Kammash, University of Michigan for his support during this time. Finally, my deep appreciation to Yvonne Harlow for all of her efforts and support during my participation in this program.

\section{NOTICE}

This report was prepared as an account of work sponsored by an agency of the United States Government. Neither the United States nor any agency thereof, nor any of their employees, makes any warranty, expressed or implied, or assumes any legal liability or responsibility for any third party's use or the results of such use of any information, apparatus, product or process disclosed in this report, or represents that its use by such third party would not infringe privately owned rights.

Printed in the United States of America

Available From

National Technical Information Service

U.S. Department of Commerce

5285 Port Ruyal Road

Springfield VA 22161

NTIS Price Codes

Printed Copy: A06

Microfiche Copy: $A 01$ 
WFPS:TME-79-030

DECEMBER 31,1979

$U C-20 d$

\section{PERFORMANCE ANALYSES OF ELMO BUMPY TORUS PLASMAS}

AND PLASMA SUPPORT SYSTEMS

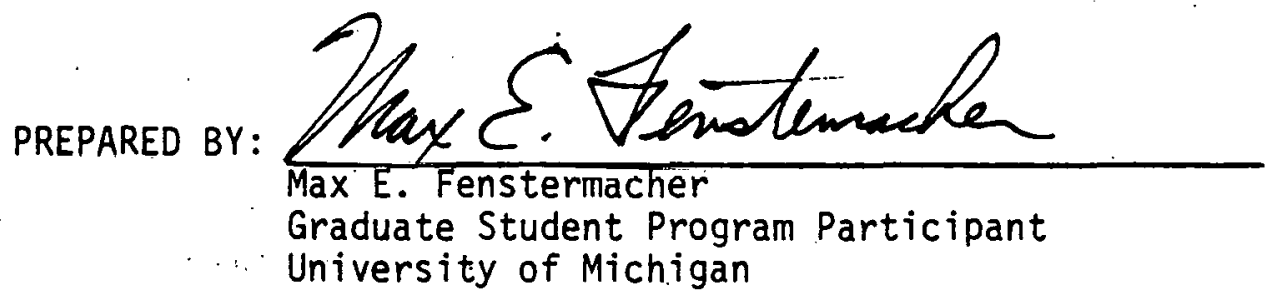

reviewed by: Hordan beloon

Gordon Gibson, Manager

Nuclear and Plasma Engineering

APPROVED BY:
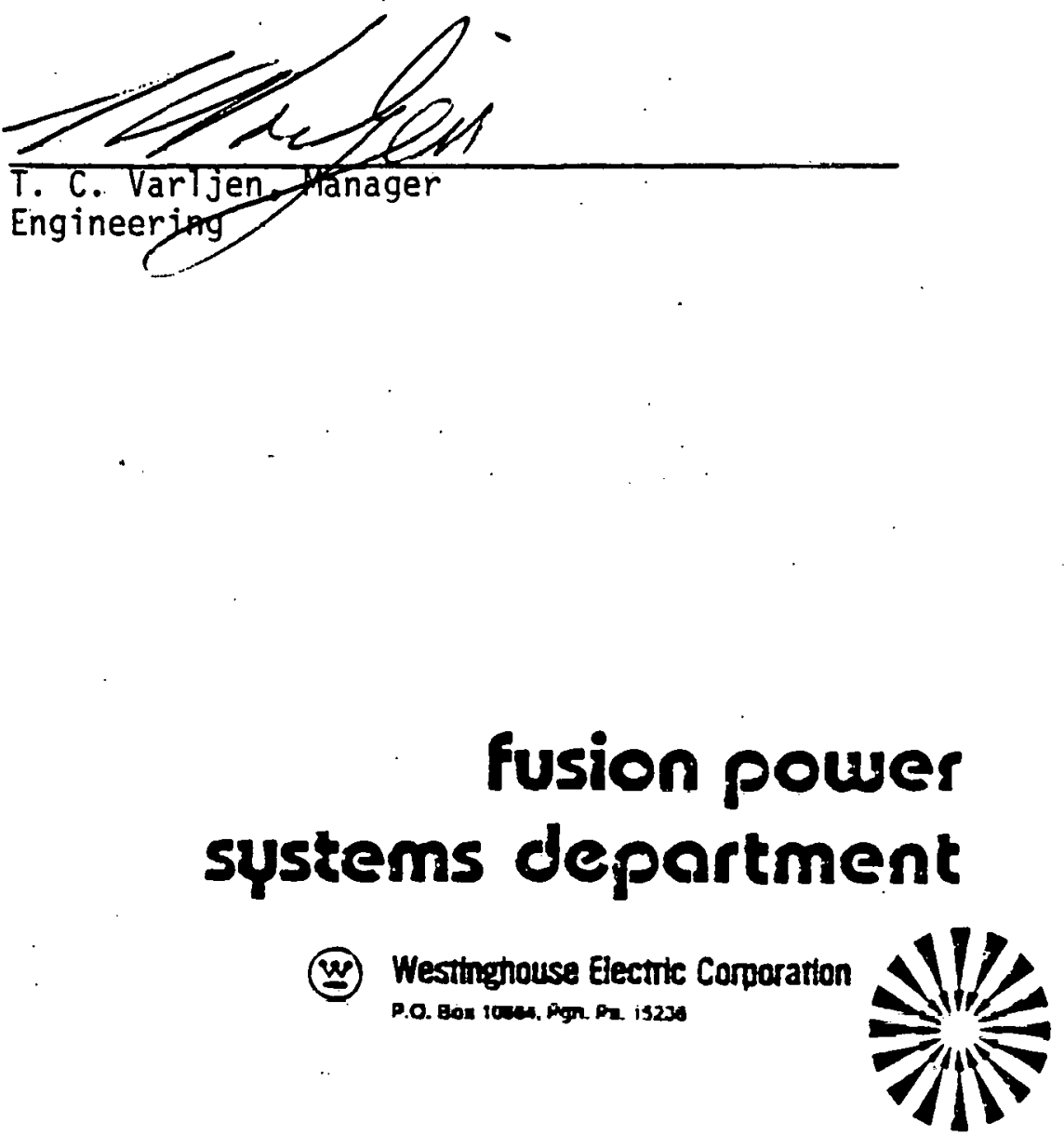
ABSTRACT

The development and application of the OASIS Code (Operational Analys is of ELMO Bumpy Torus Support and Ignition Systems) for the study of EBT device and plasma performance are presented. The code performs a time-independent, zerodimensional self-consistent calculation of plasma and plasma support systems parameters for the physics and engineering of EBT devices.

The features of OASIS modeling for the EBT plasma include: 1) particle balance of the bulk toroidal and electron ring plasma components for experimental $(H-H, D-D, H e-H e$ etc.) as well as reactor (D-T) devices; 2$)$ energy balance in the bulk and ring plasmas for externally heated or ignition devices; 3 ) alpha particle effects for reactor devices; 4) auxiliary heating effects, including microwave (ECRH), RF heating (e.g., ICRH), and neutral beam methods; and 5) ignition conditions, including fusion power, alpha power and neutron wall loading. The performance studies using OASIS focussed on variation in plasma and device size and on microwave input power and frequency. An additional study was performed to determine the characteristics of an EBT reactor proof-ofprinciple device operated with a deuterium-tritium plasma. Sensitivity studies were performed for variation in the input microwave power sharing fractions and the dependence of the bulk $n \tau$ scaling law on bulk electron temperature.

The results indicated that, for a self-consistent set of parameters in a baseline device with major radius $R_{0}=4.2 \mathrm{~m}$, variation in the plasma and device sizes produces large variation in the plasma parameters at balance while variation in the input microwave frequency used in the device produces small changes in plasma paranieters. In each of the studies all of the baseline parameters were held fixed, including input microwave power, plasma temperature and density, and plasma confinement time, except the independent variable for the study (e.g., device size, input microwave frequency) and the dependent variable of interest (e.g., required input power, plasma temperature at balance, etc.). Under these conditions, changes in device and plasma size by a 
factor of 1.4 (major radius $R_{0}$ increases from 4.0 to $5.5 \mathrm{~m}$ ) produced an increase by a factor of 2.4 in required input microwave power, a decrease by a factor of 5.0 in plasma temperatures at balance for fixed input power and a decrease by a factor of 6.0 in bulk plasma particle densities at balance: Changes in microwave frequency, proportional to magnetic field strength at resonance, by a factor of 5.8 (field strength in the coil throat $B_{C T}$ increases from 1.0 to $5.8 \mathrm{~T}$ ) produced an increase of $17 \%$ in required input microwave power, a decrease of $21 \%$ in plasma temperatures and a decrease of $20 \%$ in plasma particle densities at balance. The sensitivity studies showed that bulk plasma parameter values were linearly dependent on changes in microwave power sharing fractions while the ring parameter values showed a nonlinear response. The study of the scaling law $n \tau \propto A_{c}{ }^{2} T_{e B}{ }^{\alpha}$ showed that bulk electron temperature and scaled $n_{\tau}$ at balance increase sharply as the scaling exponent a approaches 1.0. Finally, the D-T operated EBT reactor proof-of-principle study showed that input power, either microwave resonant heating power, neutral beam power or other auxiliary heating power, significantly higher than the baseline value of $2.4 \mathrm{MW}$ will be required to achieve plasma conditions. which produce appreciable alpha particle population and fusion power. 


\section{TABLE OF CONTENTS}

Section

1.0

INTRODUCTION

Page

2.0 SCIENTIFIC AND ENGINEERING GROUND RULES $\ldots \ldots \ldots \ldots \ldots \ldots \ldots 2-1$

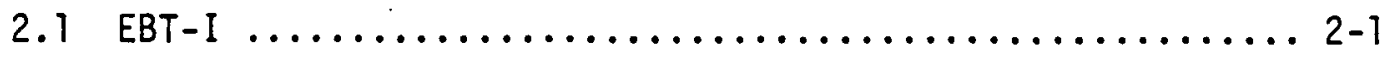

2.2 GENERAL EBT GROUND RULES $\ldots \ldots \ldots \ldots \ldots \ldots \ldots \ldots \ldots \ldots, 2-5$

3.0 OASIS DOCUMENTATION $\ldots \ldots \ldots \ldots \ldots \ldots \ldots \ldots \ldots \ldots \ldots \ldots \ldots . .1$

3.1 DESCRIPTION OF PROBLEM SOLVED $\ldots \ldots \ldots \ldots \ldots \ldots \ldots \ldots \ldots . . \ldots \ldots \ldots \ldots \ldots$

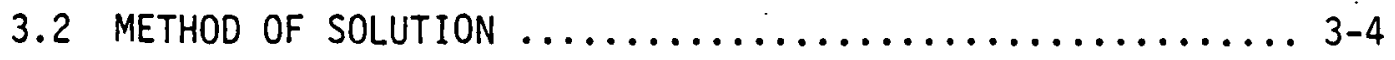

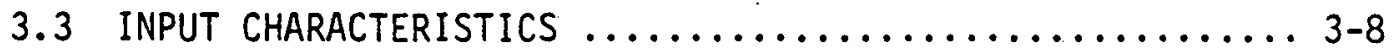

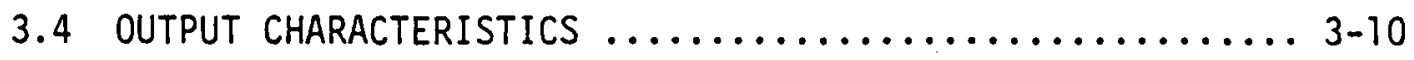

3.5 APPLICABILITY TO TRADE-OFF STUDIES $\ldots \ldots \ldots \ldots \ldots \ldots \ldots . . \ldots \ldots$

4.0 EBT THEORY AND MODELING EQUATIONS $\ldots \ldots \ldots \ldots \ldots \ldots \ldots \ldots \ldots . \ldots \ldots \ldots \ldots \ldots \ldots$

4.1 ENERGY BALANCE MODELING $\ldots \ldots \ldots \ldots \ldots \ldots \ldots \ldots \ldots \ldots \ldots .4-1$

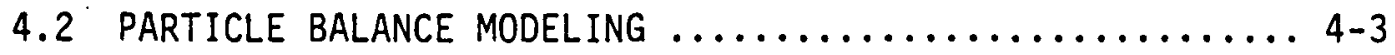

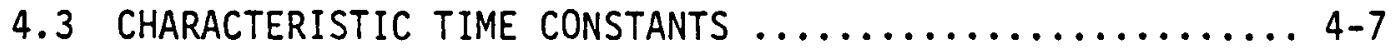

4.4 PLASMA BETA $\ldots \ldots \ldots \ldots \ldots \ldots \ldots \ldots \ldots \ldots \ldots \ldots \ldots \ldots \ldots . \ldots \ldots, 4-9$

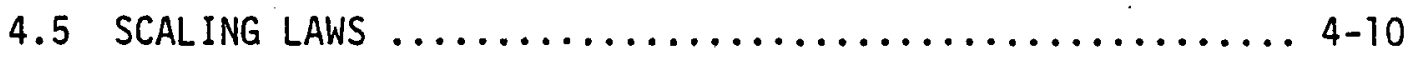

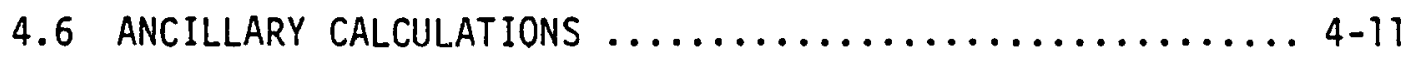

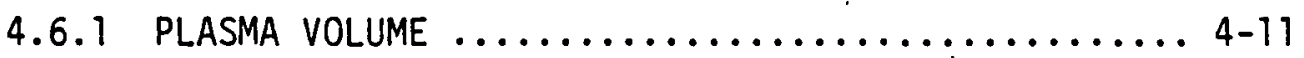

4.6 .2 SURFACE AREA OF VACUUM VESSEL $\ldots \ldots \ldots \ldots \ldots \ldots, 4-13$

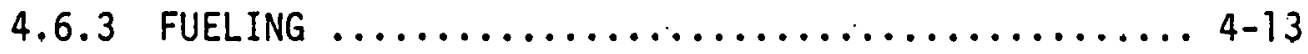

4.6 .4 FUSION EFFECTS $\ldots \ldots \ldots \ldots \ldots \ldots \ldots \ldots \ldots \ldots \ldots, 4-15$

4.6 .5 CRITICAL DENSITY ........................ 4-16

4.6 .6 MICROWAVE FREQUENCY $\ldots \ldots \ldots \ldots \ldots \ldots \ldots \ldots \ldots . .446 .16$

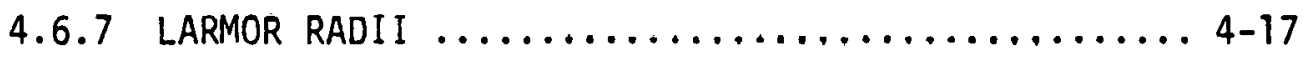

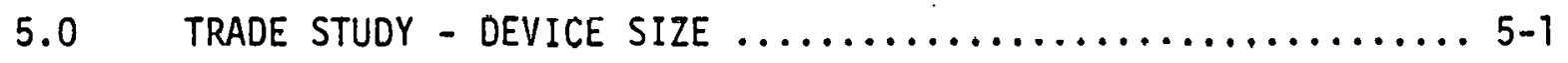

6.0 TRADE STUDY - MODES OF OPERATION $\ldots \ldots \ldots \ldots \ldots \ldots \ldots \ldots \ldots .6 \ldots \ldots \ldots \ldots \ldots$

7.0 TRADE STUDY. - D-T PROOF-OF-PRINCIPLE DEVICE $\ldots \ldots \ldots \ldots \ldots .7-1$ 
TABLE OF CONTENTS (CONTINUED)

Section

Page

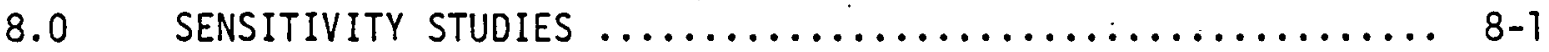

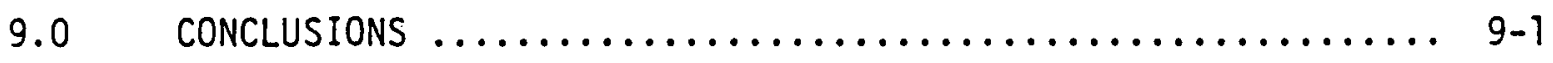

9.1 EBT PHYSICS AND OASIS MODELING $\ldots \ldots \ldots \ldots \ldots \ldots \ldots \ldots . . \ldots, 9.1$

9.2 STRENGTHS AND WEAKNESSES OF OASIS $\ldots \ldots \ldots \ldots \ldots \ldots \ldots . . \ldots . \ldots .2$

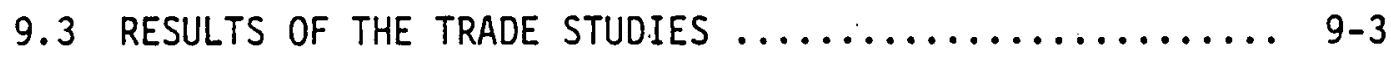

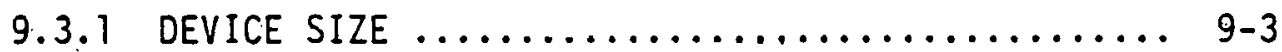

9.3.2 MODE OF OPERATION - INPUT MICROWAVE FREQUENCY .. $9-3$

9.3.3 D-T PROOF-OF-PRINCIPLE DEVICE .............. 9-4

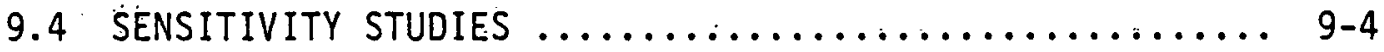

9.5 FURTHER WORK REQUIRED $\ldots \ldots \ldots \ldots \ldots \ldots \ldots \ldots \ldots \ldots . \ldots \ldots \ldots . \ldots \ldots$

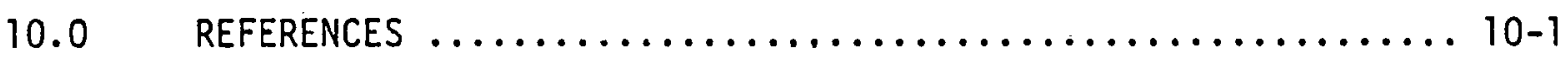

APPENDIX A - OASIS COMPUTER CODE ABSTRACT ............. A-1

APPENDIX B - OASIS INPUT DECK - VARIABLE DESCRIPTIONS ..... B- 
Figure No. $\quad$ Page

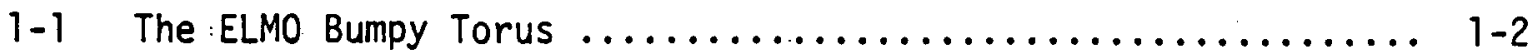

3-1 OASIS FIOW Diagram .......................... 3-2

3-2 OASIS Logic Diagram ......................... 3-3

3-3 EBT Power Balance Model ........................ 3-5

3-4 EBT Particle Balance Model ..................... 3-6

3-5 OASIS Bisection Method Flow Diagram ................ 3-9

4-1 Typical Mirror Sector in EBT .................... 4-12

4-2 Bumpy Torus Model for Surface Area Calculation ........... 4-14

5-1 Required Input Microwave Power as a Function of Device Major Radius for Fixed Plasma Density and Temperature .......... 5-4

5-2 Ring and Bulk Plasma Temperatures as a Function of Device Major Radius for Fixed Density and Input Power ........... 5-5

5-3 Ring and Bulk Electron Densities as a Function of Device Major Radius for Fixed Temperature and Input Power ....... 5-6

5-4 Ring Energy Confinement Time as a Function of Device Major Radius for. Fixed Ring Density and Temperature .......... 5-7

5-5. Scaled Bulk Electron Temperature as a Function of Device Major Radius for Fixed Density .................... 5-8

5-6 Scaled Bulk nt as a Function of Device Major Radius for Fixed Density ................................ 5-9

6-1 Required Input Microwave Power as a Function of Magnetic Field Strength in a Mirror Coil Throat for Fixed Plasma Density and Temperature ........................ $6-2$

6-2 Ring and Bulk Plasma Temperature as a Function of Magnetic Field Strength in a Mirror Coil Throat for Fixed Density

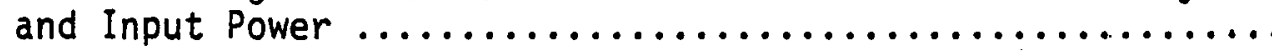

6-3 Ring and Bulk Electron Densities as a Function of Magnetic Field Strength in a Mirror Coil Throat for Fixed Temperature

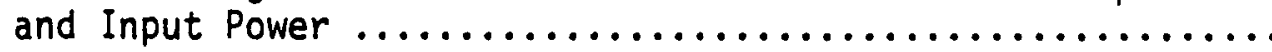

6-4 Ring Energy Confinement Time as a Function of Magnetic Field Strength in a Mirror Coil Throat for Fixed Ring Density and

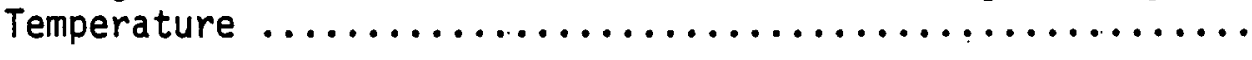

6-5 Scaled Bulk Electron Temperature as a Function of Magnetic Field Strength in a Mirror Coil Throat for Fixed Density ... 6-6 


\section{LIST OF FIGURES (CONTINUED)}

Figure No.

Page

6-6 Scaled Bulk nt as a Function of Magnetic Field Strength in a Mirror Coil Throat for Fixed Density .................. 6-7

8-1 Required Input Microwave Power as a Function of Normalized Ring and BuTk Microwave Power Sharing Fractions for Fixed

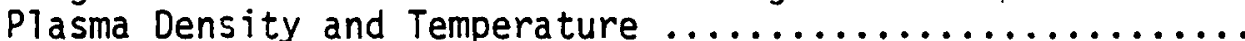

8-2 Ring and Bulk Plasma Temperature as a Function of Normalized Ring and Bulk Microwave Power Sharing Fractions for Fixed

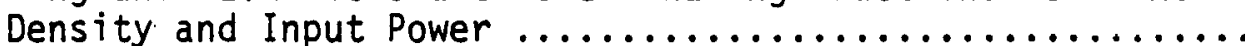

8-3 Ring and Bulk Electron Densities as a Function of Normalized Ring and Bulk Microwave Power. Sharing Fractions for Fixed

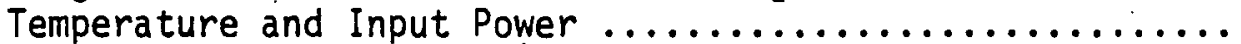

8-4. Ring and Bulk Electron Densities as a Function of Normalized Bulk Microwave Power Sharing Fraction for Fixed Temperature

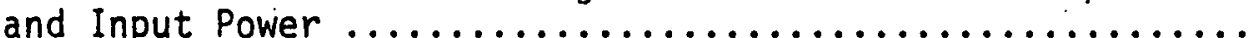

8-5 Scaled Bulk Electron Temperature as a Function of Scaling Exponent a $\left(n \tau \propto A_{C}{ }^{2} T_{e B}{ }^{\alpha}\right)$ for Fixed Density ........... 8-7

8-6 Scaled Bulk $n \tau$ as a Function of Scaling Exponent a

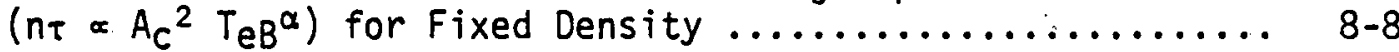

8-7 Scaled Bulk Electron Temperature $\left(n_{\tau} \propto A_{C}{ }^{2} T_{e B}{ }^{\alpha}\right)$ as a Function of Input Microwave Power for Fixed Density and

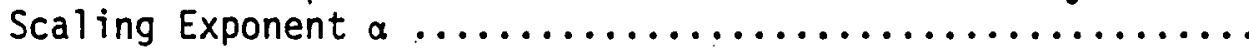

8-8 Scaled Bulk $n \tau\left(n \tau \propto A_{c}{ }^{2} T_{e} B^{\alpha}\right)$ as a Function of Input Microwave Power for Fixed Density and Scaled Exponent $\alpha . .$. . 


\section{LIST OF TABLES}

Table No. $\quad$ Page

$2-1$ EBT-I PARAMETERS LIST $\ldots \ldots \ldots \ldots \ldots \ldots \ldots \ldots \ldots \ldots \ldots \ldots \ldots \ldots \ldots \ldots \ldots, 2-2$

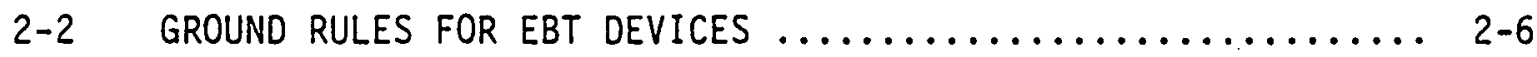

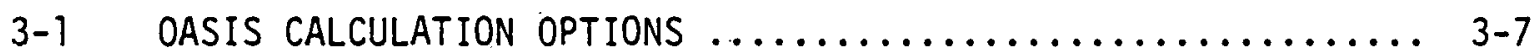

O-1 OASIS RADIATIVE LOSS MODELS $\ldots \ldots \ldots \ldots \ldots \ldots \ldots \ldots \ldots \ldots ., 4-4$

$4-2$ OASIS PARTICLE DENSITIES $\ldots \ldots \ldots \ldots \ldots \ldots \ldots \ldots \ldots \ldots \ldots \ldots, 4-5$

$4-3$ TIME CONSTANTS USED IN OASIS $\ldots \ldots \ldots \ldots \ldots \ldots \ldots \ldots \ldots \ldots, 4-8$

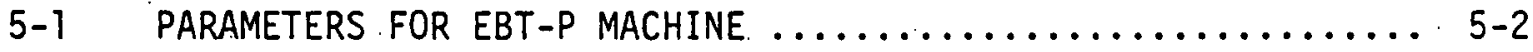

$7-1$. D-T PROOF-OF-PRINCIPLE PARAMETERS $\ldots \ldots \ldots \ldots \ldots \ldots \ldots \ldots, 7-2$

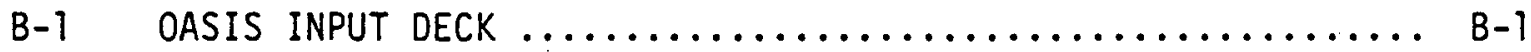




\section{NOMENCLATURE}

Variable

$\bar{a}_{p}$

aring

${ }^{a} \mathrm{CB}$

$\bar{a}_{c}$

$a_{t}$

A

B

E

I

$\bar{n}$

$\mathrm{P}$

$R_{0}$

$R_{\text {op }}$

$r_{\min }$

$r_{\text {maj }}$

$\mathrm{s}_{\mathrm{c}}$

T

$\tau$

W
Description

Units

Mean Bulk Plasma Minor Radius

m

Minor Radius to Center of Ring Cross Section m

Clear Bore Minor Radius

m

Minor Radius to Current Center

$m$

Mèan Vacuum Vessel Minor Radius

m

Particle Mass

$\mathrm{kg}$

Magnetic Field Strength

tesla

Kinetic Energy

$\mathrm{keV}$

Beam Current

Mean Particle Density.

A

$m^{-3}$

Power

kW

Major Radius.

Major Radius to Bulk Plasma Center

II

Ring Elliptical Cross Section Minor Radius

$m$

Ring Elliptical Cross Section Major Radius

$m$

Coil Width

m

Plasma Temperature

$\mathrm{keV}$

Characteristic Time

s

Power Density
$\mathrm{kW} / \mathrm{m}^{3}$ 
NOMENCLATURE (CONTINUED)

Subscript

$\begin{array}{ll}\text { R, ring } & \text { Relativistic Electron Ring Plasma } \\ \text { B, bulk } & \text { Toroidal Bulk Plasma } \\ \text { E } & \text { Energy (Confinement) } \\ \text { E } & \text { Electron Particle (Confinement) } \\ \text { i } & \text { Ion Particle (Confinement) } \\ \text { A } & \text { "Hot" Alpha Particle } \\ \text { AC } & \text { Thermalized Alpha Particle } \\ \text { NB } & \text { "Hot" Neutral Beam Particle } \\ \text { L } & \text { Particle Diffusion Losses } \\ \text { EN } & \text { Energy Conduction Losses }\end{array}$

Example

$\mathrm{B}_{\mathrm{R}}$

${ }_{B}^{B}$

$\tau_{E R}$

$\tau$ eB

$\tau_{\text {iB }}$

$\bar{n}_{A}$

$Z_{A C}$

$\bar{n}_{N B}$

WLeR

${ }_{\text {ENiB }}$
Dimensionless

Parameter

$\gamma$

Z

$Z_{E F F}$

$B$

N

M

$(v / \Omega)$
Relativistic Factor $\frac{((T+511) \times .1000) \mathrm{e}}{\mathrm{m}_{\mathrm{e}} \mathrm{c}^{2}}$

Particle Charge

Effective Plasma Charge $\sum_{\text {ions }} Z_{i}{ }^{2} \vec{n}_{i} / \sum_{i o n s} Z_{i} \vec{n}_{i}$

Plasma Beta

Number of Device Sectors

Mirror Ratio $\mathrm{B}_{\mathrm{CT}} / \mathrm{B}_{\text {mid }}$

Collisionality Factor; $v=$ collision frequency,

$\Omega=$ poloidal drift frequency 
NOMENCLATURE (CONTINUED)

Constants

e

c

me

$\varepsilon_{0}$
Value

$1.602 \times 10^{19} \mathrm{C}$

$2.998 \times 10^{8} \mathrm{~m} / \mathrm{s}$

$9.1 \times 10^{-31} \mathrm{~kg}$

$8.84 \times 10^{-12} \mathrm{c} / \mathrm{V} \cdot \mathrm{m}$
Description

Electronic Charge

Speed of Light

Electron Rest Mass

Electric Permitivity 


\subsection{INTRODUCTION}

The work presented in this report focusses on the development and application of OASIS, a computer code for the Operational Analysis of ELMO Bumpy Torus (EBT) Support and Ignition Systems, which models the plasma and plasma support systems of EBT devices. Applications of OASIS to EBT device trade-off studies are presented in detail. This effort is part of a Westinghouse program to develop a computer code which models, sizes, and costs EBT devices in a way similar to the analysis of tokamak machines performed by COAST ${ }^{(1)}$, a computer code for the Costing And Sizing of D-T Burning Iokamaks. The project was motivated by; 1) current interest in EBT as an alternate concept fusion machine, 2) experience with the successful use of COAST in many kinds of tokamak studies, and 3) immediate application of the codes to the EBT-P Proof-of-Principle project currently being coordinated by the Oak Ridge National Laboratory.

The ELMO Bumpy Torus is shown in Figure 1-1. It is essentially a series of canted mirror machines linked together to form a toroidal shape. In each of the EBT sectors (microwave resonance cavity with a magnetic mirror coil at each end) the bulk (toroidal) plasma forms along the central ring axis and a relativistic electron annulus ( $r i n g$ ) plasma forms around the bulk plasma in the cavity between the mirror coils as shown. The formation of these energetic rings was observed in mirror machines as early as 1964 and experiments concentrating on the pheriomena were conducted in 1969 (the ELMO experiment) and 1971 (the canted mirror experiment) at the Oak Ridge National Laboratory. The first ELMO Bumpy Torus experiment began operation in 1974 at ORNL with EBT-I ${ }^{(2)}$.

Computer codes which perform physics and engineering calculations, as well as device sizing and costing estimates, will be useful for future work on EBT devices. The OASIS code is immediately applicable to the complete costing and sizing of EBT's by linking it to the sizing and costing subsections of the COAST code. In this way, estimates of the design parameters and the cost of EBT experiments and the possible trade-offs involved in selecting the components of the device can be made quickly and inexpensively. 


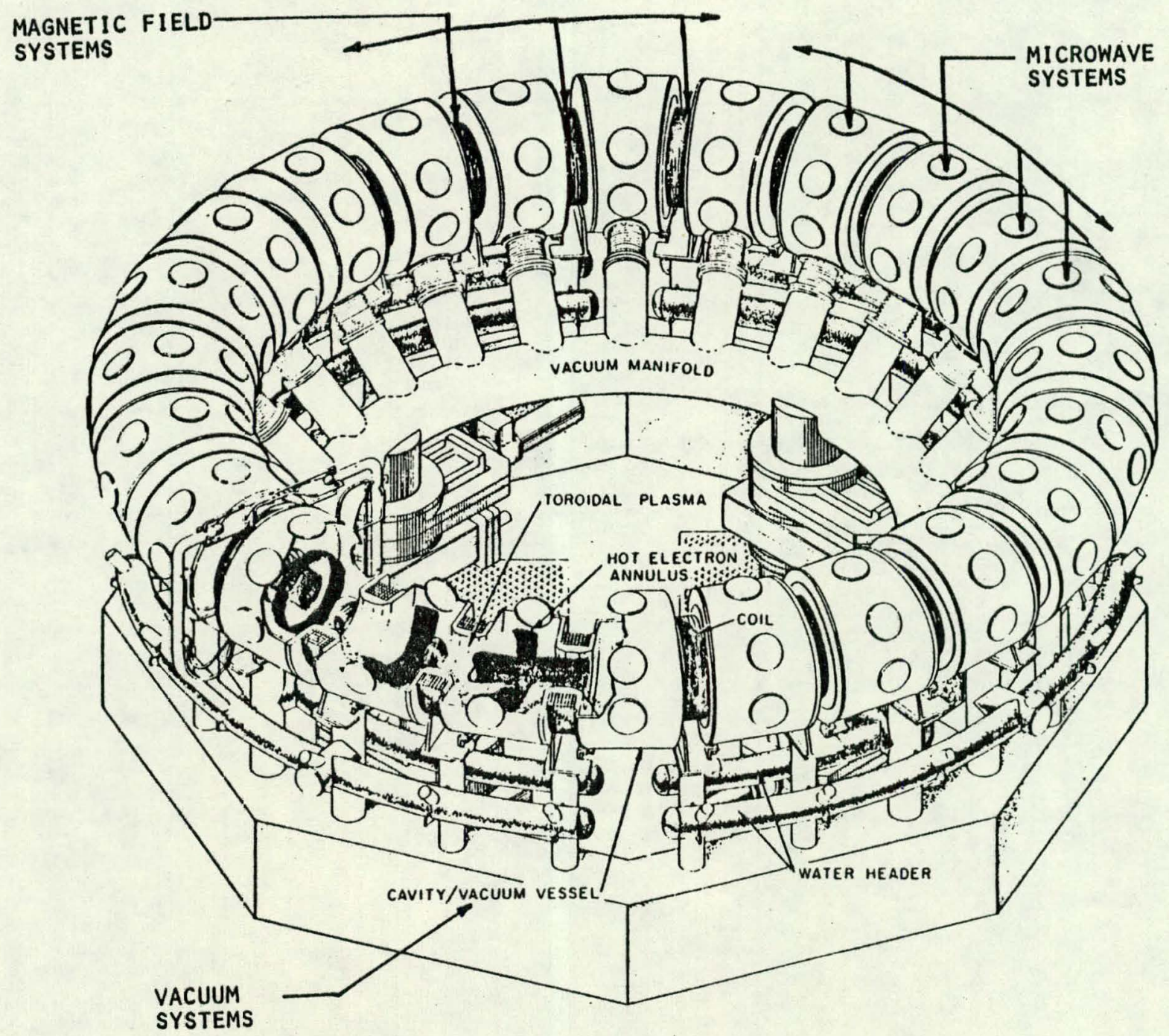

Figure 1-1. The ELMO Bumpy Torus. 
The purpose of this report is to document the computer code OASIS and present results of EBT plasma and plasma support systems trade-off studies performed using OASIS. The code documentation will focus on the capabilities and limitations of OASIS calculations in trade-off studies of EBT machines. The results of the trade-off studies performed using the code will serve as both examples of OASIS performance and as a starting point for further work of this type.

This report documents the capabilities of the OASIS code for EBT trade-off studies. Scientific and engineering ground rules used in these studies are summarized in Section 2.0. General documentation of the code is presented in Section 3.0 with a computer code abstract presented in Appendix A. A variable list and the input requirements for OASIS are presented in Appendix $B$. The listing of the Fortran card images for the code is available upon request. Finally, the physics and engineering modeling equations used by OASIS are given in Section 4.0.

Three types of trade studies were done using OASIS. In Section 5.0 several machine sizes are considered and the effects on input power requirements, plasma density, temperature, and $n \tau$ are noted. Section 6.0 presents a simulated experimental program using one EBT device in various modes of operation. Finally, a D-T burning proof-of-principle EBT machine is presented in Section 7.0. The results of sensitivity studies for various key theoretical physics parameters used by OASIS are given in Section 8.0 and conclusions are presented in Section 9.0 . 


\subsection{SCIENTIFIC AND ENGINEERING GROUND RULES}

\subsection{EBT-I}

The assumptions and ground rules used in OASIS calculations for the present trade studies are based on the EBT-I device parameters and experimental results $(3,4,5)$. Theoretical analyses and experimentally measured values were used to determine a complete set of EBT-I parameters. Table 2-1 presents typical values used as input to the code in the trade studies. The sensitivity studies focussed on the effect that changes in the key theoretical coefficients and constants had on the trade study results.

The experimental data from.EBT-I was used in conjunction with available EBT scaling laws to obtain the input values of plasma parameters. Much of this work needed for the device size and microwave frequency trade studies was performed as part of the Westinghouse EBT-P proof-of-principle study ${ }^{(4)}$. Some of the plasma support systems specifications and machine size and geometry factors required for OASIS input were also presented as part of the proof-of-principle study.

In all of the studies the assumption was made that energy conduction losses (non-negligible in obtaining energy balance with the EBT-I plasma parameters) scaled lincarly as the input mirrowave power density in both the ring and bulk plasmas. In addition, for each of the trade studies the Westinghouse proof-of-principle device with major radius $R_{0}=4.2 \mathrm{~m}$ and operated with microwave frequencies $f_{\mu}=60 / 28 \mathrm{GHz}$ was used as a point of normalization for determining OASIS input values. The parameters description for this device was obtained independent of OASIS and its self-consistency was verified by OASIS calculations. 
TABLE 2-1

EBT-I PARAMETERS LIST

MACHINE PARAMETERS

$\begin{array}{lll}N & \text { Number of Device Coils } & 24 \\ R_{0} & \text { Device Major Radius } & 1.5 \mathrm{~m} \\ \bar{a}_{C} & \text { Minor Radius of Mirror Coil (Current Weighted) } & 0.162 \mathrm{~m} \\ { }_{C}{ }_{C B} & \text { Clear Bore Minor Radius } & 0.10 \mathrm{~m} \\ \bar{a}_{T} & \text { Mean Minor Radius of Microwave Vacuum Cavity } & 0.20 \mathrm{~m} \\ { }^{B}{ }_{R} & \text { Magnetic Field at Hot Electron Rings } & 0.32 \mathrm{~T} \\ B_{B} & \text { Magnetic Field at Bulk Plasma (Average) } & 0.675 \mathrm{~T} \\ { }_{B}{ }_{m i d} & \text { Magnetic Field on Midplane Between Coils } & 0.45 \mathrm{~T} \\ { }^{B}{ }_{C T} & \text { (on Ring Axis) } & \\ A_{C} & \text { Magnetic Field in Coil Throat (on Ring Axis) } & 0.90 \mathrm{~T} \\ & \text { Mirror Coil Width } & 0.12 \mathrm{~m}\end{array}$

\section{PLASMA PARAMETERS.}

BULK PLASMA

$\begin{array}{lll}\bar{n}_{e B} & \text { Mean Electron Density } & 1.5 \times 10^{18} \mathrm{~m}^{-3} \\ T_{e B} & \text { Electron Temperature } & 0.3 \mathrm{keV} \\ T_{i B} & \text { Ion Temperature (One Species) } & 0.1 \mathrm{keV} \\ \tau_{E B} & \text { Energy Confinement Time } & 6.7 \times 10^{-3} \mathrm{~s} \\ W_{E N e B} & \text { Energy Conduction Power Density Losses } & 7.8 \mathrm{~kW} / \mathrm{m}^{3} \\ W_{E N i B} & \text { by Electrons } & \\ \bar{n}_{c r i t} & \text { Energy Conduction Power Density Losses } & 2.6 \mathrm{~kW} / \mathrm{m}^{3} \\ B & \text { Critical (Maximum) Density } & 4.4 \times 10^{18} \mathrm{~m}^{-3} \\ (v / \Omega) & \text { Bulk Beta } & 0.53 \% \\ \rho_{e} & \text { Collisionality Factor } & 0.3 \\ \rho_{j} & \text { Electron Larmor Radius (Average) } & 1.1 \times 10^{-4} \mathrm{~m} \\ V_{B} & \text { Ion Larmor Radius (Average) } & 2.6 \times 10^{-3} \mathrm{~m} \\ \tau_{\mathrm{pB}} & \text { Plasma Volume } & 0.5 \mathrm{~m}^{3} \\ & \text { Particle Confinement Time } & 1.4 \times 10^{-2} \mathrm{~s}\end{array}$




\section{RING PLASMA}

$\begin{array}{lll}\bar{n}_{e R} & \text { Mean Electron Density } & 6.3 \times 10^{17} \mathrm{~m}^{-3} \\ T_{e R} & \text { Electron Temperature } & 150 \mathrm{keV} \\ \tau_{E R} & \text { Energy Confinement Time } & 0.29 \mathrm{~s} \\ { }^{\tau} e R & \text { Particle Confinement Time } & 0.31 \mathrm{~s} \\ \beta_{R} & \text { Ring Beta } & 37 \% \\ \rho_{e} & \text { Electron Larmor Radius } & 4.3 \times 10^{-3} \mathrm{~m} \\ V_{R} & \text { Total Ring Plasma Volume } & 5.9 \times 10^{-2} \mathrm{~m}^{3} \\ W_{E N e R} & \text { Energy Conduction Power Density Losses } & 30 \mathrm{~kW} / \mathrm{m}^{3} \\ \bar{a}_{\text {ring }} & \text { by Electrons } & \\ R_{\text {maj }} & \text { Ring Mean Minor Radius } & 0.14 \mathrm{~m} \\ R_{\text {min }} & \text { Major Radius of Ring Elliptical Cross Section } & 0.065 \mathrm{~m} \\ \delta & \text { Minor Radius of Ring Elliptical Cross Section } & 0.013 \mathrm{~m} \\ & \text { Ring Cant Factor } & 6.5 \times 10^{-3} \mathrm{~m}\end{array}$

\section{SYSTEMS PARAMETERS}

$\begin{array}{llr}P_{M U} & \text { Total Input Microwave Power } & 56 \mathrm{~kW} \\ P_{N B} & \text { Neutral Beam Power } & 0 \mathrm{~kW} \\ P_{\mathrm{RF}} & R F \text { (Auxiliary) Power } & 0 \mathrm{~kW}\end{array}$

THEORETICAL COEFFTCIFNTS AND CONSTANTS

$\mathrm{E}_{\mathrm{SCl}}$

$\mathrm{E}_{\mathrm{SC2}}$

$C_{\text {NTAU }}$

$R_{\text {FRAC }}$

B FRAC

${ }^{R} C P L$

${ }^{B} \mathrm{CPL}$

RIV nז Aspect Ratio Scaling Exponent

nt Temperature Scaling Exponent

$n_{\tau}$ Scaling Constant

Fraction of Input Microwave Power to Rings

$7.1 \times 10^{14} \mathrm{~m}^{-3} \mathrm{~s} /(\mathrm{keV})^{3 / 2}$

Fraction of Input Microwave Power to Bulk

Ring Plasma/Microwaves Coupling Coefficient

Bulk Plasma/Microwaves Coupling Coefficient

Ring Microwave Power Sharing Coefficient
2.0

1.5

$17 \%$

$20 \%$

$90 \%$

$90 \%$

$19 \%$ 
TABLE 2-1 (CONTINUED)

EBT-I PARAMETERS LIST

\section{THEORETICAL COEFFICIENTS AND CONSTANTS}

\begin{tabular}{|c|c|c|}
\hline${ }^{B}$ DIV & Bulk Microwave Power Sharing Coefficient & $32 \%$ \\
\hline & Ratio of Particle Confinement Times & 1.0 \\
\hline & Ratio of Bulk Particle Temperatures & $1 / 3$ \\
\hline $\mathrm{C}_{\mathrm{COLL}}$ & Collisionality Scaling Constant & ${ }^{19}(\mathrm{keV}$ \\
\hline$R_{\text {TAUS }}$ & $\begin{array}{l}\text { Slowing-Down Time Upper Limit/Particle } \\
\text { Confinement Time }\end{array}$ & 5.0 \\
\hline$P_{\text {FRAC }}$ & Plasma Mean Minor Radius/Clear Bore Radius & 1.3 \\
\hline
\end{tabular}




\subsection{GENERAL EBT GROUND RULES}

Several ground rules reflecting EBT stability and transport analyses are incorporated in OASIS. Violation of one of these ground rules results in an error message and depending on the nature of the violation the calculation continues or is terminated.

Analyses have established that the stabilizing effect of the rings against MHD effects inherent with the toroidal bulk plasma exists only for bulk beta ring beta ${ }^{(3)}$. Code calculations check for this condition at various stages and, if unsatisfied, an error message is generated. Since violation of this stability condition does not represent an inherently nonphysical result (as would $n_{e B}<0.0$ for example) the calculation continues and error messages occur each time the stability condition is violated. In some cases this ground rule and others may be violated at an intermediate point in the calculation but may be satisfied when the final converged solution is obtained. In this case, the error messages serve only to point out that this process has occurred.

Several other ground rules for EBT devices are included in the OASIS coding. The critical density for microwave propagation at a fixed frequency through the ring and bulk plasmas is calculated throughout the balance loops and error messages are given if the current value of electron or ion density exceeds the critical density*. Alpha and neutral beam particle slowing-down times, calculated at various points in the balance loops, will produce error messages if the value exceeds an upper limit. The value of the upper limit is. controlled by input and is typically several times the bulk plasma particle confinement time. Finally, if the microwave frequency calculated for fundamental mode or second harmonic ECRH heating in the ring or bulk plasmas exceeds an upper limit an error message is produced. This represents the technological limits of the microwave generators used for ECRH heating in EBT machines. The upper limit value used in these studies is $120 \mathrm{GHz}$.

*The critical density at which microwaves no longer penetrate an EBT plasma is that density for which the plasma frequency equals the microwave frequency. 
Scaling laws are used in the code for bulk $n \tau$ and collisionality calculations. For the present trade studies the scaling laws $n \tau \propto A_{C}{ }^{2} T_{e B} 3 / 2$ and $(v / \Omega) \propto$ $\bar{n}_{e B} B_{B} \bar{a}_{C}{ }^{a} C B / T{ }_{e}^{2.5}$ have been used. Generalized $n \tau$ scaling is coded in the form $n_{\tau} \propto(A)^{X 1}\left(T_{e}\right)^{X 2}(B)^{X 3}(B)^{X 4}\left(Z_{e f f}\right)^{X 5}$ where $X 1, X 2, X 3, X 4, X 5$ are controlled by input. A summary of the ground rules used in the trade studies is presented in Table 2-2.

TABLE 2-2

GROUND RULES FOR EBT DEVICES

$$
\begin{aligned}
& \frac{\text { (ENERGY CONDUCTION LOSSES) }}{\text { BBT-I ENERGY CONDUCTION LOSSES). }}=\frac{\text { (INPUT POWER DENSITY) }}{\text { (EBT - I INPUT POWER DENSITY) }} \\
& \beta_{\text {bulk }} \lesssim \beta_{\text {ring }} \\
& \bar{n}_{e} \lesssim \bar{n}_{\text {critical }} \\
& \tau_{s}<\tau_{s} \text { upper limit } \\
& f_{\mu}<120 \mathrm{GHz} \\
& \bar{n}_{\tau} \propto A_{c}{ }^{2} T_{e B}^{3 / 2} \\
& (v / s) \propto \bar{n}_{e B} B_{B} \bar{a}_{C}{ }^{a} C B / T_{e B}{ }^{5 / 2}
\end{aligned}
$$




\subsection{OASIS DOCUMENTATION}

\subsection{DESCRIPTION OF PROBLEM SOLVED}

The OASIS code performs a self-consistent, zero-dimensional, time-independent calculation of the parameters describing EBT plasmas and plasma support systems. EBT devices operate with three plasma components, the toroidal (bulk) plasma, the relativistic electron (ring) plasma, and surface plasmas, with very different characteristics. OASIS handles the bulk and ring plasma components in separate calculations and iterates this process until the solutions obtained are self-consistent. Surface plasma effects are not modeled in the code at this time. The logic used in the code is represented schematicalily in Figures 3-1 and $3-2$.

Physics and engineering models are incorporated in OASIS for EBT plasmas and plasma support systems specifications. These models include:

- Independent energy balance modeling for the ring plasma and the bulk plasma. Both models take into account microwave ECRH methods and the bulk plasma model also includes neutral beam driven operation. For ignition devices operated with a deuterium-tritium bulk plasma, heating by fusion alpha particles is also modeled.

- Independent particle population models for the ring and bulk plasmas. Electrons, impurity ions, and up to two species of plasma ions are accounted for in both models and the bulk plasma model also includes populations of "hot" injected neutral beam particles, "hot" fusion alpha particles and "cold" (thermalized) alpha particles.

- Calculations of neutral beam particle slowing-down times in beam driven cases and alpha particle slowing-down times in ignition modes.

- Alpha particle effects, including particle densities for "hot" and "cold" (thermalized) alphas, contribution of both alpha populations to bulk plasma beta and alpha power as a heating method for the bulk plasma.

- Fusion reaction rates for plasma-plasma reactions and beam-plasma reactions (beam driven cases). 


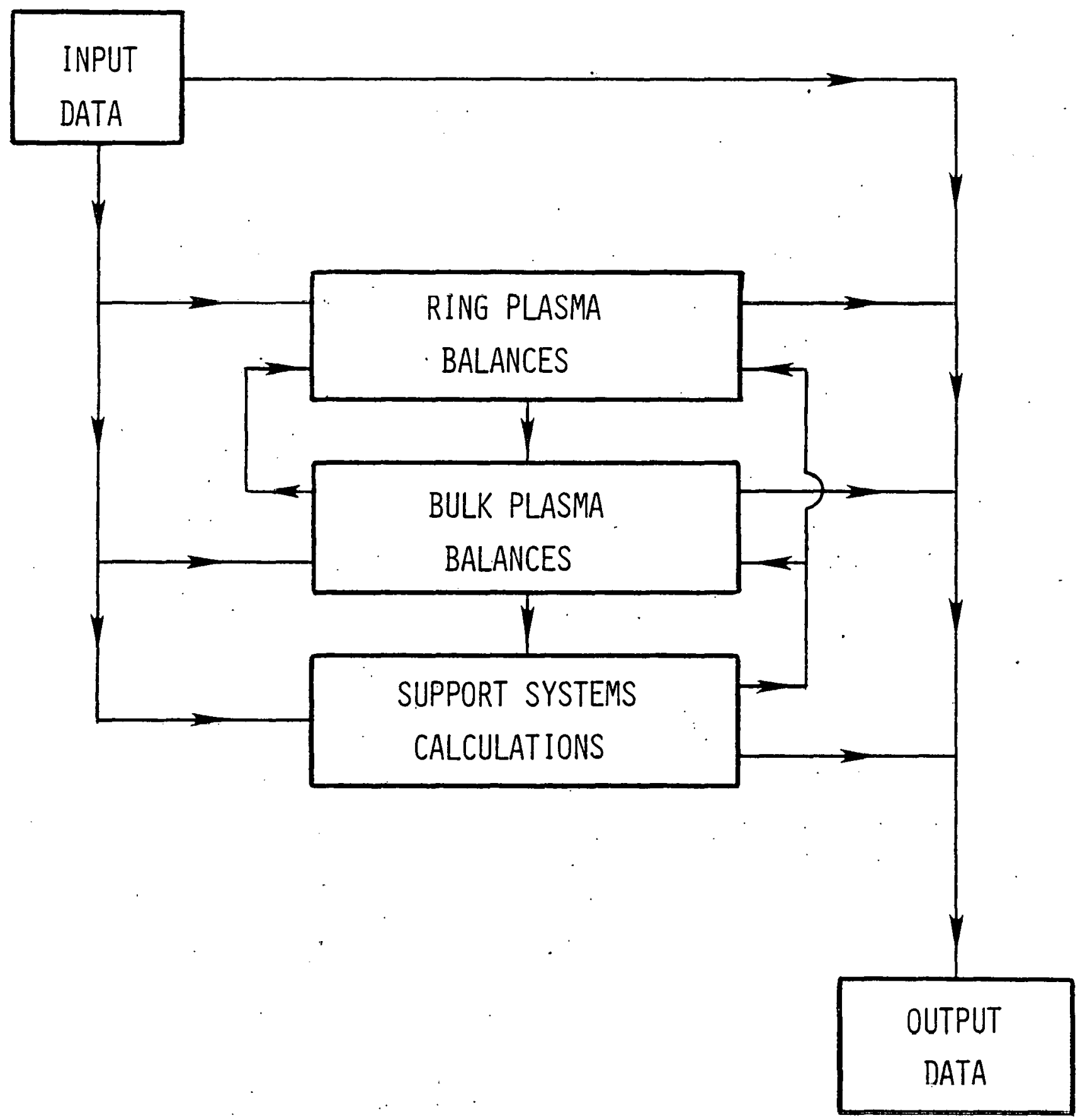

Figure $3-1$. OASIS FTOW Diagram. 


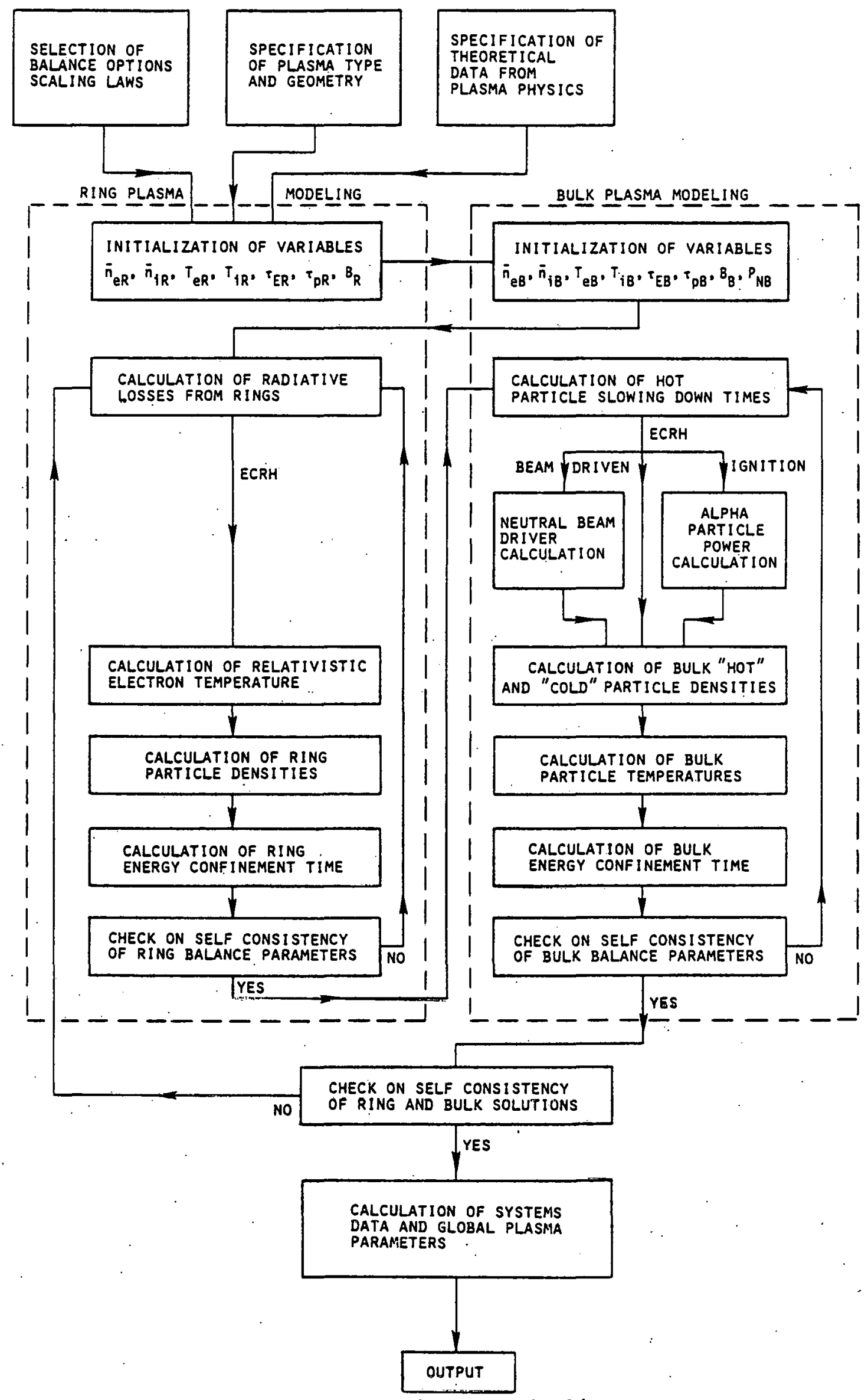

Figure 3-2. OASIS Logic Diagram. 
Impurity ion effects in the ring and bulk plasmas for one ion type, including contribution to bulk plasma $B$, displacement of bulk plasma ions, and effect on bremsstrahlung radiation losses.

- Energy losses due to radiation (e.g., bremsstrahlung, synchrotron) from both the ring and bulk plasmas. Relativistic effects are taken into account in the ring radiative loss model in the form of a drag term for relativistic particles passing through a "cold" background plasma.

- Independent ring and bulk plasma beta calculations including all particle species. The bulk plasma beta calculation also takes into account "hot" neutral beam particles and/or "hot" alpha particles if they are present.

- Separate confinement times for plasma energy, ions and electrons in the ring plasma, and the bulk plasma.

- Generalized nt scaling of the form

$$
n_{\tau} \propto\left(A_{C}\right)^{X 1}\left(T_{e}\right)^{X 2}(B)^{X 3}(B)^{X 4}\left(Z_{e f f}\right)^{X 5}
$$

- Wall loading estimates for neutrons, plasma particles, and radiation from the plasma, including contributions from the ring and bulk plasmas.

The energy balance modeling in OASIS is represented schematically in Figure 3-3. A similar schematic for the particle population modeling is shown in Figure 3-4.

\subsection{METHOD OF SOLUTION}

OASIS uses iterative methods to perform ring and bulk plasma energy and particle balances for EBT devices. Flow diagrams describing the balance. process are given in Figures $3-1$ and 3-2. In the bulk plasma temperature and density balances simple iteration of the balance parameters is sufficient to. obtain converged solutions in most cases. For the bulk balance on the energy confinement time $\tau_{E}$ and the ring balances on temperature $T_{e}$, density $\bar{n}_{e}$, and energy confinement time $\tau_{E}$, the balance is very sensitive to the value of the balance paramcter. Bisection methnds, including a self-checking algorithm for convergence, are used in these balance loops and are described below. The balance loop options are summarized in Table 3-1. 


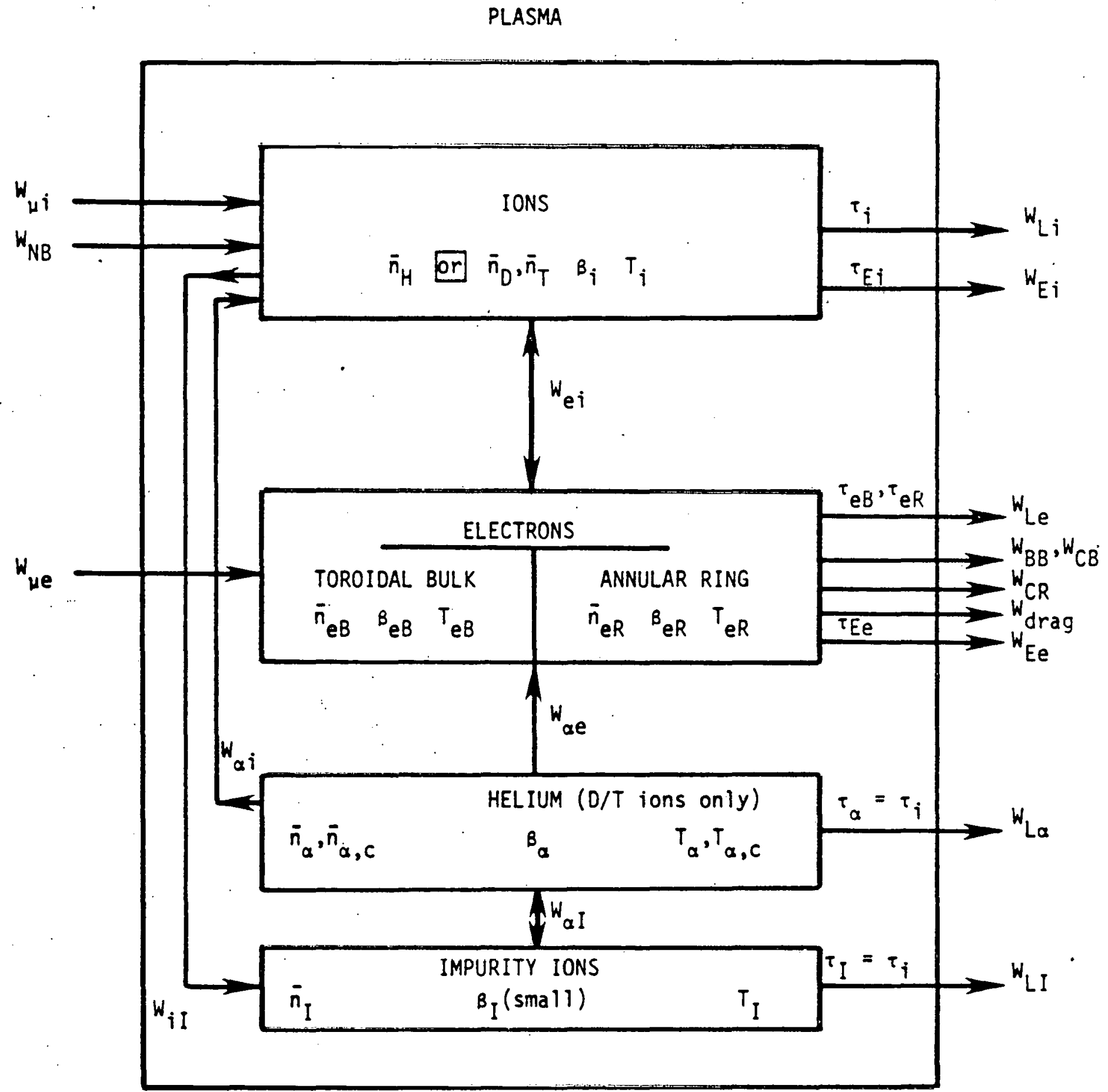

Figure 3-3. EBT Power Balance Model. 


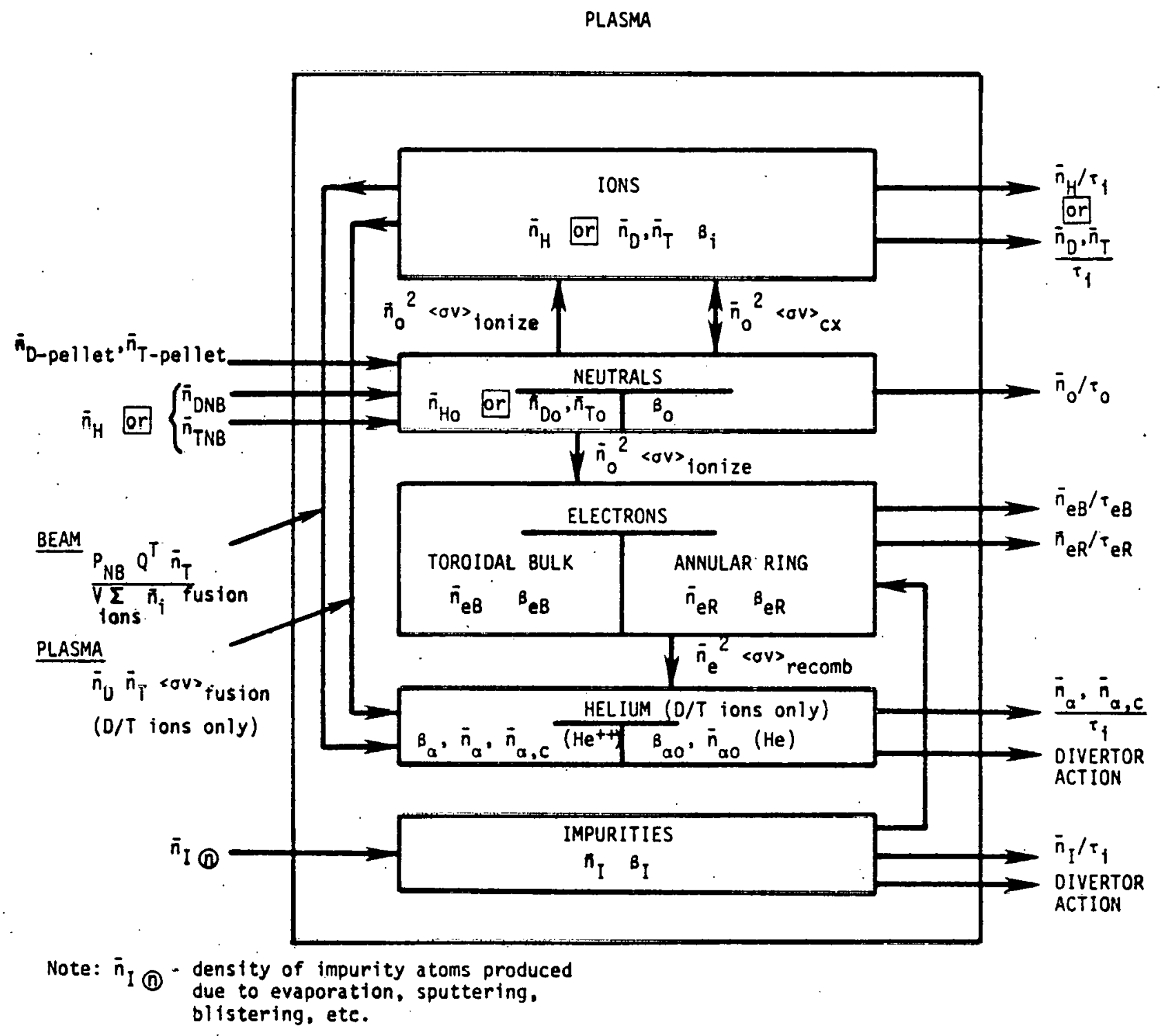

Figure 3-4. EBT Particle Balance Model. 
TABLE 3-1

OASIS CALCULATION OPTIONS

\begin{tabular}{|l|c|c|c|c|}
\hline PLASMA VARIABLE & $\begin{array}{c}\text { OPTION } \\
0\end{array}$ & $\begin{array}{c}\text { OPTION } \\
1\end{array}$ & $\begin{array}{c}\text { OPTION } \\
2\end{array}$ & $\begin{array}{c}\text { OPTION } \\
3\end{array}$ \\
\hline ELECTRON TEMPERATURE $T_{e}$ & $V$ & $F$ & $F$ & $F / C$ \\
\hline REQUIRED INPUT POWER $P_{\mu}$ & $F$ & $V$ & $F$ & $F$ \\
\hline ELECTRON DENSITY $\bar{n}_{e}$ & $F$ & $F$ & $V$ & $F$ \\
\hline$n_{e} \tau_{E}$ & $F$ & $F$ & $F / C$ & $V$ \\
\hline
\end{tabular}

$V$ - Magnitude Varied to Obtain Energy Balance

F - Magnitude Fixed at Input Value

C. - Magnitude Calculated Consistent with Scaling Law to Obtain Energy Balance 
The bisection method algorithm used in OASIS has two stages. The first stage takes the input value of the balance parameter (e.g., $T_{e R}, n_{e R}$ ) and changes it by a fixed increment with each pass through the balance loop. The increment can be positive or negative. After each pass a self-checking algorithm compares the current results of the balance equation with the results in the previous pass. If the solution is converging, the increment used in the next pass is the current value. If the solution is diverging, the increment polarity is reversed for the next pass. The first stage ends when the upper and lower bounds on the balance parameter solution are obtained.

The second stage of the algorithm uses the upper and lower limits obtained above as the input to a bisection process. Each pass through this balance loop cuts the interval between the upper and lower limits in half, while retaining the parameter solution in the interval. When the interval is small enough to meet the criteria for convergence, the value half way between the current upper and lower limit is output as the converged solution. A detailed flow diagram for these two stages of the algorithm is given in Figure 3-5.

\subsection{INPUT CHARACTERISTICS}

Input data for OASIS calculations can be put into four categories; device data, theoretical data, plasma data, and option data. Device data includes the dimensions of the EBT machine, the specifications on machine components (e.g., powers of heating systems), and geometrical data for the shapes of the anticipated toroidal (bulk) plasma and relativistic electron (ring) plasmas. Theoretical data includes scaling coefficients for $n_{\tau}$ and collisionality calculations and dimensionless parameters characterizing the plasma and plasma support systems (e.g., the ratio of bulk electron to bulk ion temperatures). Plasma data includes anticipated values of plasma densities, temperatures, particle and energy confinement times for electrons and all species of ions in the ring and bulk plasma regions. Finally, option data controls the type of energy balance performed in the calculation (see Table 3-1). 

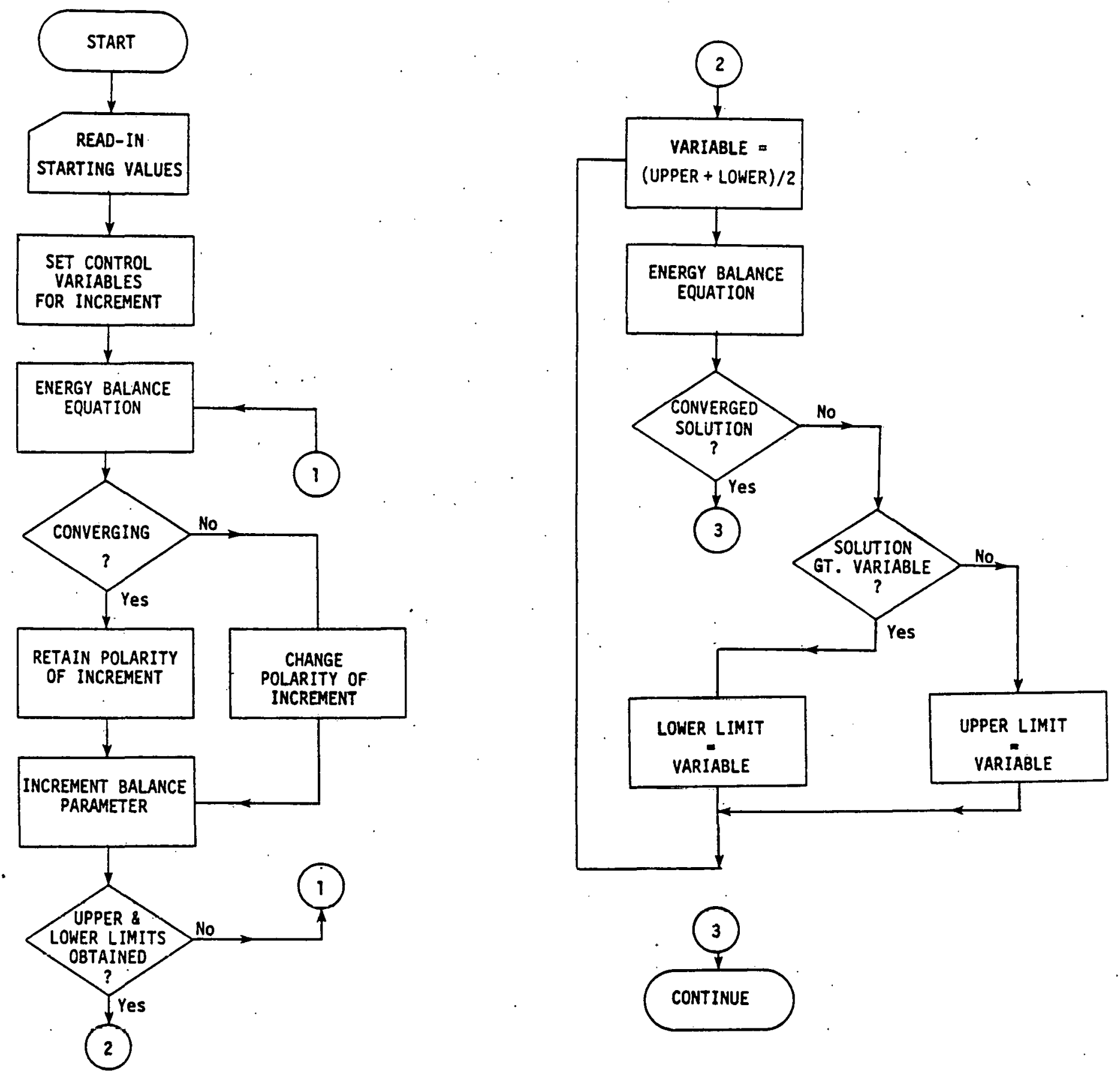

Figure 3-5. OASIS Bisection Method Flow Diagram. 


\subsection{OUTPUT CHARACTERISTICS}

The output data provided by OASIS includes the input values and the calculated values of the device parameters, plasma parameters, and theoretical constants and coefficients for a self-consistent model of an EBT plasma and plasma support system. Notable in the output are calculated values for the densities and temperatures of electrons and all species of ions in the bulk and ring plasma regions. Characteristic energy and particle confinement times, as well as slowing-down times for neutral beam particles (if used) and alpha particles (if produced), are also presented. Finally, the characteristics of the plasma support systems and device geometry are included as OASIS output data. Sufficient information is available from an OASIS run to perform sizing and costing calculations for the EBT machine being considered.

\subsection{APPLICABILITY TO TRADE-OFF STUDIES}

The OASIS code was written so that trade-off studies of many types of EBT devices could be performed quickly with one computer code. Calculations for machines using a single ion species can be handled for arbitrary ion of mass AMI, charge ZMI. In addition, EBT's operated with two ion species of masses AM2, AM3, and charges ZM2, ZM3 can also be modeled using OASIS. Finally, if the two ion species are deuterium and tritium, OASIS can model an ignition device, including neutron wall loading, fusion power, alpha power production (as a heating source for the bulk plasma) and alpha particle production, including bulk plasma beta effects. Immediate applications of these features include state-of-the-art experimental EBT machines operated with hydrogen and future experiments using other ions. A D-T proof-of-principle device will be discussed in Section 7.0 and a D-T operated EBT machine at power reactor scale could also be modeled. 


\subsection{EBT THEORY AND MODELING EQUATIONS}

The ELMO Bumpy Torus machine operates with two plasma components. The toroidal (bulk) plasma contains particles which may pass around the torus. The relativistic electron annulus (ring) plasma is made up of high-energy trapped particles in each of the bumpy torus sectors. Since these plasma components have widely different characteristics, the OASIS code was developed with separate physics and engineering modeling for each plasma. The types of modeling used for the two components are similar but the form of the particular modeling equation will be unique to the component for which it is used. The modeling is time and space indeperident, and profile effects for plasma density and temperature, important in TOKAMAK modeling, have not been included since the bulk plasma profiles near the ring axis of the device, as measured in EBT-I, have been essentially flat.

\subsection{ENERGY BALANCE MODELING}

The energy balance equations used for the ring plasma and bulk plasma components are:

\section{RING PLASMA}

$$
\frac{\left(E_{e R}+E_{i R}\right) \varepsilon}{\tau_{E R}}=W_{\mu R}-W_{E N e R}-W_{R L O S S}
$$

BULK PLASMA

$$
\frac{\left(E_{e B}+E_{i B}\right) \varepsilon}{{ }^{T} E B}=W_{H B}+W_{A U X}-W_{E N e B}-W_{E N i B}-W_{B L O S S}
$$


where

$$
\begin{aligned}
& \varepsilon=1.602 \times 10^{-19} \mathrm{~kW}-\mathrm{s} / \mathrm{keV} \\
& E_{e R}, E_{i R}=\text { electron and ion kinetic energy densities in } \\
& \text { ring region }\left(\mathrm{keV} / \mathrm{m}^{3}\right) \\
& =3 / 2 n_{e R} T_{e R}, 3 / 2 n_{i R} T_{i R} \\
& E_{e B}, E_{i B}=\text { electron and ion kinetic energy densities in } \\
& \text { bulk region }\left(\mathrm{keV} / \mathrm{m}^{3}\right) \\
& =3 / 2 n_{e B} T_{e B}, 3 / 2 \sum_{j}^{\text {species }} n_{j B} T_{j B} \\
& \tau_{E R}, \tau_{E B}=\begin{array}{l}
\text { energy confinement times for ring and bulk plasma } \\
\text { components }(s)
\end{array} \\
& \tau_{e R}, \tau_{e B}=\text { particle confinement times of electrons for ring } \\
& \text { and bulk plasma components ( } \mathrm{s} \text { ) } \\
& \begin{aligned}
\tau_{i B}= & \text { particle confinement time of ions for bulk plasma } \\
& \text { component }(s) \text {. }
\end{aligned} \\
& W_{\mu R}, W_{\mu B}=\begin{array}{l}
\text { microwave input power densities for ring and bulk } \\
\text { plasma components }\left(\mathrm{kW} / \mathrm{m}^{3}\right)
\end{array} \\
& W_{\text {AUX }}=\text { auxiliary heating input power density for the bulk } \\
& \text { plasma component }\left(\mathrm{kW} / \mathrm{m}^{3}\right) \\
& =W_{\text {NEUTRAL }}+W_{\text {RF }}+W_{\text {ALPHA }} \\
& \text { BEAM } \\
& W_{\text {LeR }}, W_{\text {LeB }}=\text { power density losses due to electron particle } \\
& \text { diffusion for the ring and bulk plasma components } \\
& \left(\mathrm{kW} / \mathrm{m}^{3}\right) \\
& \begin{aligned}
W_{L 1 B}= & \text { power density losses due to ion particle diffusion } \\
& \text { for bulk plasma component }\left(\mathrm{kW} / \mathrm{m}^{3}\right)
\end{aligned} \\
& W_{E N e R}, W_{E N e B}=\text { power density losses due to energy conduction by } \\
& \text { electrons for ring and bulk plasma components }\left(\mathrm{kW} / \mathrm{m}^{3}\right) \\
& W_{E N i B}=\text { power density losses due to energy conduction by ions } \\
& \text { for bulk plasma component }\left(\mathrm{kW} / \mathrm{m}^{3}\right) \\
& W_{\text {BLOSS }}=\begin{array}{l}
\text { radiative power density losses for bulk plasma } \\
\text { component }\left(\mathrm{kW} / \mathrm{m}^{3}\right)
\end{array} \\
& =W_{\text {BREMSSTRAHLUNG }}+W_{\text {SYNCHROTRON (see below) }}
\end{aligned}
$$




$$
\begin{aligned}
W_{\text {RLOSS }}= & \text { radiative power density losses for ring plasma } \\
& \text { component }\left(\mathrm{kW} / \mathrm{m}^{3}\right) \\
= & (\text { see below })
\end{aligned}
$$

Several options are available to the OASIS user for calculation of the radiative losses from the ring plasma. These options are controlled by $I_{\text {LOSS }}$ in OASIS. The terms which make up the ring radiative loss model are ${ }^{(5,6)}$ :

$$
\begin{aligned}
& W_{\text {BREMSSTRAHLUNG }}=5.35 \times 10^{-37} n_{e R}{ }^{2} Z_{E F F R}\left(T_{e R}\right)^{1 / 2}\left(\text { watts } / m^{3}\right) \\
& W_{\text {SYNCHROTRON }}=6.2 \times 10^{-17} B_{R}^{2} n_{e R} \cdot T_{e R}\left(1+T_{e R} / 204\right)\left(\text { watts } / \mathrm{m}^{3}\right) \\
& W_{\text {SCATTERING }} \cong 5.0 \times 10^{-31} n_{\mathrm{eR}}{ }^{2}\left(\frac{1}{\mathrm{~T}_{\mathrm{eR}}}\right)^{1 / 2} \text { (watts } / \mathrm{m}^{3} \text { ) } \\
& W_{\text {DRAG } 1} \cong 4.0 \times 10^{-32} n_{e R} n_{e B} \frac{\gamma^{2}}{\left(\gamma^{2}-1\right)^{1 / 2}}\left(\text { watts } / m^{3}\right) \\
& W_{D R A G 2} \cong 4.0 \times 10^{-32} n_{e R} n_{e C O L D} \frac{\gamma^{2}}{\left(\gamma^{2}-1\right)^{1 / 2}}\left(\text { watts } / m^{3}\right) \\
& \left.W_{\text {DRAG3 }} \cong 4.0 \times 10^{-32} n_{\mathrm{eR}}\left(\frac{\mathrm{n}_{\mathrm{eB}}}{2}\right) \frac{r^{2}}{\left(\gamma^{2}-1\right)^{1 / 2}} \text { (watts/m }{ }^{3}\right)
\end{aligned}
$$

The model used is controlled by the input value of I LOSS (see Table 4-1).

\subsection{PARTICLE BALANCE MODELING}

The mean particle densities for electrons and various species of ions are handled separately for the ring and bulk plasma components in OASIS modeling. Charge neutrality is modelled for each of the components. Neutral beam particles and fusion produced alpha particles are assumed to be present in the bulk plasma component only. The complete list of particle densities accounted for in CASIS is given in Table 4-2.

The ion species in the bulk plasma component include $\bar{n}_{A}=$ average particle density for "hot" (nonthermalized) alpha particles, $\bar{n}_{A, C}=$ average particle 
TABLE 4-1

OASIS RADIATIVE LOSS MODELS

\begin{tabular}{|c|c|}
\hline ILOSS & $W_{\text {RLOSS }}$ \\
\hline 0 & $w_{\text {BREM }}+w_{\text {SYNC }}+w_{\text {SCAT }}+w_{\text {DRAGI }}+w_{\text {DRAG2 }}$ \\
\hline 1 & $w_{\text {BREM }}+w_{\text {SYNC }}+w_{\text {SCAT }}+w_{\text {DRAGT }}$ \\
\hline 2 & $\left(w_{B R E M}+w_{S Y N C}+w_{S C A T}+w_{D R A G}\right) R L C F F *$ \\
\hline 3 & $W_{\text {BREM }}+W_{\text {SYNC }}$ (used for BULK model) \\
\hline 4 & $w_{\text {BREM }}+w_{\text {SYNC }}+w_{\text {SCAT }}+w_{\text {DRAG3 }}$ \\
\hline 5 & $w_{\text {BREM }}+w_{\text {SYNC }}+w_{\text {SCAT }}+w_{\text {DRAG3 }}+w_{\text {DRAG2 }}$ \\
\hline
\end{tabular}


TABLE 4-2

OASIS PARTICLE DENSITIES

\begin{tabular}{|c|c|c|}
\hline $\begin{array}{l}\text { PARTICLE } \\
\text { DENSITY } \\
\end{array}$ & $\begin{array}{r}\text { PLASMA ( } B=\text { bulk) } \\
\text { COMPONENT ( } R=\text { ring) } \\
\end{array}$ & DESCRIPTION \\
\hline $\bar{n}_{M 1}$ & $B, R$ & . \\
\hline $\bar{n}_{M 2}$ & $B, R$ & $\begin{array}{l}\text { MEAN PARTICLE DENSITIES } \\
\text { FOR PLASMA IONS }\end{array}$ \\
\hline $\bar{n}_{M 3}$ & $B, R$ & $M 1, M 2, M 3, M 4$ \\
\hline $\bar{n}_{M 4}$ & $B, R$ & \\
\hline $\bar{n}_{\mathrm{eB}}$ & B & MEAN ELECTRON DENSITY IN BULK \\
\hline $\bar{n}_{e R}$ & $R$ & MEAN ELECTRON DENSITY IN RING \\
\hline $\bar{n}_{I B}$ & B & MEAN INPURITY DENSITY IN BULK \\
\hline $\bar{n}_{I R}$ & R & MEAN IMPURITY DENSITY IN RING \\
\hline $\bar{n}_{A}$ & B & MEAN "HOT" ALPHA DENSITY \\
\hline $\bar{n}_{A, C}$ & B & MEAN "COLD" ALPHA DENSITY \\
\hline $\bar{n}_{\mathrm{NB}}$ & B & $\begin{array}{l}\text { MEAN "HOT" NEUTRAL BEAM PARTICLE } \\
\text { DENSITY }\end{array}$ \\
\hline
\end{tabular}


density for "cold" (thermalized) alpha particles, and $\bar{n}_{\mathrm{NB}}=$ average particle density of "hot" injected neutral beam particles. In this way, the code does not assume that fusion born alphas and high-energy injected neutral beam particles are thermalized instantly, but rather that these "hot" particles will make up some fraction of the bulk plasma with a finite thermalization (slowingdown) time.

The particle balance equations modeling charge neutrality in the bulk and ring plasma components are:

BULK PLASMA

$$
\begin{aligned}
\bar{n}_{e B}= & z_{M 1} \bar{n}_{M 1 B}+z_{M 2} \bar{n}_{M 2 B}+z_{M 3} \bar{n}_{M 3 B}+z_{M 4} \bar{n}_{M 4 B}+z_{I} \bar{n}_{I B}+ \\
& z_{A} \bar{n}_{A}+z_{A, C} \bar{n}_{A, C}+z_{N B} \bar{n}_{N B}
\end{aligned}
$$

RING PLASMA

$$
\bar{n}_{e R}=z_{M 1} \bar{n}_{M 1 R}+z_{M 2} \bar{n}_{M 2 R}+z_{M 3} \bar{n}_{M 3 R}+z_{M 4} \bar{n}_{M 4 R}+z_{I} \bar{n}_{I R}
$$

where $z_{j}$ is the charge on the " $j$ th particle.

The average impurity densities in the bulk and ring components are calculated from these relations, assuming $Z_{A}=2$ ("hot" alphas), $Z_{M 4}=2$ (helium), $Z_{M I}=$ $Z_{M 2}=Z_{M 3}=1$ (hydrogen isotopes):

BULK PLASMA

$$
\bar{n}_{I B}=\left[\bar{n}_{e B}\left(z_{E F F B}-1\right)-2\left(\bar{n}_{M 4}+\bar{n}_{A}+\bar{n}_{A}\right)\right] /\left(Z_{I}\left(z_{I}-1\right)\right)
$$

RING PLASMA

$$
\bar{n}_{I R}=\left[\bar{n}_{e R}\left(z_{E F F R}-1\right)-2 \bar{n}_{M 4}\right] /\left(z_{I}\left(z_{I}-1\right)\right)
$$

where $\quad z_{E F F R}=\frac{\sum_{i} \bar{n}_{i} z_{i}^{2}}{\sum_{i} \bar{n}_{i} z_{i}}$ for ring ions $i$ 


$$
z_{E F F B}=\frac{\sum_{j} \bar{n}_{j} z_{j}^{2}}{\sum_{j} n_{j} z_{j}} \text { for bulk ions } j
$$

The densities of alpha particles and "hot" neutral beam particles are calculated as:

$$
\begin{aligned}
& \bar{n}_{A}=\frac{W_{\alpha}}{\left.\varepsilon E_{\alpha} \times 1000\right)} \tau_{\alpha S} \\
& \bar{n}_{A, C}=\frac{f_{2} W_{\alpha}}{\varepsilon\left(E_{\alpha} \times 1000\right)} \tau_{i B} \\
& \bar{n}_{N B}=\frac{W_{N B}}{\varepsilon E_{N B}} \tau_{N B S}
\end{aligned}
$$

where

$$
\begin{aligned}
E_{\alpha} & =3.5 \mathrm{MeV} \\
\varepsilon & =1.602 \times 10^{-19} \mathrm{~kJ} / \mathrm{keV} \\
\tau_{\alpha S}, \tau_{N B S}= & \begin{array}{l}
\text { alpha particle and hot neutral beam particle } \\
\text { slowing-down times }
\end{array} \\
\tau_{i B}= & \text { bulk ion particle confinement time } \\
f_{2}= & \begin{array}{l}
\text { fraction of fusion born alpha particles retained } \\
\text { in the bulk plasma until thermalized }
\end{array}
\end{aligned}
$$

\subsection{CHARACTERISTIC TIME CONSTANTS}

In addition to the alpha particle and "hot" neutral beam particle slowing-down times., code modeling includes the particle and energy confinement times for the ring and bulk plasmas. Table 4-3 gives all of the time constants used in OASIS. The energy confinement times are input by the user and may be calculated to balance with other plasma parameters by using the $n_{\tau}$ balance options. The particle confinement times are also input by the user and remain fixed throughout the calculation.

Finally; the slowing-down times for alpha particles and neutral beam particles are given by Jassby ${ }^{(7)}$ and Spitzer ${ }^{(8)}$ : 
TABLE 4-3

TIME CONSTANTS USED IN OASIS

$$
\begin{array}{ll}
\tau_{E R}, \tau_{E B} & - \text { RING, BULK ENERGY CONFINEMENT TIMES } \\
\tau_{e R}, \tau_{e B} & - \text { RING, BULK ELECTRON CONFINEMENT TIMES } \\
\tau_{i B} & - \text { BULK ION CONFINEMENT TIME } \\
\tau_{\text {NBS }} & - \text { NEUTRAL BEAM PARTICLE SLOWING-DOWN TIME } \\
\tau_{\alpha S} & - \text { ALPHA PARTICLE SLOWING-DOWN TIME }
\end{array}
$$


ALPHA PARTICLES

$$
\tau_{\alpha S}=0.664 \times 10^{19} \frac{\left(T_{e B}(k e V)\right)^{3 / 2}}{\bar{n}_{e B}\left(m^{-3}\right) \ln \Lambda_{e B}} \ln \left[1+\left(\frac{E_{\alpha}(M e V) \times 1000}{W_{c}(k e V)}\right)^{3 / 2}\right]
$$

NEUTRAL BEAM PARTICLES

$$
\tau_{\mathrm{NBS}}=1.328 \times 10^{19} \frac{\left(T_{\mathrm{eB}}(\mathrm{keV})\right)^{3 / 2}}{\bar{n}_{\mathrm{eB}}\left(\mathrm{m}^{-3}\right) \text { en } \Lambda_{\mathrm{eB}}} \ln \left[1+\left(\frac{E_{\mathrm{NB}}(\mathrm{keV})}{\mathrm{W}_{\mathrm{c}}(\mathrm{keV})}\right)^{3 / 2}\right]
$$

where $E_{\alpha}=3.5 \mathrm{MeV}$

$E_{\mathrm{NB}}=$ neutral beam particle input energy (keV)

$$
\Lambda_{e B}=11.6 \times 10^{16} \frac{\left(T_{e B}(\mathrm{keV})\right)^{3 / 2}}{\left(\bar{n}_{e B}\left(\mathrm{~m}^{-3}\right)\right)^{1 / 2}}
$$

The transition energy $W_{C}$ is given by:

$$
\begin{aligned}
W_{C}= & 14.8 T_{e B} A_{h}\left[\left(\frac{Z_{I}{ }^{2} \bar{n}_{I B}}{A_{I}}+\frac{Z_{A, C}{ }^{2} \bar{n}_{A, C}}{A_{A, C}}+\frac{Z_{M 1}{ }^{2} \bar{n}_{M 1 B}}{A_{M 1}}+\right.\right. \\
& \left.\left.\frac{Z_{M 2}{ }^{2} \bar{n}_{M 2 B}}{A_{M 2}}+\frac{Z_{M 3}{ }^{2} \bar{n}_{M 3 B}}{A_{M 3}}+\frac{Z_{M 4}{ }^{2} \bar{n}_{M 4 B}}{A_{M 4}}\right) \frac{1}{n_{e B}} \frac{\ln \Lambda_{i}}{\ln \Lambda_{e}}\right]
\end{aligned}
$$

where $A_{j}=$ mass of $j^{\text {th }}$ particle $(\mathrm{kg})$

$A_{h}=$ mass of injected neutral beam particle or fusion
born alpha $(\mathrm{kg})$

$$
\Lambda_{i}=4.86 \times 10^{17} \frac{\left(T_{i B}(\mathrm{keV})\right)^{3 / 2}}{\left(\bar{n}_{\mathrm{eB}}\left(\mathrm{m}^{-3}\right)\right)^{1 / 2}}
$$

\subsection{PLASMA 3ETA}

The calculation of plasma beta in OASIS takes into account all species of particles present. Beta calculations are performed at various points in the balance loops to check for the stability condition ring beta $\lambda$ bulk beta. 
The model equations are:

RING PLASMA

$$
\beta_{R}=\frac{0.8 \pi \bar{n}_{e R}\left(m^{-3}\right)\left(T_{e R}(\mathrm{keV})+T_{i R}(\mathrm{keV})\right) \varepsilon}{\left(B_{R}(T)\right)^{2} \times 1000}
$$

\section{BULK PLASMA}

$$
\begin{aligned}
\beta_{B}= & 0.8 \pi\left[\left(\bar{n}_{e B}\left(m^{-3}\right) T_{e B}(k e V)+\bar{n}_{M 1 B} T_{M 1 B}+\bar{n}_{M 2 B} T_{M 2 B}+\right.\right. \\
& \left.\bar{n}_{M 3 B} T_{M 3 B}+\bar{n}_{M 4 B} T_{M 4 B}\right)+\frac{2}{3} \bar{n}_{N B}\left(\frac{E_{N B}(k e V)+T_{e B}}{2}\right)+ \\
& \left.\frac{2}{3} \bar{n}_{A}\left(\frac{1000 E_{\alpha}(M e V)+T_{e B}}{2}\right)+\frac{2}{3} \bar{n}_{A, C} T_{M 2 B}\right] /\left(B_{B}(T)\right)^{2} \times 1000
\end{aligned}
$$

$$
\text { where } \begin{aligned}
\varepsilon= & 1.602 \times 10^{-16} \mathrm{~J} / \mathrm{keV} \\
T_{j}= & \text { temperature of the } \mathrm{j}^{\text {th }} \text { particle species in the bulk } \\
E_{\alpha}= & 3.5 \mathrm{MeV} \\
E_{\mathrm{NB}}= & \text { neutral beam injection energy }(\mathrm{keV}) \\
\mathrm{B}_{\mathrm{R}}, \mathrm{B}_{\mathrm{B}}= & \begin{array}{l}
\text { mean magnetic field strength associated with the ring } \\
\text { and bulk plasmas }(T)
\end{array}
\end{aligned}
$$

\subsection{SCALING LAWS}

Scaling laws obtained from the EBT-I results are used by OASIS to calculate the collisionality factor and the $n \tau$ product for the bulk plasma. When the bulk $n_{\tau}$ balance loop is used without a scaling law it is a once through calculation of the energy confinement time $\tau_{E B}$ required for balance with the other plasma parameters. The scaling laws used for collisionality and bulk ni $\operatorname{are}^{(4)}$ :

\section{COLLISIONALITY}

$$
(\nu / \Omega) \propto \bar{n}_{A B} B_{B} \bar{a}_{C} a_{C B} / T_{e B}^{5 / 2}
$$


$\underline{\mathrm{n}_{\mathrm{eB}}{ }^{\tau} E B}$

$$
\bar{n}_{e B} \tau_{E B} \propto A_{C}^{2} T_{e B}^{3 / 2}
$$

where $\quad \bar{a}_{c}=$ mean minor radius of coil (current weighted)

$$
\begin{aligned}
& a_{C B}=\text { "clear bore" radius } \\
& A_{C}=\text { coil aspect ratio }=R_{0} / \bar{a} c
\end{aligned}
$$

Since the scaling of $n_{\tau}$ goes as $T^{3 / 2}$ the bulk plasma $n_{\tau}$ balance loop used with this scaling law balances both $\tau_{E B}$ and $T_{e B}$ with the other bulk plasma parameters and the scaling law simultaneously. A generalized $n_{\tau}$ scaling has been included in the code of the form

$$
n \tau \propto\left(A_{C}\right)^{X 1}\left(T_{e}\right)^{X 2}(B)^{X 3}(B)^{X 4}\left(Z_{e f f}\right)^{X 5}
$$

This permits some flexibility in using OASIS with new scaling laws as they are developed.

\subsection{ANCILLARY CALCULATIONS}

Other important calculations performed by the code to complete the description of an EBT device are described below. Many of these parameter values would be required as input for EBT sizing and costing calculations.

\subsubsection{PLASMA VOLUME}

The volumes of the bulk and ring plasmas in EBT are estimated as (see Figure 4-T),

BULK PLASMA

$$
V_{B}=2 \pi^{2} a_{p}^{2} R_{0}
$$

\section{RING PLASMA}

$$
V_{R}=N\left(2 \pi^{2} a_{\text {ring }} R_{\text {min }}\left(R_{\text {maj }}+\delta / 2\right)\right)
$$



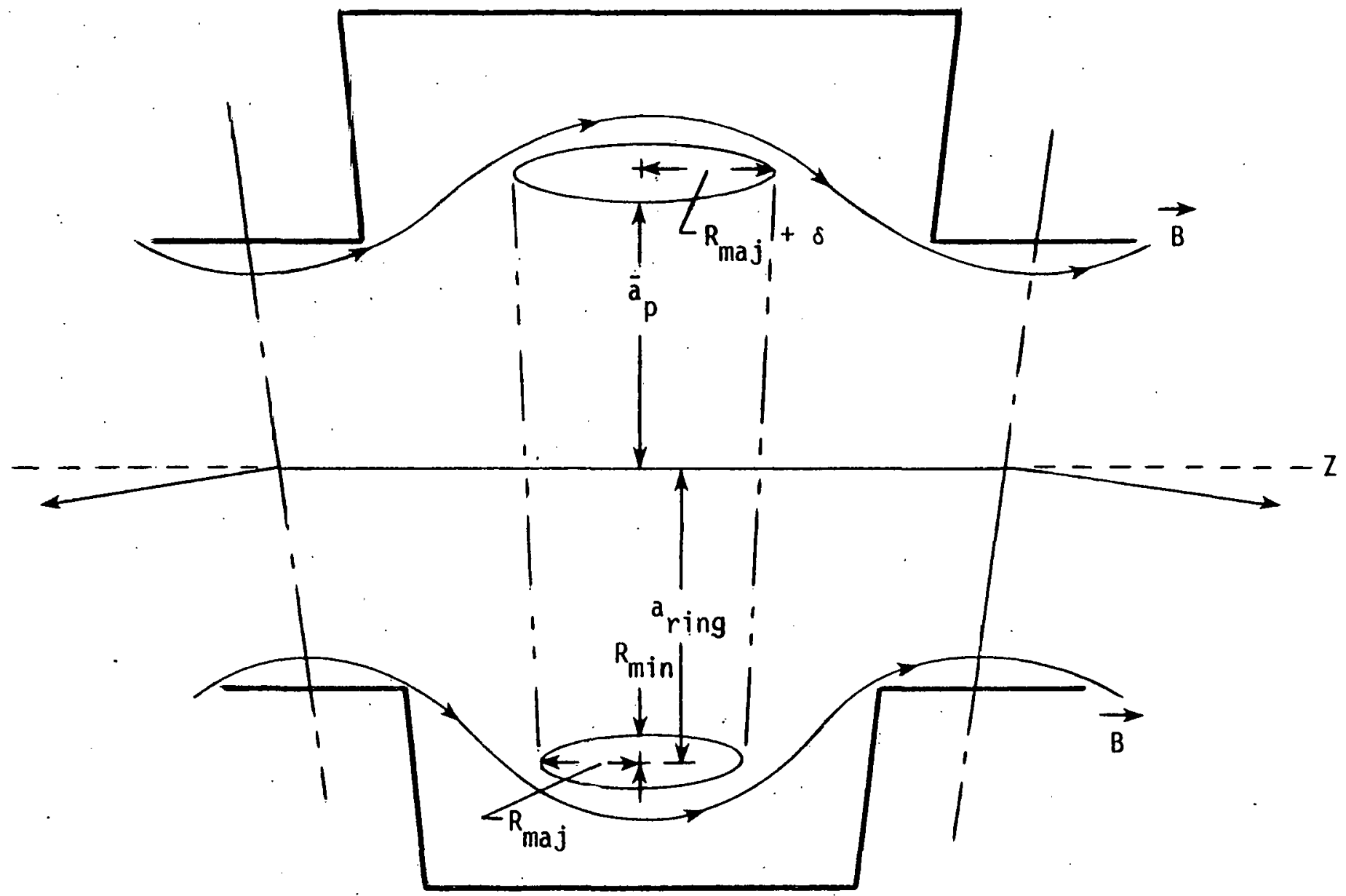

Figure 4-1. Typical Mirror Sector in EBT. 
where $\quad R_{0}=$ major radius of the bumpy torus

$\bar{a}_{p}=$ average bulk plasma minor radius

$N=$ number of EBT sectors

$a_{\text {ring }}=\begin{aligned} & \text { radius of relativistic electron annulus about torus } \\ & \text { ring axis }\end{aligned}$

$R_{\min }, R_{\text {maj }}=$ minor and major radii of ring elliptical cross section

$\delta=$ cant factor for major radius of the ring elliptical cross section

EBT-I values for these parameters are given in Table 2-1.

\subsubsection{SURFACE AREA OF VACUUM VESSEL}

The surface area of the vacuum vessel used for the wall loading calculations in OASIS is approximated by (see Figure 4-2):

$$
S_{v a c} \cong E_{F}\left(4 \pi^{2} R_{0} a_{t}+2 \pi N s_{C}\left(a_{C B}-a_{t}\right)+2 \pi N\left(a_{t}{ }^{2}-a_{C B}{ }^{2}\right)\right)
$$

where $E_{F}=$ effectiveness factor

$a_{t}=$ vacuum vessel minor radius between mirror coils

$s_{c}=$ mirror coil width

The approximation improves for fixed $a_{t} / a_{C B}$ ratio as the clear bore aspect ratio $R_{0} / a C B$ increases.

\subsubsection{FUELING}

The bulk plasma fueling fraction by neutral beam particles is modeled in OASIS by:

$$
F_{N B}=\frac{f_{B 1} \dot{N}_{N B} \tau_{p e B}}{v_{B} \bar{n}_{i B}\left(1-f_{R C Y C}\right)}
$$




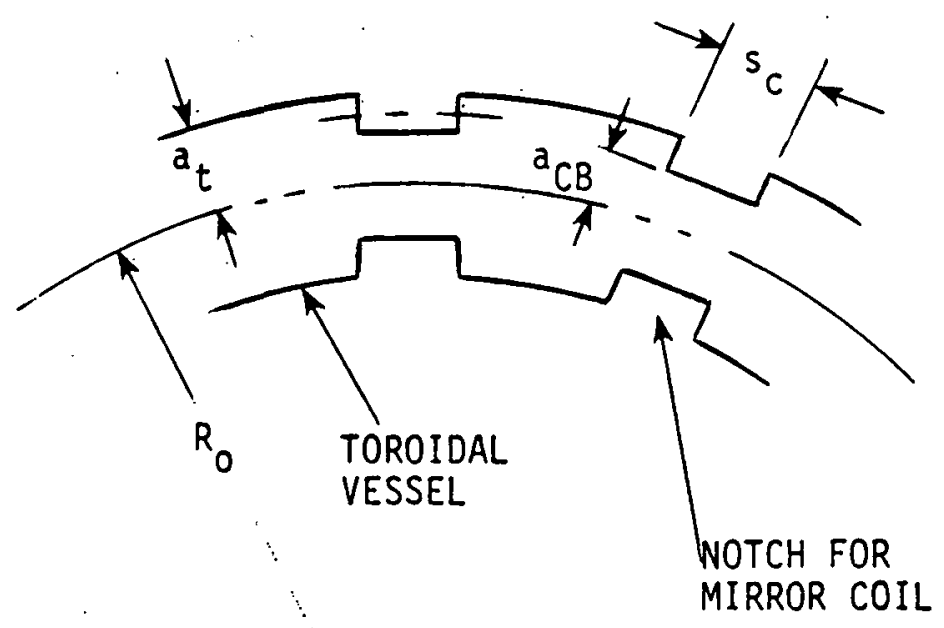

Figure 4-2. Bumpy Torus Model for Surface Area Calculation.

where $\quad f_{B I}=$ fraction of input neutral beam particles which are retained in the plasma

$$
\begin{aligned}
\dot{N}_{N B}= & \text { neutral beam particle feed rate } \\
\bar{n}_{i B}= & \text { average density of bulk ion species (species Ml or } \\
& M 2 \text { (deuterium), depending on plasma option) } \\
f_{R C Y C}= & \text { recycle fraction for particles striking the vessel wall }
\end{aligned}
$$

The particle fueling rate required to sustain the bulk plasma for a single ion species is

$$
\dot{\mathrm{N}}_{M T}=\left[\frac{\left(j-F_{N B}\right) \bar{n}_{M T B} V_{B}}{\tau_{p e B}}\right]\left(1-f_{R C Y C}\right)
$$

When two ion species are present (i.e., deuterium and tritium) the particle fueling rate is

$$
\dot{N}_{i B}=\dot{N}_{M 2 B}+\dot{N}_{M 3 B}
$$

where $\quad \dot{N}_{M 2 B}=\left[\frac{\left(1-F_{N B}\right) \bar{n}_{M 2 B} V_{B}}{\tau_{p e B}}\right]\left(1-f_{R C Y C}\right)$ 


$$
\dot{N}_{M 3 B}=\left[\frac{\bar{r}_{M 3 B} V_{B}}{\tau_{p e B}}\right]\left(1-f_{R C Y C}\right)
$$

\subsubsection{FUSION EFFECTS}

For ignition EBT devices the code calculates the fusion power and neutron wall loading. The modeling equations are:

$$
\begin{aligned}
& P_{\text {FUS }}=\left(\frac{17.6}{3.5}\right) W_{A} V_{B} \\
& W_{\text {LOADN }}=\left(\frac{14.1}{3.5}\right) W_{A} V_{B} / S_{V A C}
\end{aligned}
$$

The alpha power density $W_{\alpha}$ is the sum of the power densities for alphas produced in plasma-plasma and beam-plasma reactions. This is given by:

$$
\begin{aligned}
W_{\alpha}= & f_{1}\left(\overline { n } _ { M 2 B } \overline { n } _ { M 3 B } \left\langle\sigma V{ }_{F U S} \varepsilon\left(E_{\alpha} \times 1000\right)+\right.\right. \\
& \left.\left(\frac{3.5}{17.6}\right) \frac{P_{N B} Q^{\top}}{V_{B}} \frac{\bar{n}_{M 3 B}}{\sum_{j} \bar{n}_{j B}}\right) .
\end{aligned}
$$

where $\varepsilon=1.602 \times 10^{-16} \mathrm{~J} / \mathrm{keV}$

$f_{1}=$ fraction of alpha power retained in the bulk plasma $<\sigma V\rangle$ FUS is obtained using a polynomial fit to the $D-T$ fusion
cross section curve

$$
\begin{aligned}
E_{A}= & 3.5 \mathrm{MeV} \\
P_{N B}= & \text { input neutral beam power (keV) } \\
Q^{\top}= & \text { factor to account for deuterium background plasma } \\
& \text { effects with (deuteron beam) - (tritium plasma) fusions } \\
\sum_{j} \bar{n}_{j B}= & \bar{n}_{M 1 B}+\bar{n}_{M 2 B}+\bar{n}_{M 3 B}+\bar{n}_{M 4 B}+\bar{n}_{I B} .
\end{aligned}
$$




\subsubsection{CRITICAL DENSITY}

The critical density for microwave penetration into the ring and bulk plasmas of EBT is given by:

RING PLASMA

$$
\bar{n}_{C R I T R}=C B_{R}^{2}
$$

BULK PLASMA

$$
\bar{n}_{C R I T B}=C B_{B}^{2}
$$

where $\quad c=\frac{e_{0}}{\gamma m_{e}}$

$$
e_{0}=1.602 \times 10^{-19} \mathrm{C}
$$

Relativistic effects for the ring plasma electrons are taken into account by

$r=\frac{\left(\left(T_{e R}+511\right) \times 1000\right) \varepsilon}{m_{e} c^{2}}$

$$
\varepsilon=1.602 \times 10^{-19} \mathrm{~J} / \mathrm{eV}
$$

\subsubsection{MICROWAVE FREQUENCY}

The Electron Cyclotron Resonance Heating (ECRH) frequencies for the ring and bulk plasmas are

\section{RING PLASMA}

$$
\begin{array}{ll}
f_{R 1}=\frac{e B_{R}}{2 \pi m_{e}} & \text { FUNDAMENTAL } \\
f_{R 2}=2 f_{R 1} & 2^{\text {nd }} \text { HARMONIC }
\end{array}
$$

\section{BULK PLASMA}

$$
f_{B T}=\frac{e B_{B}}{2 \pi m_{e}} \quad \text { FUNDAMENTAL }
$$

Relativistic effects in the rings are not taken into account in this model. 


\subsubsection{LARMOR RADII}

OASIS calculates the Larmor radii for electrons and all ion species in the ring and bulk plasmas. The modeling equation used is

$$
\rho_{j}=\frac{\gamma A_{j} \bar{v}_{j}}{e B}
$$

where $A_{j}=$ mass of the $j^{\text {th }}$ particle

$\bar{v}_{j}=$ average velocity of the $j^{\text {th }}$ particle

$B=B_{R}$ or $B_{B}$ for particles in the ring or bulk plasma respectively

The average velocity $v_{j}$ is obtained by

$$
\begin{array}{ll}
v_{j}=\left(\frac{3\left(T_{j} \times 1000\right) e}{M_{j}}\right)^{1 / 2} & T_{j}<100 \mathrm{keV} \\
v_{j}=\left(\frac{r^{2}-1}{r^{2}}\right) c^{2} & T_{j} \geq 100 \mathrm{keV} .
\end{array}
$$

This model assumes that the average particle velocity $v_{j}$ is all perpendicular to the magnetic field lines and calculates the maximum Larmor radius for the $j^{\text {th }}$ particle with temperature $T_{j}$. 


\subsection{TRADE STUDY - OEVICE SIZE}

The plasma dimensions and volume are important considerations for an EBT machine since they impact the input power requirements necessary to maintain a given set of operating conditions. The effects of changes in device and plasma size on input power requirements and key plasma parameters are shown in Figures 5-1 through 5-6.

The parameters obtained from the EBT-I experimental data were used to establish the values of the theoretical constants and coefficients used in OASIS for this trade study. Key machine parameters, plasma parameters, and theoretical physics data for EBT-I are given in Table 2-1. This is a self-consistent set as verified by OASIS calculations. The theoretical coefficients and constants listed in the table were used in the trade studies without modification, except the input microwave fractions $R_{F R A C}, B_{F R A C}$, and the power sharing coefficients $R_{D I V}$ and $B_{D I V}$. These coefficients were changed consistent with changes in the energy conduction loss terms $W_{E N e R}, W_{E N e B}$, and $W_{E N i B}$ (see Section 4.0 ) so that the study was normalized to a baseline set of parameters (Table 5-1) operated in a device with major radius $R_{0}=4.2 \mathrm{~m}$. Hand calculations were iterated to obtain a set of input power fractions and energy conduction loss terms, which were consistent with the baseline set of plasma parameters in the $R_{0}=4.2 \mathrm{~m}$ device. The power fractions and energy conduction loss terms were then used in the calculations for different size devices.

The baseline set of plasma parameters and device parameters for the trade study are essentially those of a hydrogen operated proof-of-principle EBT machine as defined in a recent Westinghouse report ${ }^{(4)}$. The study was normalized by holding constant dimensionless parameters related to the device size, viz, aspect ratio to the coil current center $A_{C}=17.5$, the mirror ratio ${ }^{B} C T / B_{\text {mid }}=2.53$, the ratio of coil mean spacing to current center minor radius $R_{D C}=D_{C} / 2 \bar{a}_{C}=1.52$, and the clear bore aspect ratio $A_{C B}=28.0$. The choices of major radii $R_{0}=4.0,4.2,4.8,5.25,5.5(\mathrm{~m})$ were stimulated by the 
TABLE 5-1

PARAMETERS FOR THE EBT-P BASELINE DEVICE

\section{MACHINE PARAMETERS}

$\begin{array}{lll}N & \text { Number of Device Coils } & 36 \\ R_{0} & \text { Device Major Radius } & 4.2 \mathrm{~m} \\ \bar{a}_{C} & \text { Minor Radius of Mirror Coil (Current Weighted) } & 0.24 \mathrm{~m} \\ { }^{a} \mathrm{CB} & \text { Clear Bore Minor Radius } & 0.15 \mathrm{~m} \\ \bar{a}_{\mathrm{T}} & \text { Mean Minor Radius of Microwave Vacuum Cavity } & 0.30 \mathrm{~m} \\ { }_{\mathrm{B}} & \text { Magnetic Field at Hot Electron Rings } & 1.1 \mathrm{~T} \\ \mathrm{~B}_{\mathrm{B}} & \text { Magnetic Field at Bulk Plasma (Average) } & 2.2 \mathrm{~T} \\ { }_{\mathrm{B}} \mathrm{mid} & \text { Magnetic Field on Midplane Between Coils } & 1.25 \mathrm{~T} \\ { }^{\mathrm{B}} \mathrm{CT} & \text { (On Ring Axis) } & 3.16 \mathrm{~T} \\ { }_{\mathrm{S}} & \text { Magnetic Field in Coil Throat (On Ring Axis) } & \text { Mirror Coil Width }\end{array}$

\section{PLASMA PARAMETERS}

BULK PLASMA

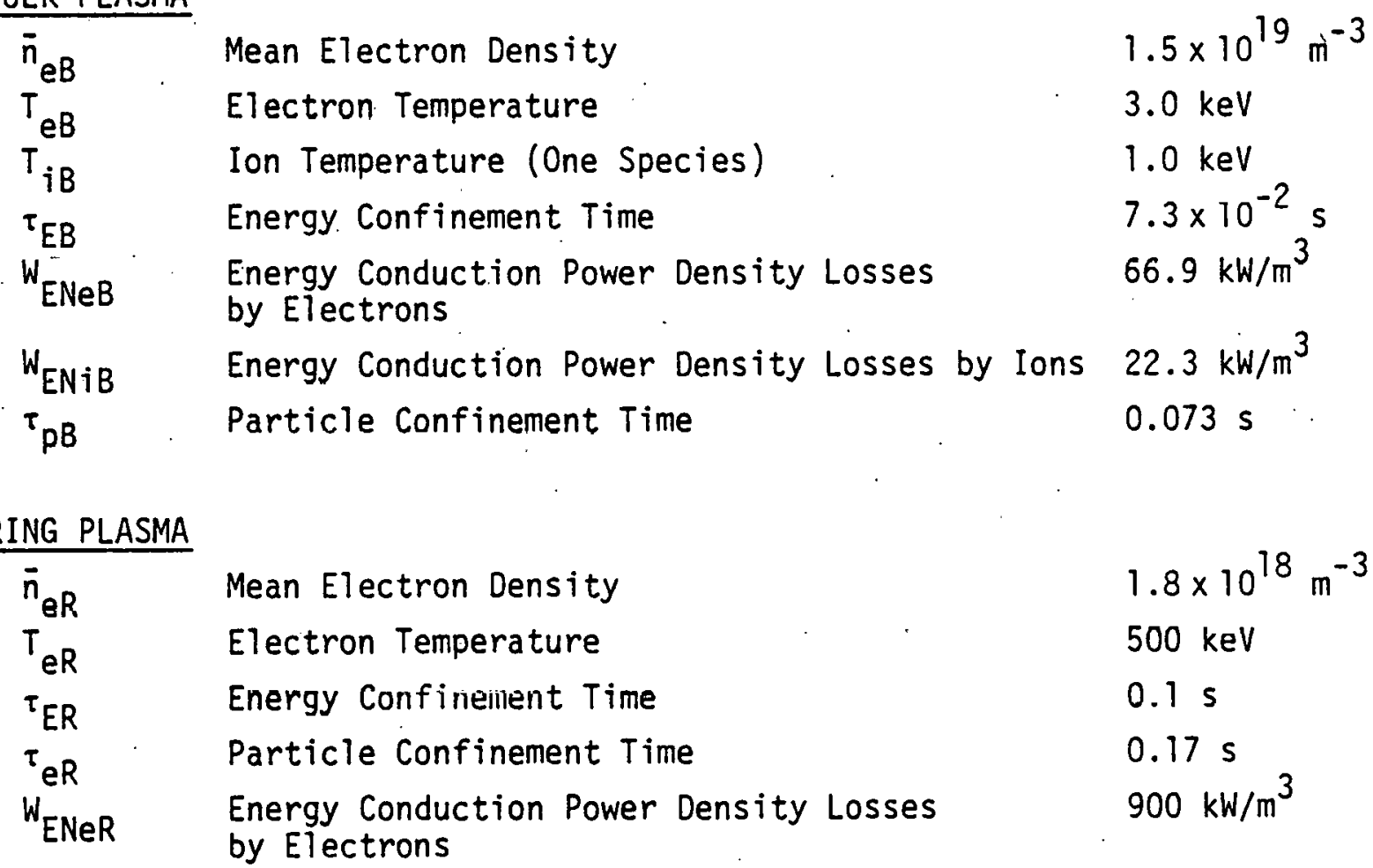


TABLE 5-1 (CONTINUED)

PARAMETERS FOR THE EBT-P BASELINE DEVICE

THEORETICAL COEFFICIENTS AND CONSTANTS

$\begin{array}{lll}R_{F R A C} & \text { Fraction of Input Microwave Power to Rings } & 18.5 \% \\ B_{F R A C} & \text { Fraction of Input Microwave Power to Bulk } & 39.5 \% \\ R_{C P L} & \text { Ring Plasma/Microwaves Coupling Coefficients } & 90 \% \\ { }^{B} B_{C P L} & \text { Bulk Plasma/Microwaves Coupling Coefficients } & 90 \% \\ R_{D I V} & \text { Ring Microwave Power Sharing Coefficients } & 20.6 \% \\ B_{D I V} & \text { Bulk Microwave Power Sharing Coefficients } & 43.9 \%\end{array}$

CONSTANT TRADE STUDY PARAMETERS

$\begin{array}{lll}A_{C} & \text { Aspect Ratio to Current Center } R_{0} / \bar{a} & \\ & & 17.5\end{array}$

$M$ Mirror Ratio $B_{C T} / B_{\text {mid }}$

$R_{D C} \quad$ Mean Distance Between Coils/2 $\bar{a}_{C} \quad 1.52$

$A_{C B} \quad$ Aspect Ratio to Clear Bore $R_{0} / a_{C B}$

SYSTEMS PARAMETERS

$\begin{array}{llr}P_{H} & \text { Input Microwave Power } & 2.4 \mathrm{MW} \\ P_{\mathrm{NB}} & \text { Input Neutral Beam_Power } & 0 \mathrm{MW} \\ P_{\mathrm{RF}} & \text { Input RF Auxiliary Power } & 0 \mathrm{MW}\end{array}$ 


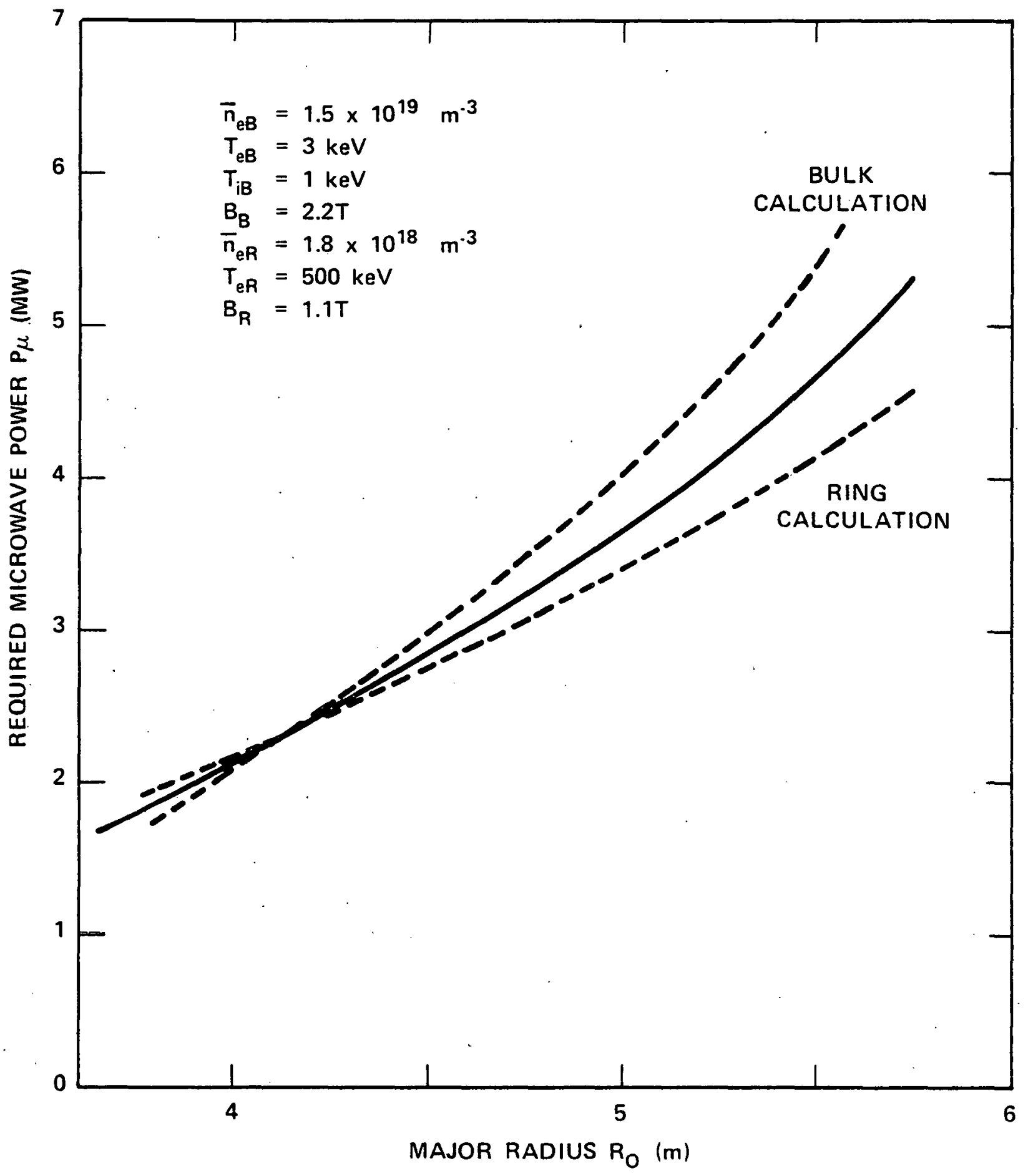

Figure 5-1. Required Input Microwave Power as a Function of Device Major Radius for Fixed Plasma Density and Temperature. 


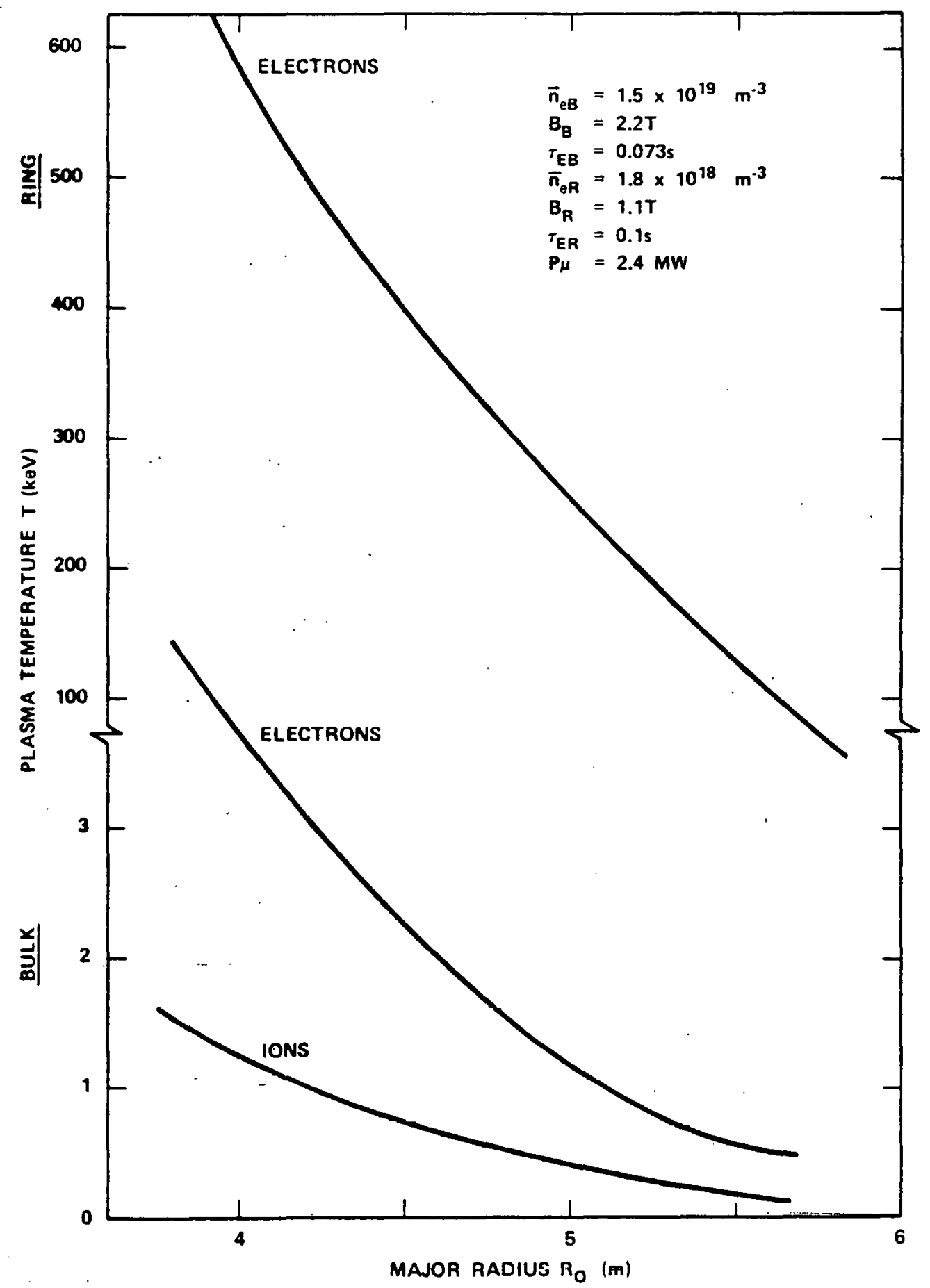

Figure 5-2. Ring and Bulk Plasma Temperatures as a Function of Device Major Radius for Fixed Density and Input Power. 


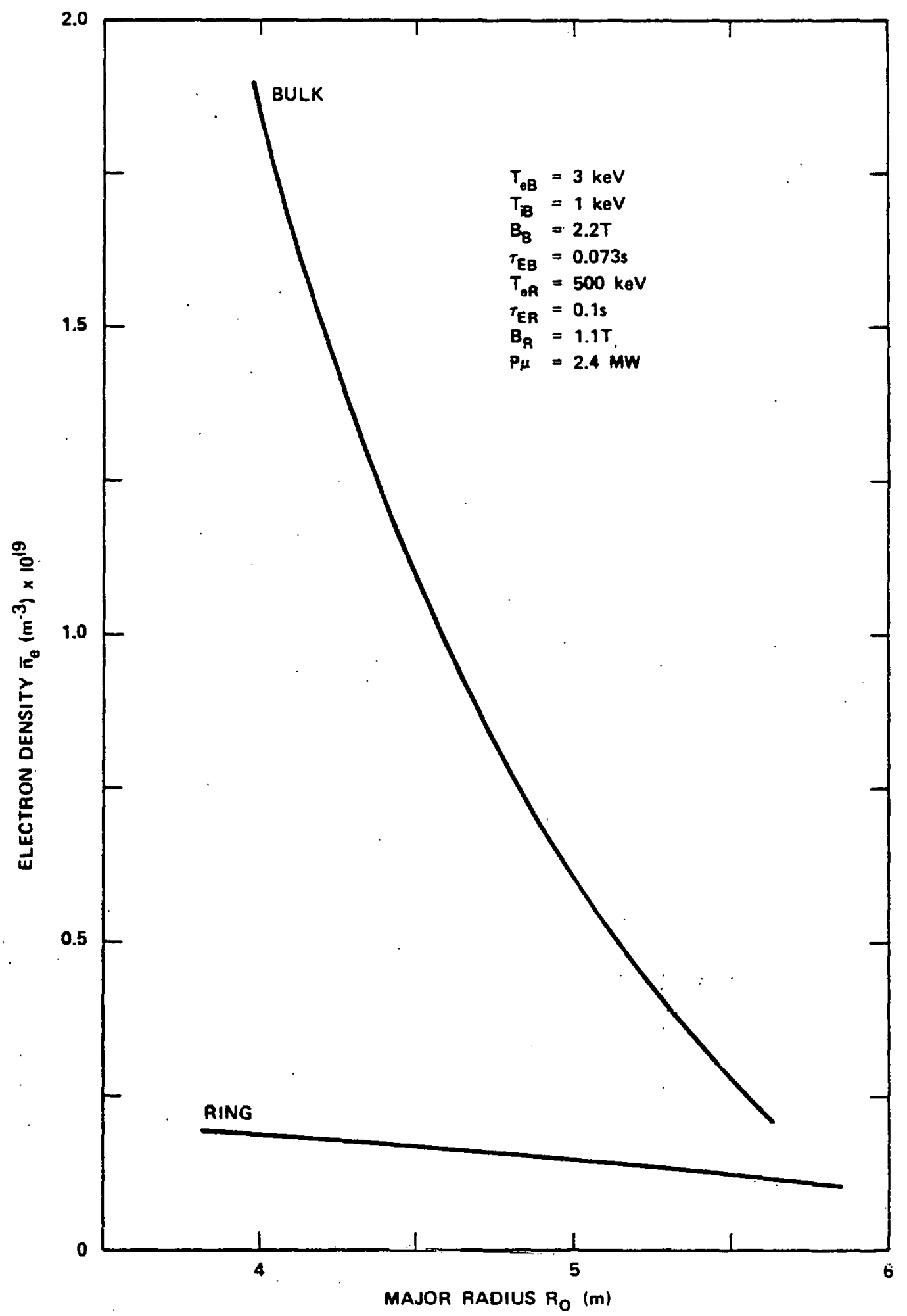

Figure 5-3. Ring and Bulk Electron Densities as a Function of Device Major Radius for Fixed Temperature and Input Power. 


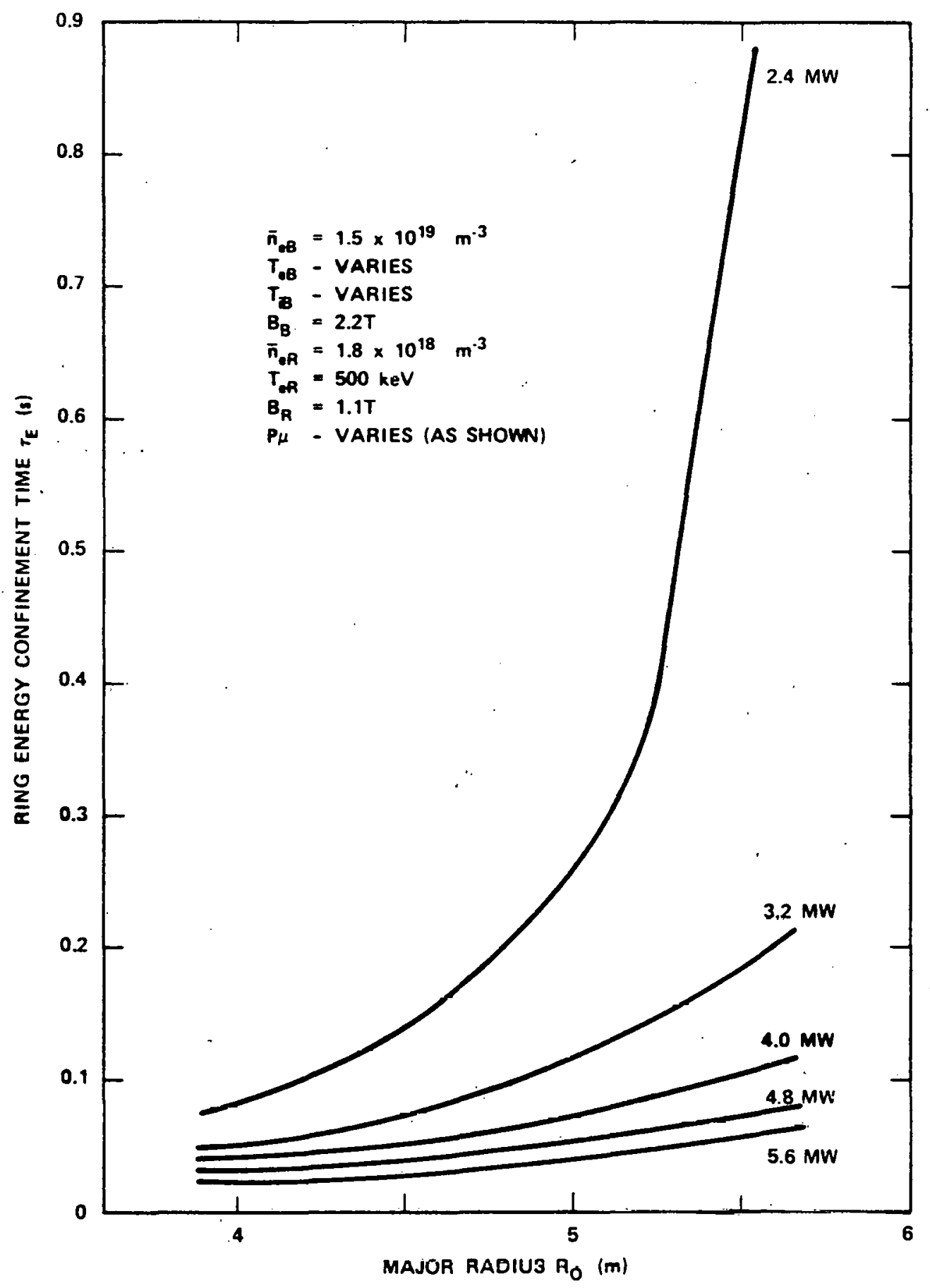

Figure 5-4. Ring Energy Confinement Time as a Function of Device Major Radius for Fixed Ring Density and Temperature. 


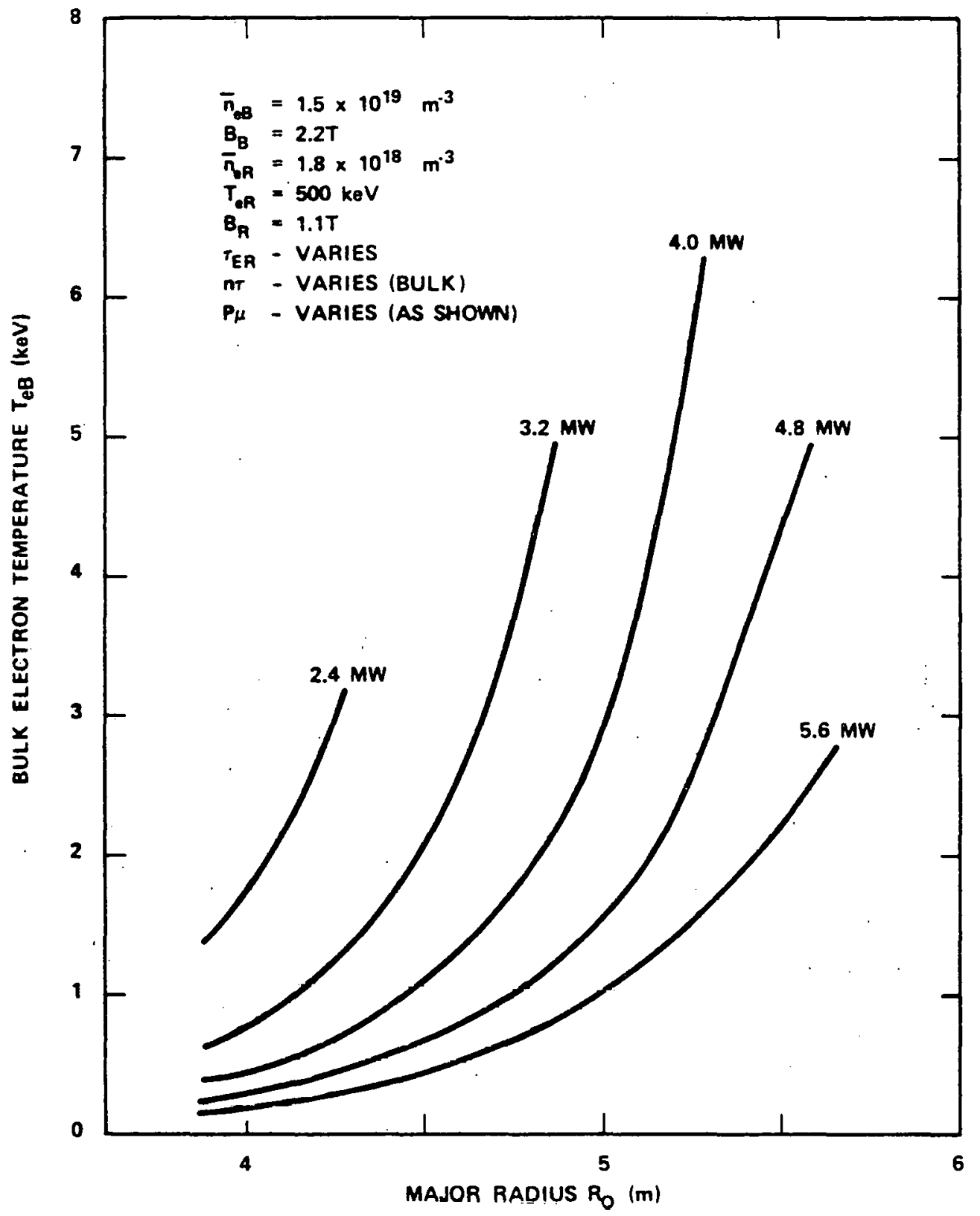

Figure 5-5. Scaled Bulk Electron Temperature as a Function of Device Major Radius for Fixed Density. 


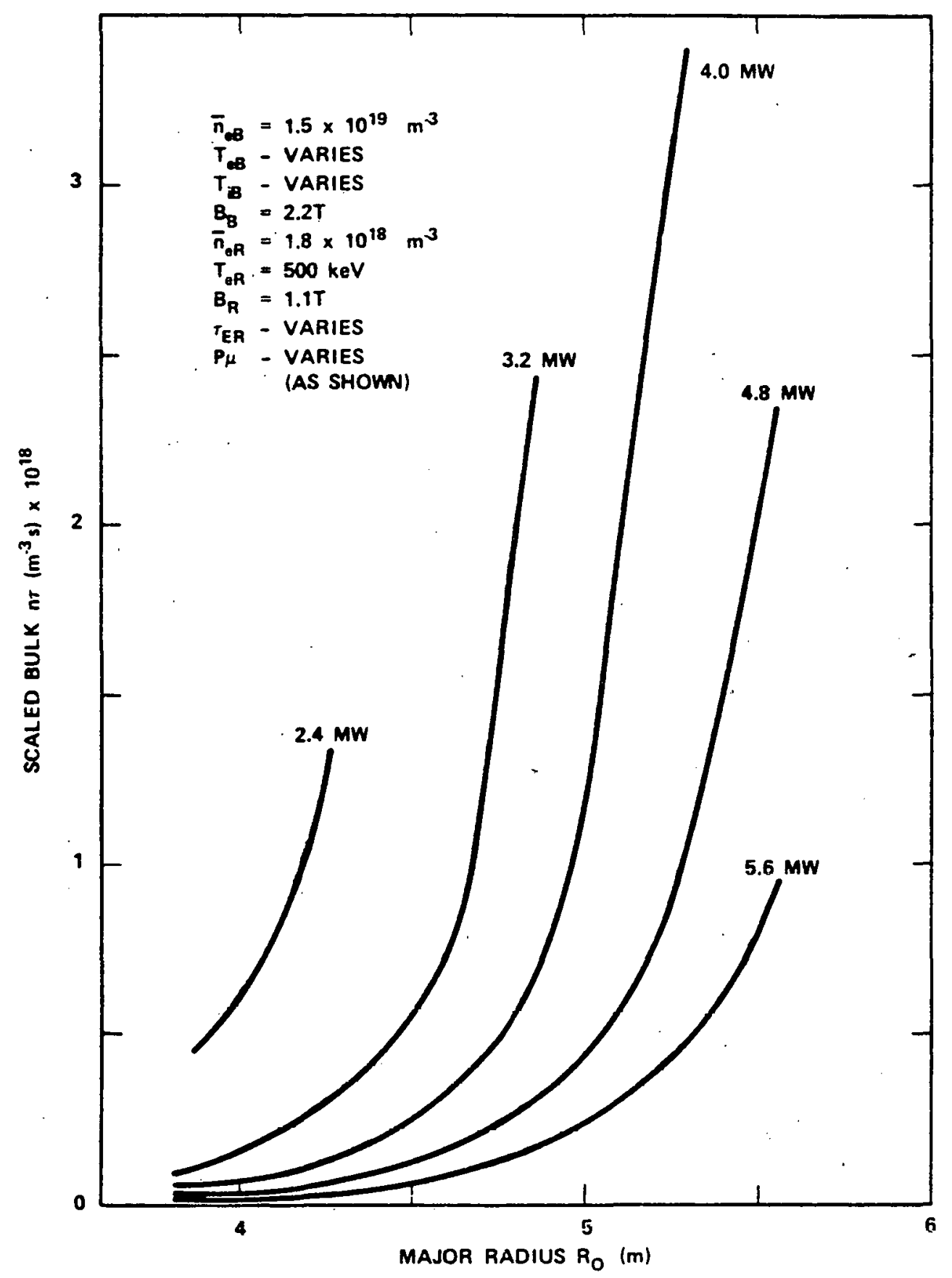

Figure 5-6. Scaled Bulk $n \tau$ as a Function of Device Major Radius for Fixed Density. 
results of proof-of-principle design studies by other industrial companies (e.g., EBASCO, MCDonnel-Douglas, Grumman).

The impact of changes in device size on the input power required to maintain the baseline set of plasma conditions is shown in Figure 5-1. OASIS calculates the total input power required for the device in both the ring and bulk plasma models. The envelope shown in Figure 5-1 results because the assumed input power fractions to the rings and bulk are held constant for all major radii, but the ratio of the ring plasma volume to the bulk plasma volume varies as $R_{0}$ varies. The total power required for a given radius is estimated to be within the upper and lower limits as shown. The larger devices required significantly more power to maintain a given set of plasma conditions due to the larger ring and bulk plasma volumes. For the range of device and plasma sizes considered the required input power scales approximately as $P_{\mu} \propto R_{0}^{2.4}$.

An input power $P_{\mu}=2.4 \mathrm{MW}$ was chosen and the affect of changes in device size on ring and bulk particle temperatures was obtained (Figure 5-2). In each case a factor of five decrease in particle temperature is observed when the major radius increases from 4.0 to $5.5 \mathrm{~m}$. In this study the ring plasma volume increases by a factor of two from $87 \ell$ to $165 \ell$ and the bulk plasma volume increases by a factor of 2.6 from $2730 \ell$ to $7050 \ell$.

For fixed ring density and magnetic field strength the ring $B$ decreases by a factor of five over the range of device sizes considered. EBT-I experimental results indicate that ring $\beta \gtrsim 15 \%$ is required for bulk plasma stability and $T$-mode operation. In this study the ring $\beta$ values for the devices with. $R_{0}=5.25$ and $5.5(\mathrm{~m})$ were $11.5 \%$ and $7.8 \%$ respectively; below the criteria for bulk plasma stability. The device with $R_{0}=4.8(\mathrm{~m})$ showed ring $\beta=18.2 \%$, marginally within the stability criteria while the values of ring $B$ for the devices with $R_{0}=4.0$ and $4.2(\mathrm{~m})$ were $35.0 \%$ and $29.6 \%$, respectively.

The effect of changes in device size on particle densities required for energy balance at constant temperatures is shown in Figure 5-3. The ring particle density changes by less than a factor of two for the range of device sizes considered. However, the bulk densities of electrons and ions decrease by 
more than a factor of six as the major radius of the device increases from 4.0 to $5.5 \mathrm{~m}$.

EBT-I experimental results have indicated that the stability of the hot electron rings is sensitive to the ratio of cold electron to hot electron density in the ring region. A ratio of eight or more may be required for ring stability. In this study only the devices with $R_{0}=4.0$ and $4.2(\mathrm{~m})$ showed density ratios greater than eight ( 9.72 and 8.40 , respectively). The larger devices with $R_{0}=4.8,5.25$, and $5.5(\mathrm{~m})$ had density ratios of $5.14,3.12$, and 2.31, respectively; below the criteria for ring stability.

Figures 5-4 through 5-6 show the required ring energy confinement time, bulk electron temperature and bulk $n_{\tau}$ (scaled as $A_{C}{ }^{2} T_{e B}{ }^{3 / 2}$ ) for energy balance in devices with major radii from 4.0 to $5.5 \mathrm{~m}$. These results impact on the required magnitude of energy confinement time in EBT plasmas for various operating conditions. The study was run for microwave input powers of $2.4,3.2$, 4.0, and 4.8 MW. The plots show that for fixed input power levels a higher energy confinement time is required to maintain the plasmas at the given conditions as the size of the device increases. In addition, for a single device size, better energy confinement is required to maintain the plasma conditions as the input power decreases. For some combinations of input power and device size, the confinement requirements are greater than the range of the calculation, and no energy balance is obtained.

The trends presented in Figures 5-5 and 5-6 show the implications of $A_{C}{ }^{2} T_{e B}{ }^{3 / 2}$ scaling for $n_{\tau}$ in the bulk plasma. The $n_{\tau}$ obtained at energy balance rises rapidiy as the device size increases; but the $T_{e B}^{3 / 2}$ scaling requires that the bulk electron temperature also rise rapidly for balance. Yet, the figures show that the input power to maintain the bulk plasma must decrease if $n \tau$ is to increase consistent with the $\mathrm{T}_{e B}{ }^{3 / 2}$ scaling law. This can be observed by examining a single size device operated with different input powers. For the device with $R_{0}=4.8 \mathrm{~m}$ a decrease in input power from 4.8 to $3.2 \mathrm{MW}$ results in increases in bulk electron temperature (from $1.2 \mathrm{keV}$ to $4.2 \mathrm{keV}$ ) and increases in scaled $n_{\tau}$ (from $2.6 \times 10^{17} \mathrm{~m}^{-3} \mathrm{~s}$ to $18.8 \times 10^{17} \mathrm{~m}^{-3} \mathrm{~s}$ ). This relationship between input power and bulk electron temperature occurs because the kinetic 
energy term (see Section 4.0) $\frac{E_{e B}}{\tau_{E B}}=\frac{3 / 2\left(\bar{n}_{e B}\right)^{2} T_{e B}}{\bar{n}_{e B} \tau_{E B}}$ is large in the bulk energy balance equation. Since $n t$ scales as $T^{3 / 2}$ this term scales as $T^{-1 / 2}$ for fixed density. When the input power decreases this kinetic energy term must decrease for balance resulting in increases in $T_{e B}$. 


\subsection{TRADE STUDY - MODES OF. OPERATION}

A single EBT device can be operated in several modes by using gyrotrons of different frequency for the ECR heating of the ring and bulk plasmas. Since the cyclotron resonance frequency is proportional to the magnetic field strength for constant magnetic field shape in the cavity, the modes of operation of a single EBT device can be characterized by the value of $|\vec{B}|$ at some point in the machine. The calculated values of required input power, particle temperatures, particle densities and characteristic time constants are plotted against $\left|\vec{B}_{C T}\right|$ in Figures $6-1$ through 6-6.

The values of the theoretical coefficients and constants used in OASIS for this study were obtained from the EBT-I data with the same methods used in preparation of the input for the device size trade study. The same set of baseline parameters were used (Table 5-2), and the study was normalized to the device operated with $\left|\vec{B}_{C T}\right|=3.16 T$ (ECRH frequencies $=55 / 28 \mathrm{GHz}$ ). The choice of magnetic field strengths $\left(\left|\vec{B}_{C T}\right|=0.95,1.49,3.16,4.50,5.80\right.$ tesla $)$ was motivated by the current development of 28,55 , and $110 \mathrm{GHz}$ tubes and the existence of $18 \mathrm{GHz}$ tubes on EBT-I. The shape of the magnetic field was held constant in the study by fixing key dimensionless parameters, viz, mirror ratio $M=2.53$, ratio of average field strength in the bulk plasma to $\left|\vec{B}_{C T}\right|=$ 0.70 , and the ratio of field strength at the electron rings to average field strength in the bulk plasma $B_{\text {ring }} / B_{\text {bulk }}=0.50$.

Error messages from the OASIS calculations indicated that the baseline densities exceeded the critical density for microwave propagation in both the ring and bulk plasmas for the two low field cases, $\left|\vec{B}_{C T}\right|=0.95$ and $1.49 \mathrm{~T}$. Since the density dependence of energy conduction loss scaling is not known, the study was conducted using the baseline densitites in all cases. The trends shown in Figures 6-1 to 6-6 are representative of the energy balance dependence on magnetic field strength but do not represent the optimum operating conditions for the EBT device in all cases. For example, in both the ring electron 


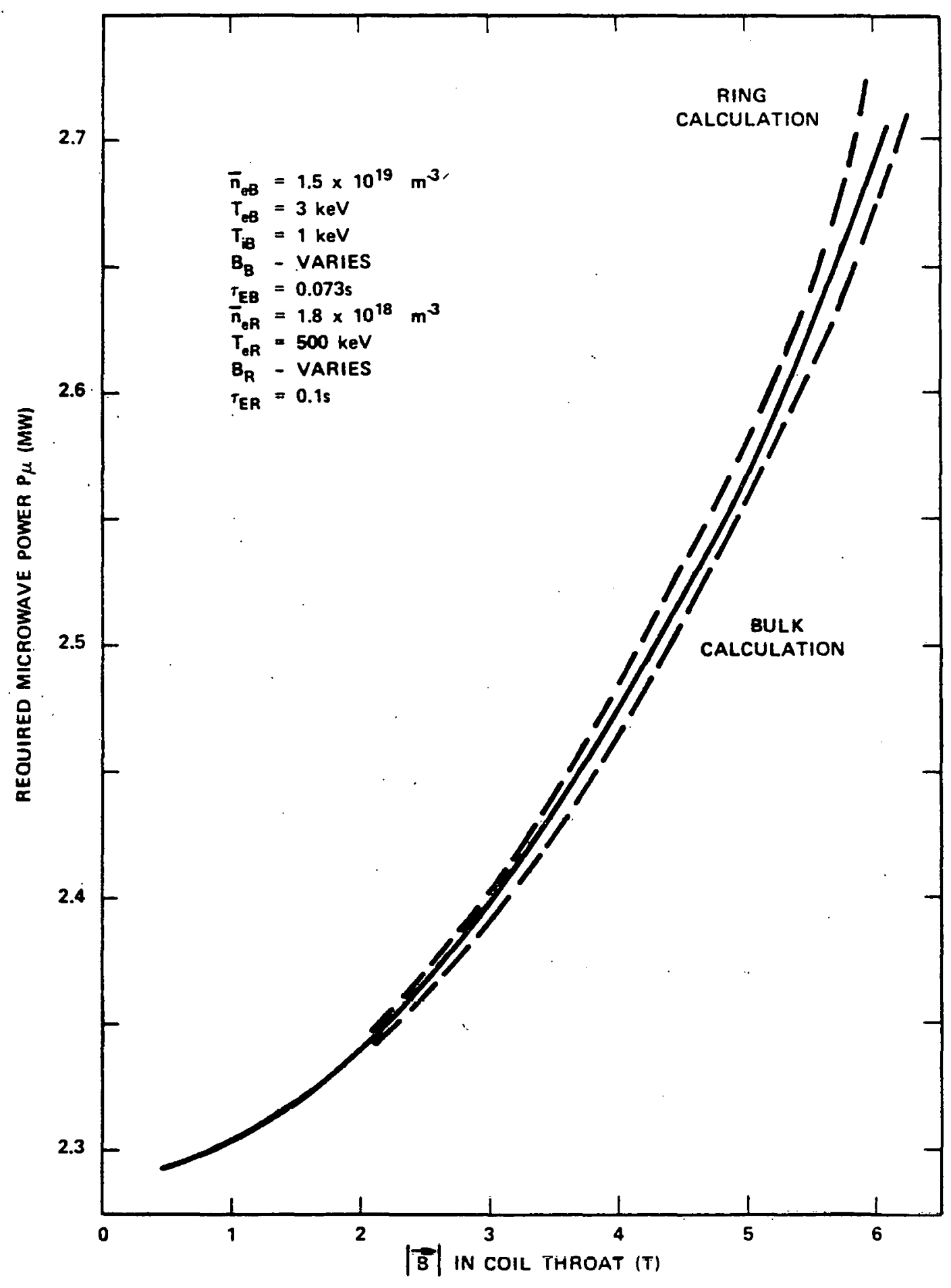

Figure 6-1. Required. Input Microwave Power as a Function of Magnetic Field Strength in a Mirror Coil Throat for Fixed Plasma Density and Temperature. 


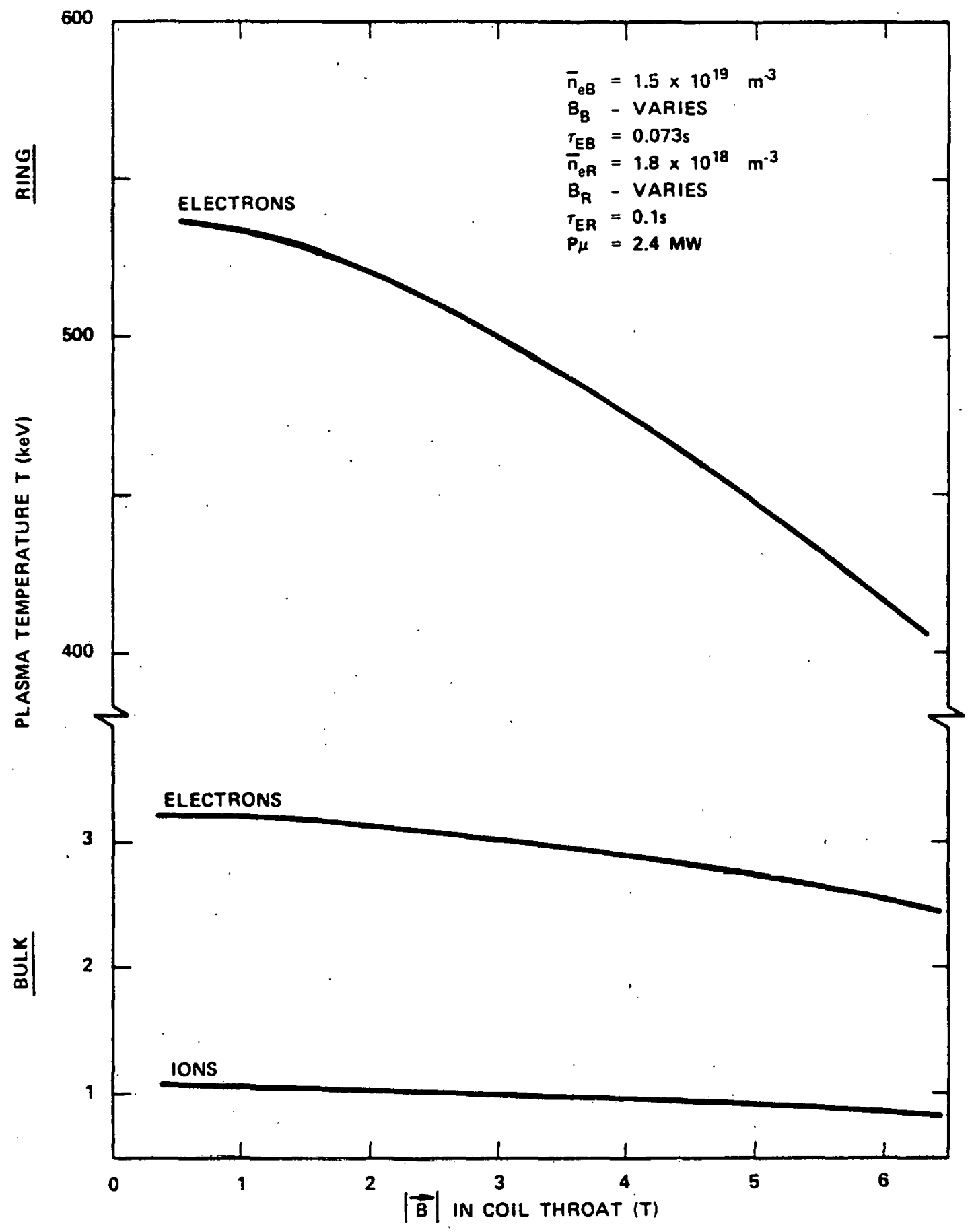

Figure 6-2. Ring and Bulk Plasma Temperature as a Function of Magnetic Field Strength in a Mirror Coil Throat for Fixed Density and. Input Power. 


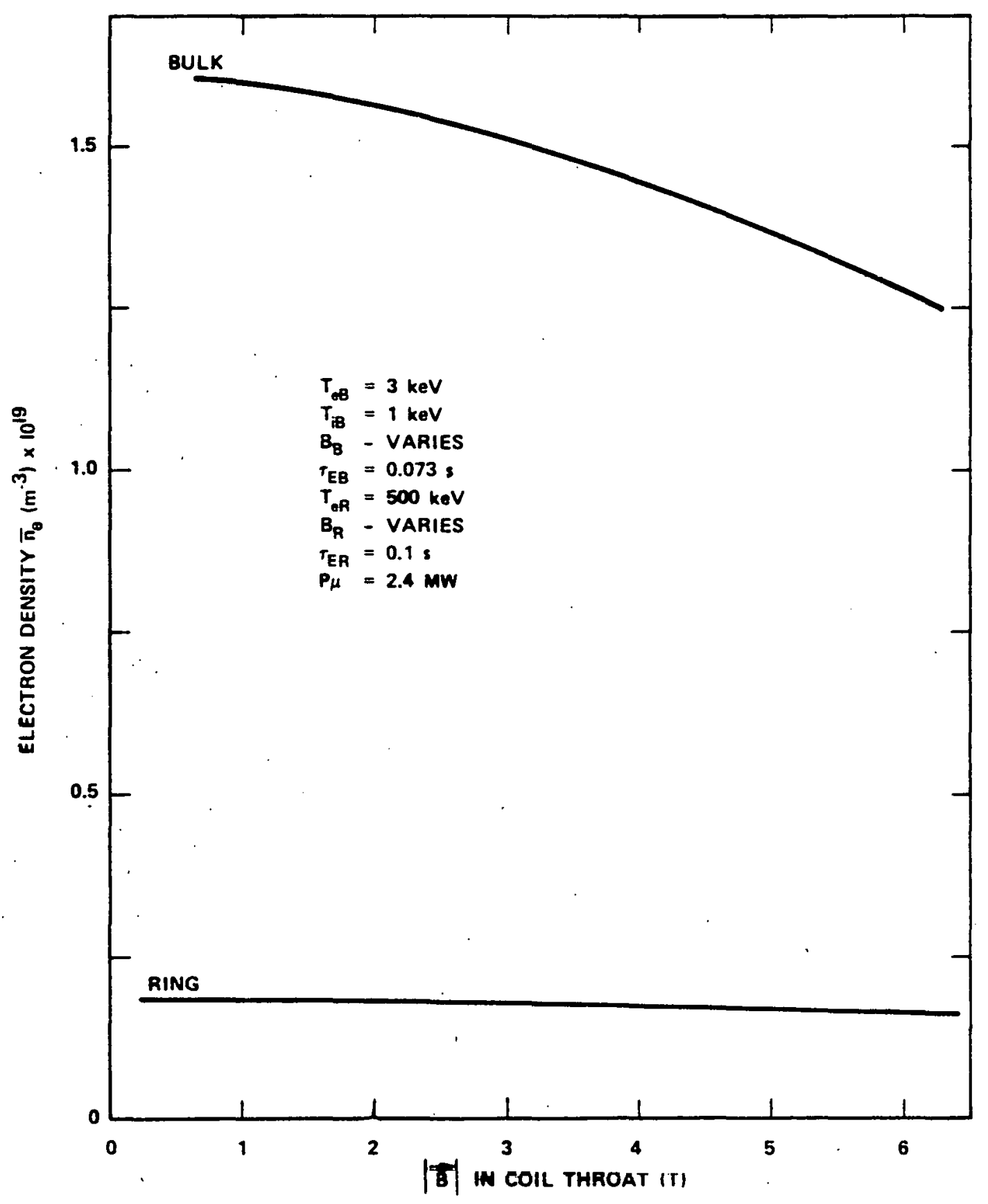

Figure 6-3. Ring and Bulk Electron Densities as a Function of Magnetic Field Strength in a Minor Coil Throat for Fixed Temperature and Input Power. 


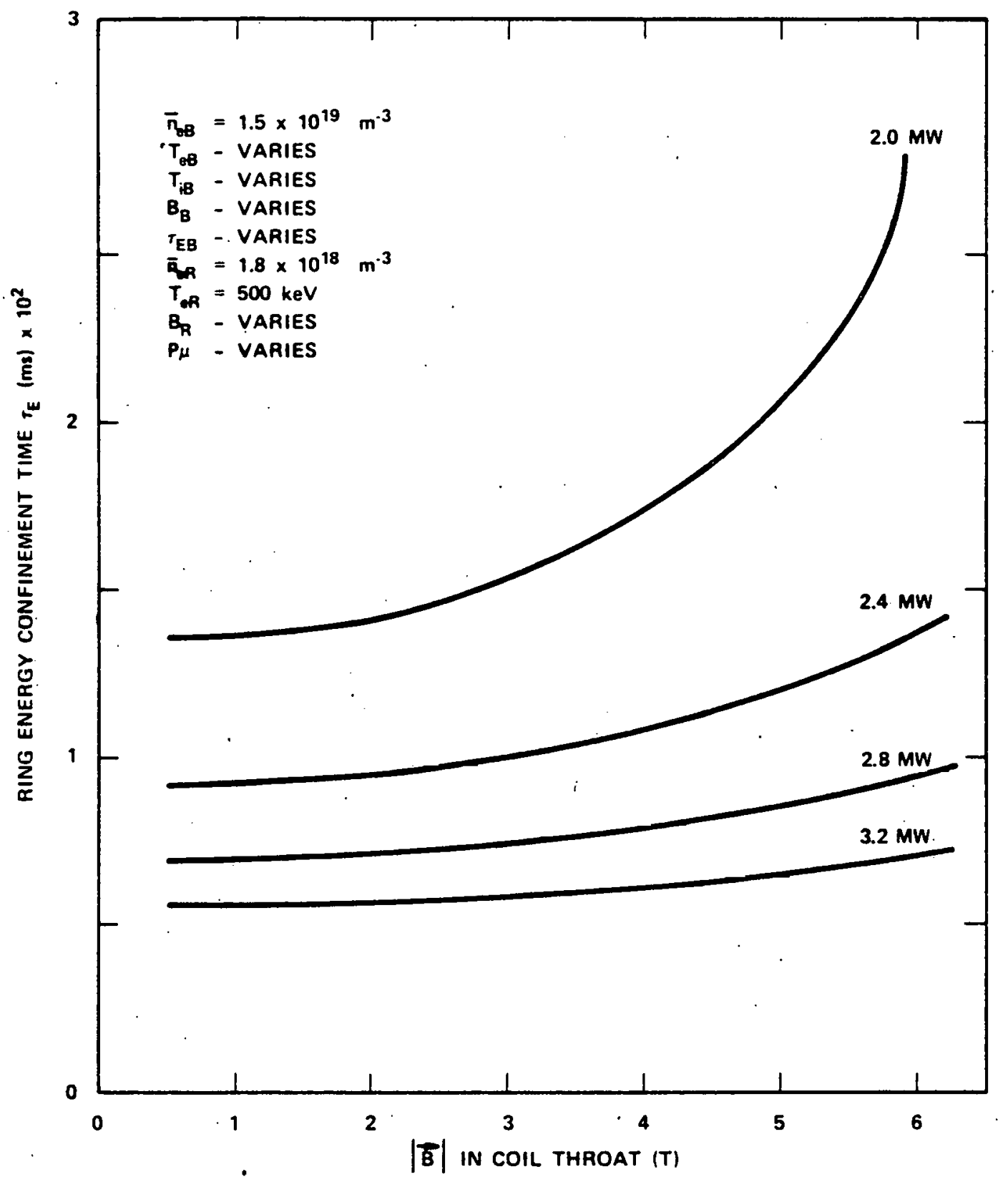

Figure 6-4. Ring Energy Confinement Time as a Function of Magnetic Field Strength in a Mirror Coil

Throat for Fixed Ring Density and Temperature. 


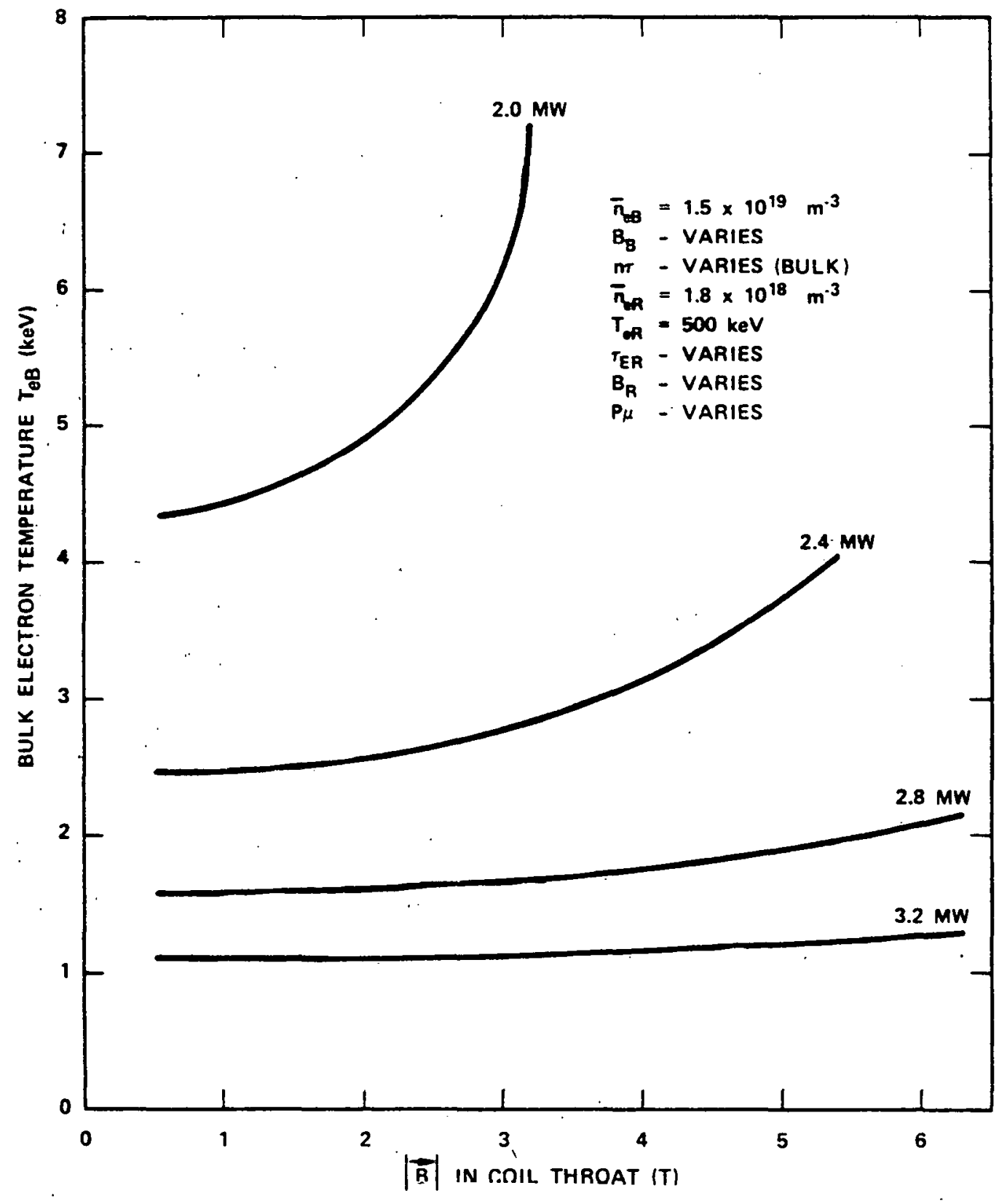

Figure 6-5. Scaled Bulk Electron Temperature as a Function of Magnetic Field Strength in a Mirror Coil Throat for Fixed Density. 


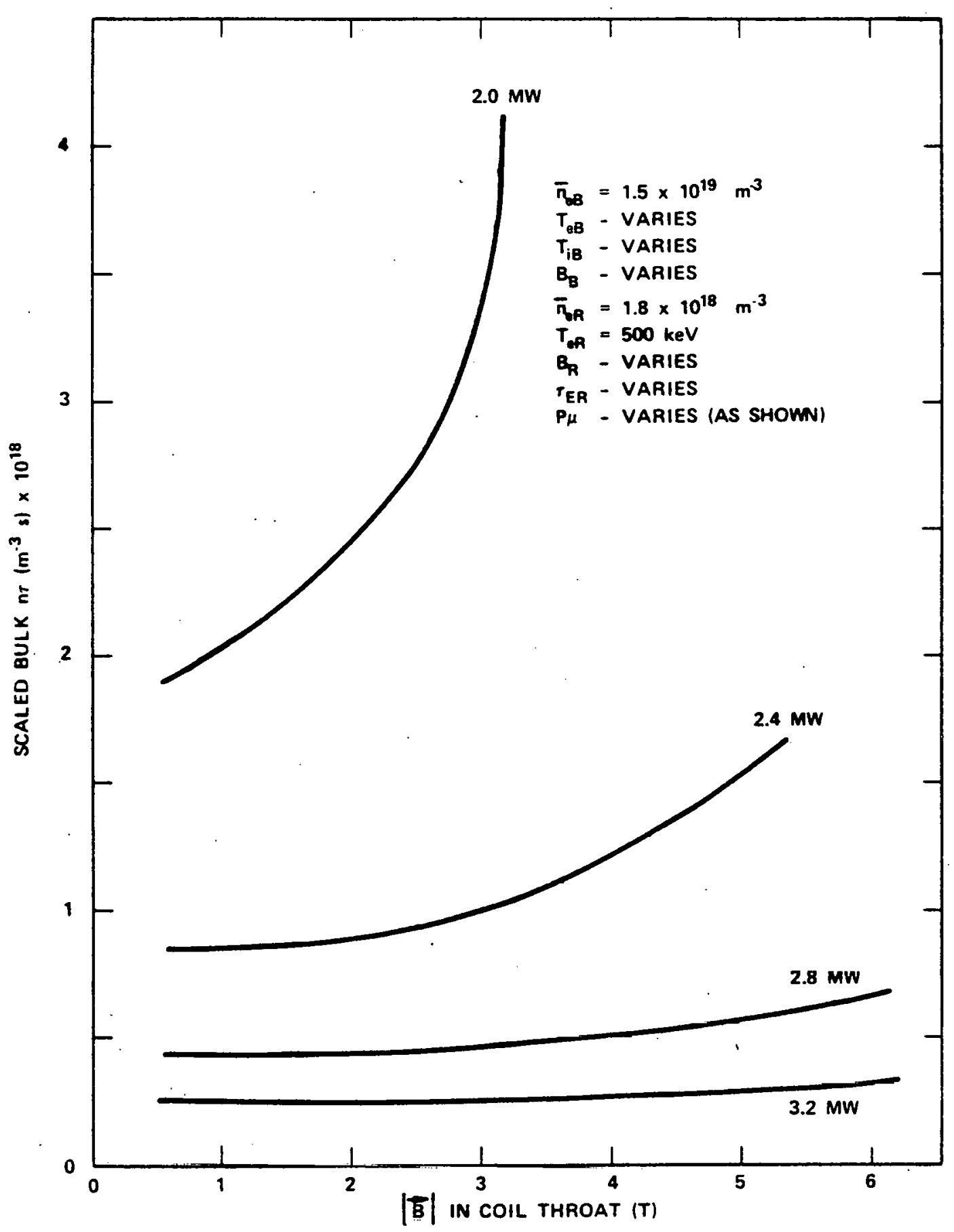

Figure 6-6. Scaled Bulk $n_{\tau}$ as a Function of Magnetic Field Strength in a Mirror Coil Throat for Fixed Density. 
temperature and density balances the values obtained for the cases where $\left|\vec{B}_{C T}\right|=0.95$ and $1.49 \mathrm{~T}$ result in ring $B>1.0$, exceeding the ring $B$ operating criteria $15 \% \lesssim$ ring $B \lesssim 50 \%$. Also, for the cases where $\left|\vec{B}_{C T}\right|=4.50$ and $5.80 \mathrm{~T}$ the ring temperature and density balances produced ring $B$ values less than $15 \%$, again outside the operating criteria. More detailed studies are required to completely represent the optimum parameters for each of the modes of operation suggested in this study. The trends in this study provide a first step in obtaining the optimum conditions for each mode of operation.

The required input power is weakly dependent on magnetic field strength as shown in Figure 6-1. The required power increases by $17 \%$ as the field strength is increased from 1.0 to $6.0 \mathrm{~T}$. The scaling in this range is approximately $P_{\mu} \propto|\vec{B}|^{0.125}$. In this case, the ring and bulk plasma models calculate different total input power requirements because the synchrotron radiation losses (proportional to $\mathrm{B}^{2}$ ) are less significant compared with other radiative loss mechanisms at low electron temperatures. Since the electron rings are at high temperature, synchrotron radiation losses are more significant compared to other losses in the ring calculation and increases in field strength result in higher calculated power requirements than in the bulk calculation. The expected power requirement is taken to be within the envelope of two calculations as shown.

The affect of changes in $\left|\vec{B}_{\mathrm{CT}}\right|$ on plasma temperature is shown in Figure 6-2. In the range $1.0 T \leq\left|\vec{B}_{C T}\right| \leq 6.0 \mathrm{~T}$ the ring electron temperature decreases $20 \%$ as the field increases and the bulk electron and ion temperatures decrease $19 \%$. This shows a weak dependence on magnetic field strength for both plasmas over the range tested. Optimizing the plasma parameters in the ring calculation to achieve constant ring 8 within the theoretical operating criteria would result in stronger temperature dependence on magnetic field strength for constant input power. For example, in the low field cases the optimum ring density would be lower than the baseline density, to satisfy the critical density cutoff requirement and the maximum ring $B$ criteria (ring $B \leqslant 50 \%$ ), increasing the ring temperature obtained at energy balance (see Section 4.0). In addition, lower input powers may be required to achieve energy balance when the critical density 
and maximum ring $B$ criteria are satisfied simultaneously. An iterative process of code calculations and hand calculations would be required to find the optimum operating conditions:

The effect of changes in magnetic field strength on required ring and bulk particle densities at constant temperature is shown in Figure 6-3. The ring density decreases less than $8 \%$ over the range of field strengths considered. The bulk density shows a stronger dependence on the field strength, decreasing more than $20 \%$ for field strength increases from $1.0 \mathrm{~T}$ to $6.0 \mathrm{~T}$. The density values in this study meet or exceed the criteria for ring stability; $\bar{n}_{e B} / \bar{n}_{e R} z$ 8.0. However, ring $B$ values exceed 1.0 for the cases with $\left|\vec{B}_{C T}\right|=0.95$ and $1.49 \mathrm{~T}$ and are below $15 \%$ for the cases with $\left|\vec{B}_{\mathrm{CT}}\right|=4.50$ and $5.80 \mathrm{~T}$ as in the temperature balance (see Figure 6-2). In the cases for which $\left|\vec{B}_{C T}\right|=0.95$ and $1.49 \mathrm{~T}$ the calculated-densities exceed the critical density for microwave propagation at the corresponding frequency. To achieve energy balance in these low field cases, while satisfying the criteria for ring and bulk stability, lower input powers are required. The trends in this study and the temperature balance study show that an EBT device operated with a range of input microwave frequencies (and corresponding magnetic field strengths) can not be operated consistently with fixed input power. Low frequency operation requires significantly lower input power to avoid over-driving the plasmas beyond $\beta$ and density limits.

Finally, the required ring energy confinement time, required bulk electron temperature and bulk $n_{\tau}$ (scaled as $A^{2} T_{e B}{ }^{3 / 2}$ ) at balance show trends which are similar, for increasing field strength, to those presented in the device size study (Section 5.0) for increasing major radius. The study was run for input powers of $2.0,2.4,2.8$, and $3.2 \mathrm{MW}$. For fixed input power, higher energy confinement times are required to maintain the plasma at the baseline conditions as the magnetic field strength (and microwave frequency) increases. Also, for a fixed mode of operation better energy confinement is required to maintain the plasma conditions as the input power decreases. As in the study of device size, for some combinations in input power and mode of operation (input frequency and field strength) the energy confinement requirements exceeded the range of the calculation and energy balance could not be obtained. 
The trends presented in Figures 6-4 through 6-6 for increasing magnetic field strength are similar but less extreme than those presented in Figures 5-4 through 5-6 for increases in device size, over the ranges considered. In both studies the total radiative power lost from the plasma increases as the independent variable of the study increases. For the given plasma conditions the total radiative losses scale as the device size cubed. Increases in magnetic field strength produce small increases in total radiated power from the plasma since synchrotron losses (scaled as $|\vec{B}|^{2}$ ) are not the dominant radiative loss mechanism for the given plasma temperatures. Figures 5-1 and 6-1 show that the input power required increases by a factor of 2.3 for increase in device size by. a factor of 1.4 but power requirement increases of less than $20 \%$ result when the magnetic field strength increases by a factor of six. For fixed input power the effect on confinement requirements, bulk temperature, and scaled bulk $n_{T}$ will be more severe for increases in device size than for increases in magnetic field strength (and input microwave frequency). 


\subsection{TRADE STUDY - D-T PROOF-OF-PRINCIPLE DEVICE}

The results and trends presented in Sections 5.0 and 6.0 can be used to estimate the plasma and plasma support systems parameters for a D-T operated EBT proof-of-principle device. Several iterations of OASIS code calculations and hand calculations were performed, and a tentative description of a D-T operated device with proof-of-principle characteristics is presented. Parameter values are given in Table 7-1 for a device of this type operated with neutral beam injection. The radius $R_{0}$ and particle densities and temperatures were arbitrarily selected and hold no special significance.

Code results from this study showed that a converged self-consistent solution is more difficult to obtain for a D-T operated case than for the single ion (hydrogen) cases. Problems with convergence occur primarily in the bulk plasma model where $D$-T operation implies alpha power production, non-negligible alpha particle populations, and the need for neutral beam injection to sustain the bulk plasma at proof-of-principle conditions. Significant code improvements are required for the bulk temperature and density balance options to assure convergence in D-T operated cases. The use of iterative bisection methods for these balance loops may be sufficient for convergence in most proof-of-principle studies. More sophisticated methods may be required for EBT reactor studies.

Further work of this type on D-T proof-of-principle EBT devices would focus on:

- the implications of changes in the number of device sectors;

- the effect of improved field coil technology providing higher fields in the device, higher operating microwave frequencies, and higher cutoff densities for microwave propagation;

- the effect of auxiliary (e.g., ICRH) heating methods for the bulk plasma;

- the implications of improved particle and energy confinement. 
TABLE 7-1

\section{D-T PROOF-OF-PRINCIPLE PARAMETERS}

\section{IETERS}

\begin{tabular}{|c|c|c|}
\hline & Number of Device Coils & 36 \\
\hline & Device Major Radius & $10 \mathrm{~m}$ \\
\hline • & Minor Radius of Mirror Coil (Current Weighted) & $0.571 \mathrm{~m}$ \\
\hline$\vdots$ & Clear Bore Minor Radius & $0.371 \mathrm{~m}$ \\
\hline & Mean Minor Radius of Microwave Vacuum Cavity & $0.71 \mathrm{~m}$ \\
\hline & Coil Width & $0.43 \mathrm{~m}$ \\
\hline & Magnetic Field at Hot Electron Rings. & $2.14 \mathrm{~T}$ \\
\hline & Magnetic Field at Bulk Plasma (Average) & $4.28 \mathrm{~T}$ \\
\hline $3_{\text {mid }}$ & $\begin{array}{l}\text { Magnetic Field at Midplane Between Coils } \\
\text { (on Ring Axis) }\end{array}$ & $2.3 \mathrm{~T}$ \\
\hline & Magnetic Field in Coil Throat (on Ring Axis) & $5.8 \mathrm{~T}$ \\
\hline & Mirror Coil Current Aspect Ratio & 9.25 \\
\hline
\end{tabular}

PLASMA PARAMETERS

\section{BULK PLASMA}

\begin{tabular}{|c|c|c|}
\hline & Mean Electron Density & $1.5 \times 10^{20} \mathrm{~m}^{-3}$ \\
\hline ' & Mean Deuteron Density & $6.7 \times 10^{19} \cdot \mathrm{m}^{-3}$ \\
\hline & Mean Triton Density & $6.7 \times 10^{19} \mathrm{~m}^{-3}$ \\
\hline & Mean "hot" Alpha Density & $5.2 \times 10^{17} \mathrm{~m}^{-3}$ \\
\hline & Mean "cold" Alpha Density & $2.6 \times 10^{17} \mathrm{~m}^{-3}$ \\
\hline & Mean Neutral Beam Particle (Deuteron) Density & $1.5 \times 10^{19} \mathrm{~m}^{-3}$ \\
\hline & Electron Temperature & $15 \mathrm{keV}$ \\
\hline & $\begin{array}{l}\text { Ion (Deuteron, Triton, "cold" Alpha) } \\
\text { Temperature }\end{array}$ & $15 \mathrm{keV}$ \\
\hline & Energy Confinement Time & $0.15 \mathrm{~s}$ \\
\hline $\mathrm{NeB}$ & $\begin{array}{l}\text { Energy Conduction Power Density Losses } \\
\text { by Electrons }\end{array}$ & $1.386 \mathrm{MW} / \mathrm{m}^{3}$ \\
\hline $\mathrm{NiB}$ & $\begin{array}{l}\text { Energy Conduction Power Density Losses } \\
\text { by Ions }\end{array}$ & $0.462 \mathrm{MW} / \mathrm{m}^{3}$ \\
\hline erit & Critical (Maximum) Density & $1.73 \times 10^{20} \mathrm{~m}^{-3}$ \\
\hline & Bulk Beta & $12 \%$ \\
\hline
\end{tabular}


TABLE 7-1 (CONTINUED)

D-T PROOF-OF-PRINCIPLE PARAMETERS

$\begin{array}{lll}(v / \Omega) & \text { Collisionality Factor } & 0.14 \\ \rho_{e} & \text { Electron Larmor Radius (Average) } & 1.2 \times 10^{-4} \mathrm{~m} \\ \rho_{i} & \text { Ion Larmor Radius (Average) } & 8.2 \times 10^{-3} \mathrm{~m} \\ V_{B} & \text { Plasma Volume } & 42.5 \mathrm{~m}^{3} \\ \tau_{\mathrm{pB}} & \text { Particle Confinement Time } & 0.15 \mathrm{~s} \\ \mathrm{P}_{\mathrm{alpha}} & \text { Alpha Power Produced } & 41.6 \mathrm{MW} \\ \bar{n}_{\mathrm{eB}} / \bar{n}_{\mathrm{ec}} & \text { Bulk/Ring Electron Density Ratio } & 44.5\end{array}$

RING PLASMA

$\begin{array}{lll}\bar{n}_{e R} & \text { Mean Electron Density } & 3.37 \times 10^{18} \mathrm{~m}^{-3} \\ T_{e R} & \text { Electron Temperature } & 1.0 \mathrm{MeV} \\ \tau_{E R} & \text { Energy Confinement Time } & 0.2 \mathrm{~s} \\ \tau_{p R} & \text { Particle Confinement Time } & 0.34 \mathrm{~s} \\ \rho_{e} & \text { Electron Larmor Radius } & 2.2 \times 10^{-3} \mathrm{~m} \\ V_{R} & \text { Total Ring Plasma Volume } & 1.3 \mathrm{~m}^{3} \\ W_{E N e R} & \text { Energy Conduction Power Density Losses } & 31.0 \mathrm{MW} / \mathrm{m}^{3} \\ \bar{a}_{\text {ring }} & \text { by. Electrons } & \\ R_{\text {maj }} & \text { Ring Mean Minor Radius } & 0.429 \mathrm{~m} \\ R_{\text {min }} & \text { Major Radius of Ring Elliptical Cross Section } & 0.214 \mathrm{~m} \\ \delta & \text { Minor Radius of Ring Elliptical Cross Section } & 0.019 \mathrm{~m} \\ B . & \text { Ring Cant Factor } & 0.021 \mathrm{~m}\end{array}$

SYSTEMS PARAMETERS

$\begin{array}{lll}P_{M U} & \text { Total Input Microwave Power } & 520 \mathrm{MW} \\ P_{\text {NB }} & \text { Neutral Beam Input Power } & 100 \mathrm{MW} \\ P_{\text {RF }} & \text { RF (Auxilliary) Input Power } & 0 \\ I_{\text {beam }} & \text { Neutral Beam Current } & 6.2 \times 10^{21} \mathrm{~s}^{-1} \\ E_{\text {beam }} & \text { Neutral Beam Particle Energy } & 100 \mathrm{keV} \\ \text { W }_{\text {LOADN }} & \text { Neutral Wall Loading (Estimate) } & 0.51 \mathrm{MW} / \mathrm{m}^{2}\end{array}$


TABLE 7-1 (CONTINUED)

D-T PROOF-OF-PRINCIPLE PARAMETERS

THEORETICAL COEFFICIENTS AND CONSTANTS

\begin{tabular}{|c|c|c|}
\hline $\begin{array}{l}E_{S C 1} \\
E_{S C 2} \\
C_{N T A U}\end{array}$ & 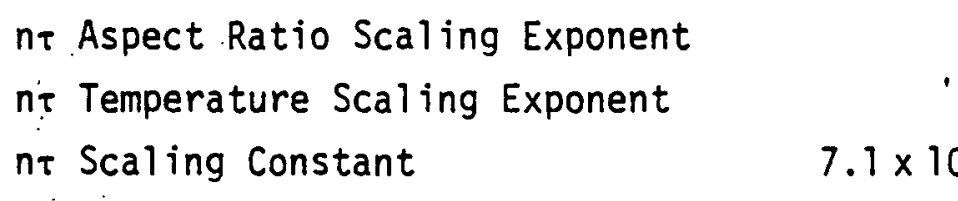 & $\begin{array}{l}2.0 \\
1.5 \\
4 \mathrm{~m}^{-3} \mathrm{~s} /(\mathrm{keV})^{3 / 2}\end{array}$ \\
\hline & Fraction of Input Microwave Power to Rings & $18.2 \%$ \\
\hline EAC & Fraction of Input Microwave Power to Bulk & $40.9 \%$ \\
\hline$e^{/ \tau} p i$ & Ratio of Particle Confinement Time & 1.0 \\
\hline $\mathrm{COLL}_{\mathrm{B}} / \mathrm{T}_{\mathrm{eB}}$ & $\begin{array}{l}\text { Ratio of Bulk Particle Temperatures } \\
\text { Collisionality Scaling Constant }\end{array}$ & $-19^{1.0}(\mathrm{keV})^{5 / 2} \mathrm{~m}^{-1} \mathrm{~T}$ \\
\hline TAUS & $\begin{array}{l}\text { Slowing-Down Time Upper Limit/Particle } \\
\text { Confinement Time }\end{array}$ & 2.0 \\
\hline & Plasma Minor Radius/Clear Bore Radius & 1.3 \\
\hline & Deuteron Density/(Triton + Deuteron) Density & 0.5 \\
\hline alphat & $\begin{array}{l}\text { Fraction of Alpha Particles Retained } \\
\text { in Plasma }\end{array}$ & 0.9 \\
\hline Falpha2 & $\begin{array}{l}\text { Fraction of Alpha Power Absorbed in } \\
\text { in Bulk k.Plasma }\end{array}$ & 0.9 \\
\hline am 1 & $\begin{array}{l}\text { Fraction of Neutral Beam Particles Retained } \\
\text { in Plasma }\end{array}$ & 0.9 \\
\hline & $\begin{array}{l}\text { Fraction of Neutral Beam Power Absorbed } \\
\text { by Plasma }\end{array}$ & 0.9 \\
\hline
\end{tabular}


Finally, this study shows that the goal of energy breakeven in EBT's remains a difficult problem. High input microwave power is required to sustain the plasmas in $D-T$ operated devices even at operating conditions which produce comparitively low fusion power. Significantly improved microwave absorption in the ring and bulk plasmas may be necessary for breakeven in EBT. 


\subsection{SENSITIVITY STUDIES}

The theoretical coefficients and constants used in OASIS runs for the trade studies were derived from EBT-I experimental and theoretical data. Since the input microwave power to the ring and bulk plasmas determines the plasma conditions for a given device, the power sharing coefficients describing the fraction of the total input power absorbed by each plasma are important. The values used in the trade studies were calculated using EBT-I experimental data and can not be verified by direct measurement. The effects of small changes in the power sharing coefficients on total required input power, plasma temperature and particle densities are given in Figure 8-1 through 8-4.

The microwave power required to sustain the ring and bulk plasmas at the baseline conditions is shown in Figure 8-1. for variations in the ring and bulk power sharing coefficients of $\pm 40 \%$. The power sharing fractions were varied simultaneously in this study and the energy conduction losses for both plasmas were scaled linearly with the anticipated changes in the input power density (i.e., with the changes in the power sharing coefficients). The results show that a $40 \%$ increase in the absorbed power fraction for both plasmas gives a $26 \%$ reduction in the total required input power and decreases of $40 \%$ in the absorbed power fraction produce increases of $50 \%$ for the total input power. The assumption that the energy conduction losses scale with the input power density (i.e., in this study with the absorbed power fractions) produces a nonlinear plot. The bulk and the ring calculations differ because the significance of the energy conduction loss term compared with other terms in the energy balance equations is different for the two plasmas. The anticipated total input power is shown within the envelope of the two calculations.

The effects on plasma temperatures and particle densities for changes in the absorbed power fractions by $\pm 40 \%$ are shown in Figures $8-2$ and $8-3$. The energy conduction losses were scaled with input power density for both plasmas and the absorbed power fractions were varied simultaneously. The bulk plasma 


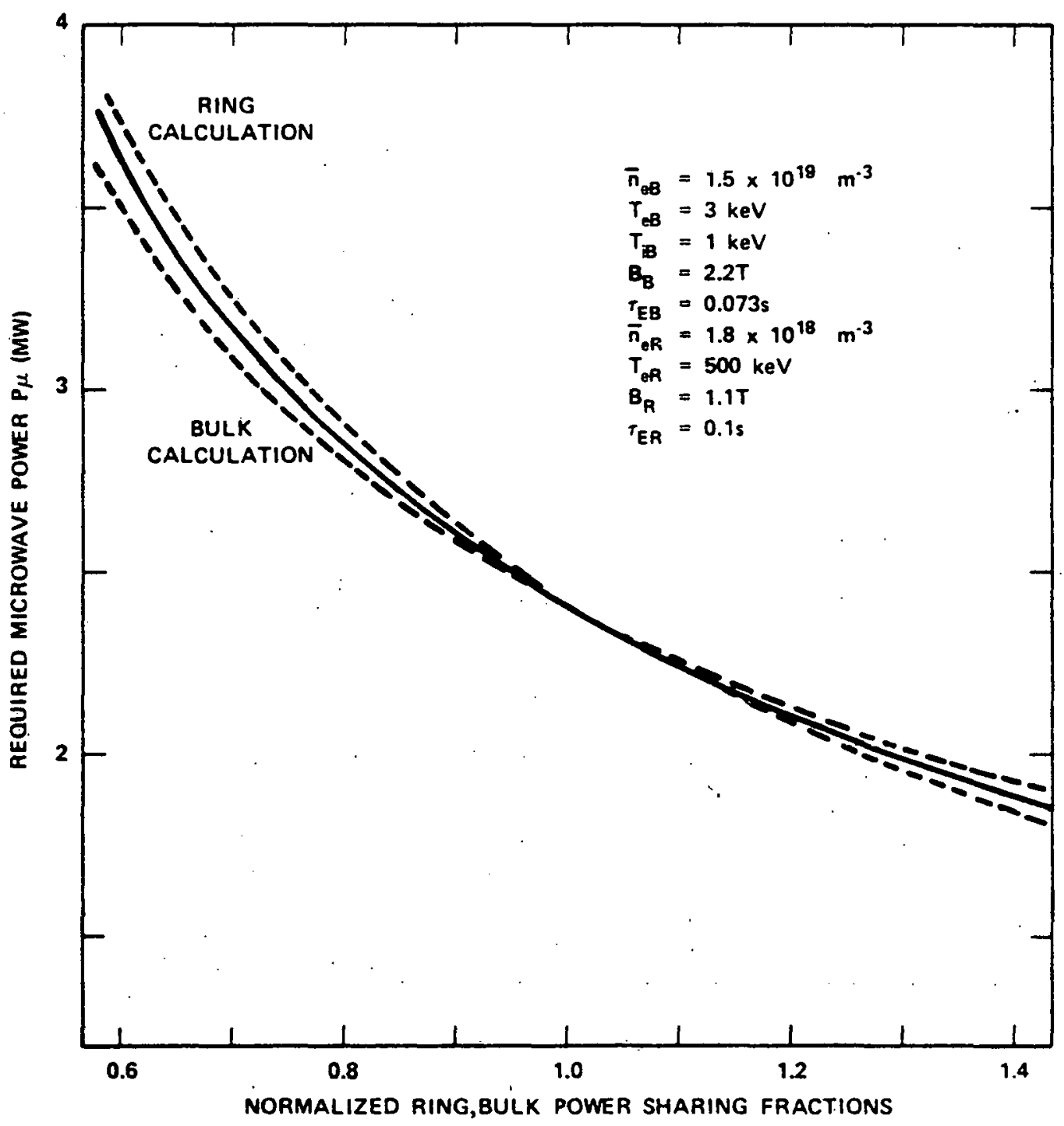

Figure 8-1. Required Input Microwave Power as a Function of Normalized Ring and Bulk Microwave Power Sharing Fractions for Fixed Plasma Density and Temperature. 


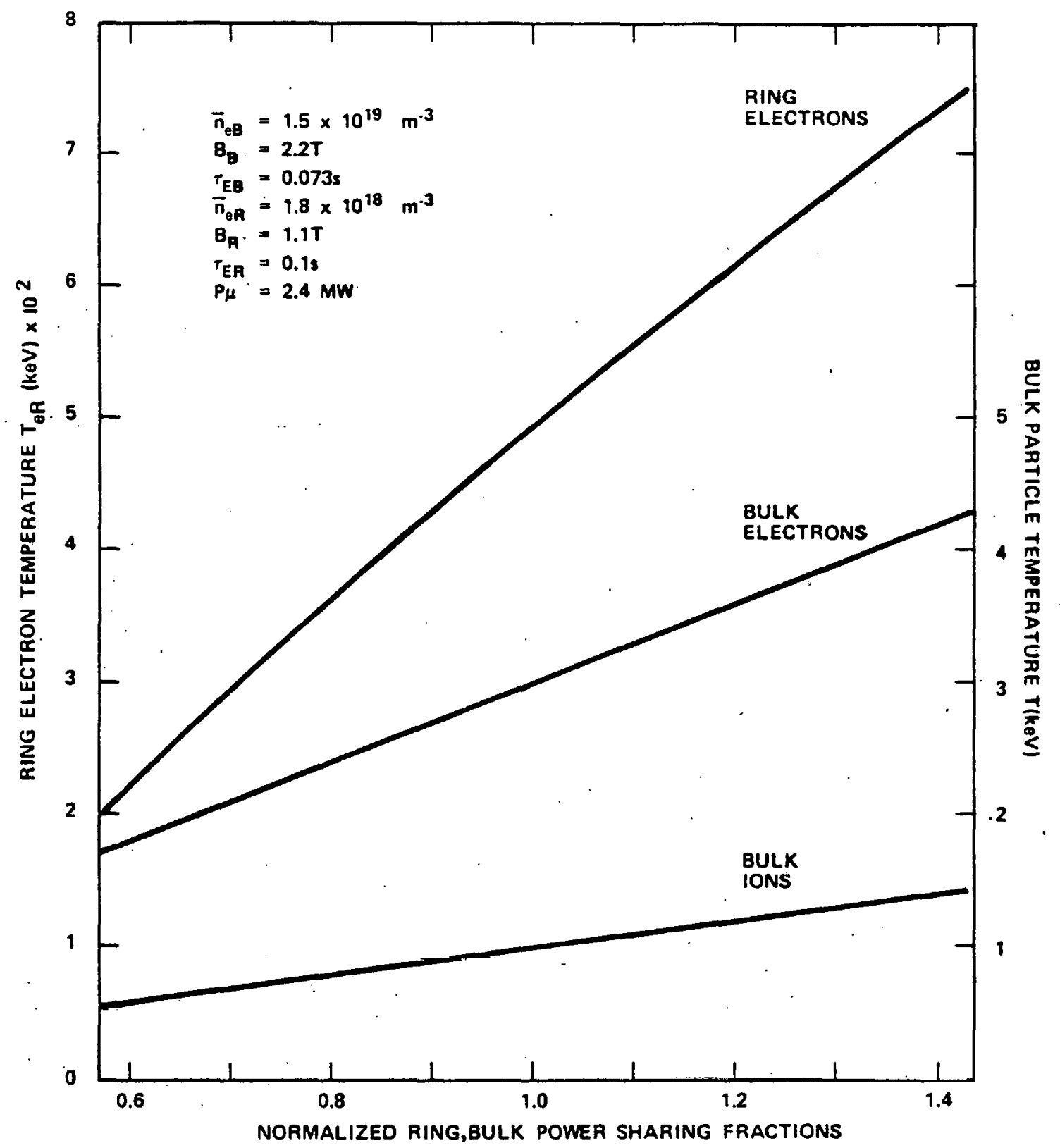

Figure 8-2. Ring and Bulk Plasma Temperature as a Function of Normalized Ring and Bulk Microwave Power Sharing Fractions for Fixed Density and Input Power. 


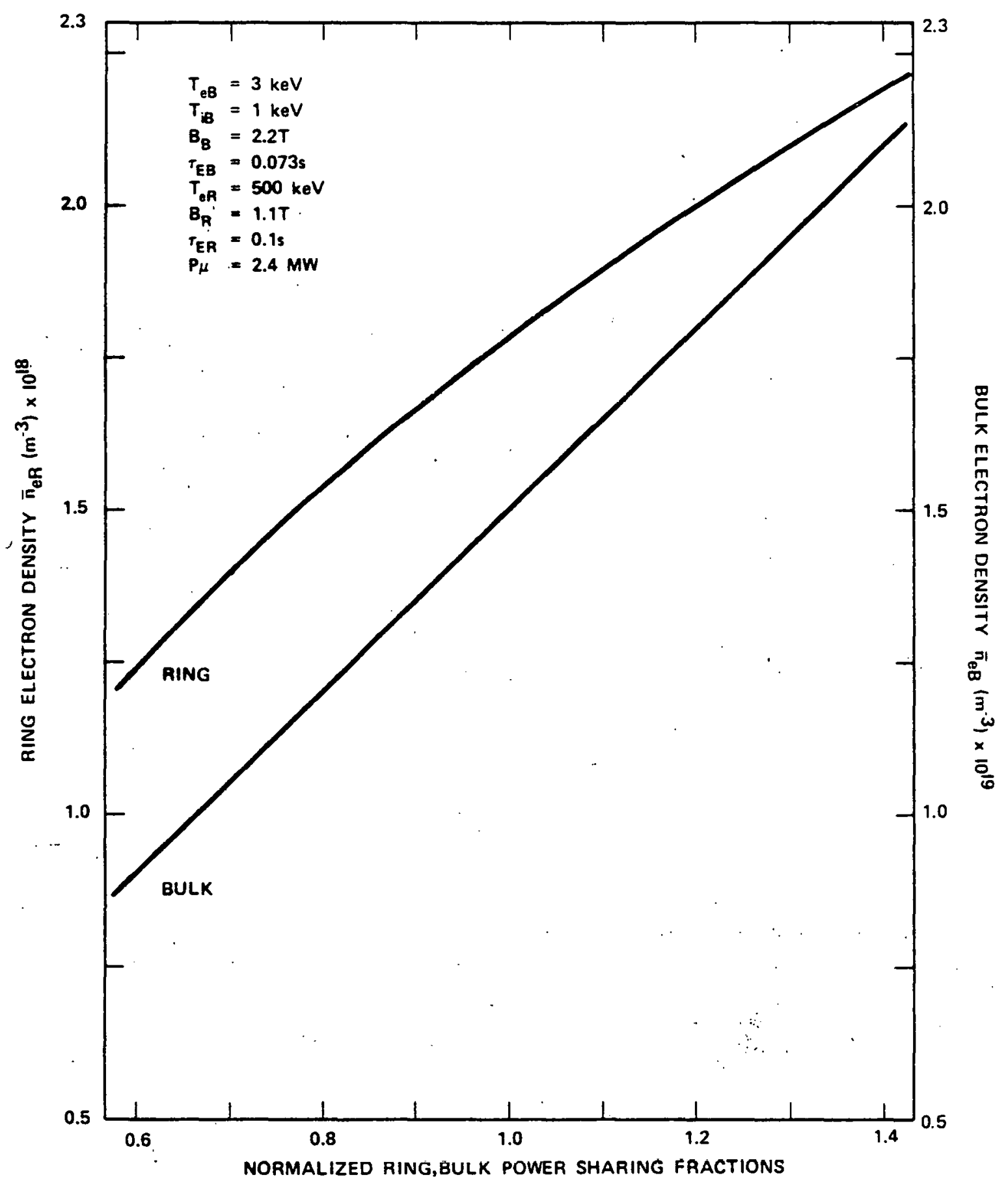

Figure 8-3. Ring and Bulk Electron Densities as a Function of Normalized Ring and Bulk Microwave Power Sharing Fractions for Fixed Temperature and Input Power. 


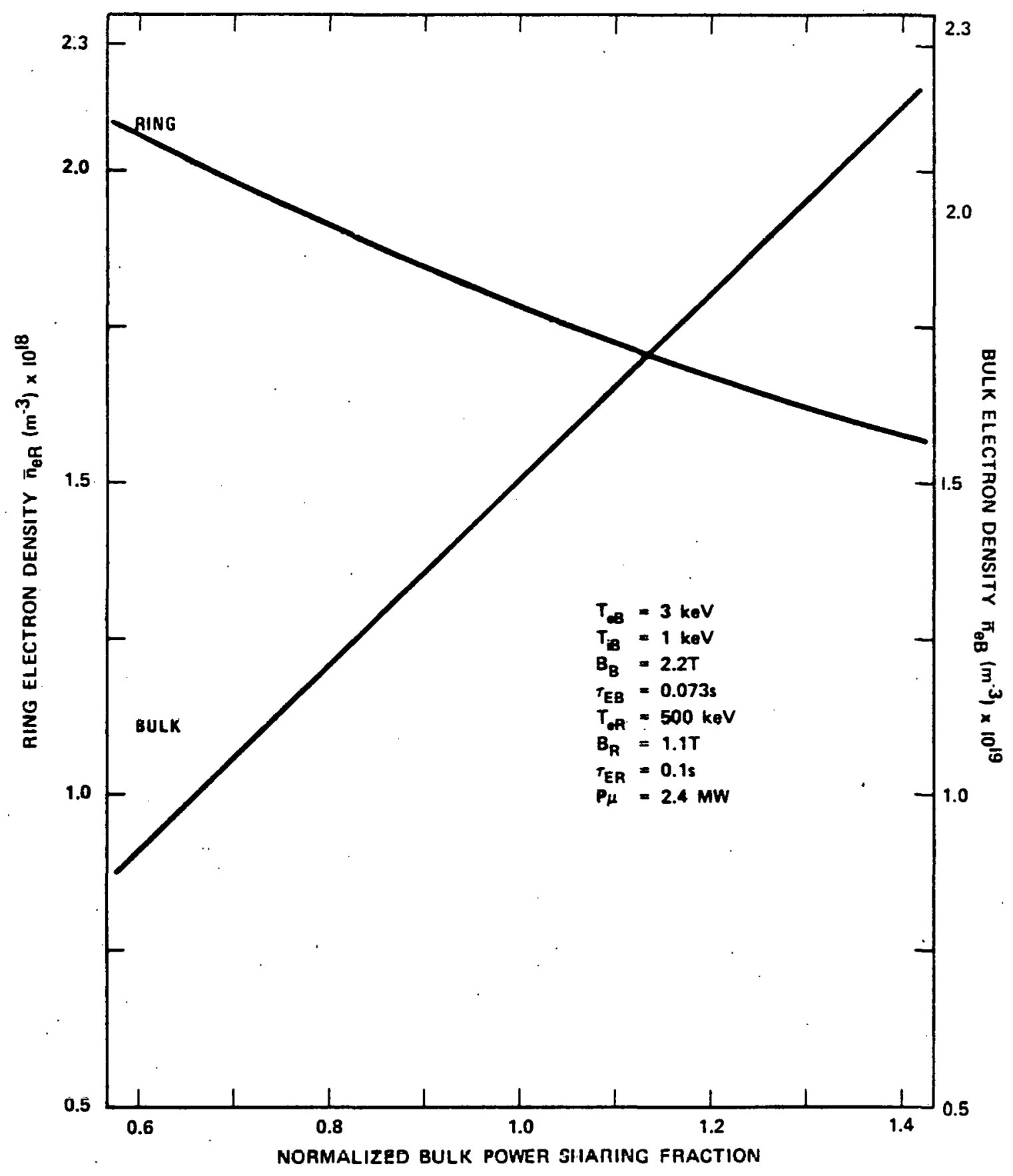

Figure 8-4. Ring and Bulk Electron Densities as a Function of Normalized Bulk Microwave Power Sharing Fraction for Fixed Temperature and Input Power. 
effects are linear over the range considered with $\pm 40 \%$ variation in plasma parameters for $\pm 40 \%$ variation in the absorbed power fractions. The ring parameters show nonlinear dependence on the absorbed power fractions, especially in the particle density balance where an increase in electron density of $22 \%$ results when the absorbed power fractions increase by $40 \%$ and a decrease of $44 \%$ occurs when the power fractions decrease by $40 \%$. The energy balance in the ring model depends on the bulk density and nonlinearity is observed in the ring parameters response at balance when the absorbed power fractions are varied simultaneously for both plasmas. Finally, Figure 8-4 shows the effect on particle densities when only the bulk plasma absorbed power fraction is varied. The bulk electron density response is the same as in Figure 8-3 because there is no coupling with the ring parameters in the bulk energy balance. The ring electron density decreases as the bulk density increases because the relativistic drag radiation loss term in the ring electron energy balance scales as the bulk electron density (see Section 4.0).

The scaling law for the bulk plasma, $n \tau \propto A_{C}{ }^{2} T_{e B}^{3 / 2}$, was developed as part of the theoretical work accompanying the EBT-I experiment. Good agreement has been obtained for EBT-I parameters between experimental data and this scaling law. However, for larger devices operated at different microwave power/ frequency and different plasma characteristics there is no evidence that this scaling will be valid. A study was performed using the baseline parameters (Table 5-1) with bulk $n \tau$ scaling as $A_{c}{ }^{2}{ }_{T}{ }_{e B}{ }^{\alpha}$ where a varied from 1.0 to 2.0. The bulk temperature and $n_{\tau}$ obtained at energy balance consistent with these scaling laws are shown in Figures $8-5$ and $8-6$ for input microwave power in the range from 2.4 to $4.0 \mathrm{MW}$.

For each of the input microwave powers considered the bulk electron temperature and scaled bulk $n \tau$ decreased as the scaling exponent $\alpha\left(n \tau \propto A_{c}{ }^{2} T_{e B}{ }^{\alpha}\right)$ increased. The scaling laws. for various a were normalized to the EBT-I parameters such that for each a with $A_{C}=9.25, T_{e B}=0.3 \mathrm{keV}$ and $n_{\tau}=1.0 \times 10^{16}\left(\mathrm{~m}^{-3} \mathrm{~s}\right)$ the scaling. law proportionality constant was calculated as $C_{s}=n_{\tau} / A_{C}{ }^{2} T_{e B}{ }^{\alpha}$. In addition, for fixed $\alpha$ the bulk electron temperature and $n \tau$ at balance decreased as the power increased. This trend occurs for $\alpha>1.0$ in a scaling law of this form due to the significance of the kinetic energy term compared 


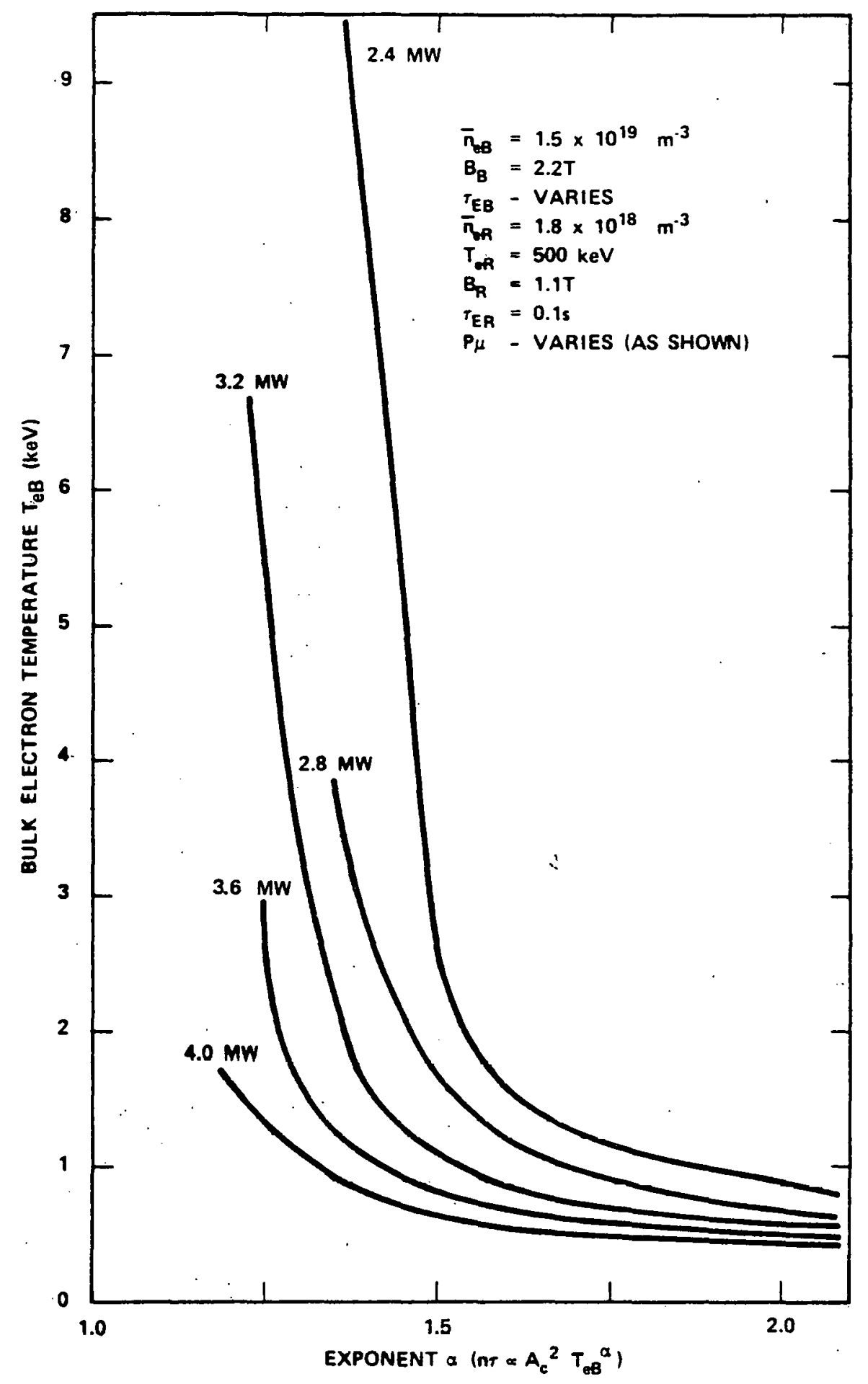

Figure 8-5. Scaled Bulk Electron Temperature as a Function of Scaling Exponent $\alpha\left(n \tau \propto n_{C}{ }^{2} T_{e B}^{\alpha}\right)$ for Fixed Density. 


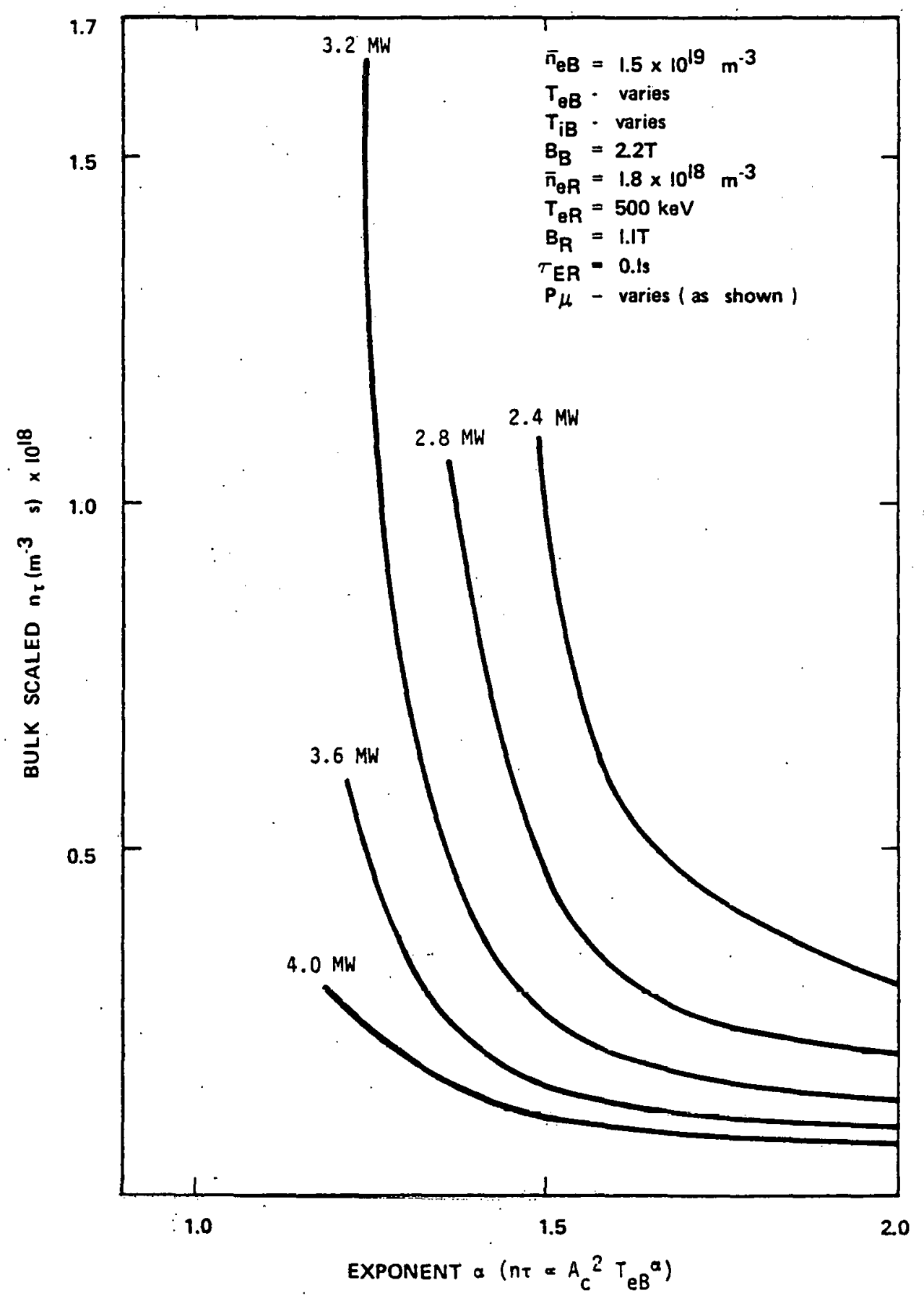

Figure 8-6. Scaled Bulk $n_{\tau}$ as a Function of Scaling Exponent $\alpha\left(n_{\tau} \propto A_{C}{ }^{2} T_{e B}{ }^{\alpha}\right)$ for Fixed Density. 
with other terms in the bulk energy balance (see Sections 4.0 and 5.0). Finally, the plots show that energy balance requires significantly higher bulk electron temperature and scaled $n \tau$ as the scaling approaches $n \tau \propto A_{c}{ }^{2} T_{e B}{ }^{1.0}$. No balance could be obtained with code calculations using this scaling law. This is consistent with the bulk kinetic energy term and the discussion in Section 5.0 since $\alpha=1.0$ gives a kinetic energy term independent of temperature. Very high bulk temperatures and scaled $n \tau$ would be required for balance in this case since bulk radiation losses (small at low temperature) would be the only loss mechanism depending on temperature. The results of this study are replotted in Figures 8-7 and 8-8 with a separate curve for each scaling law over the range of input powers. considered. 


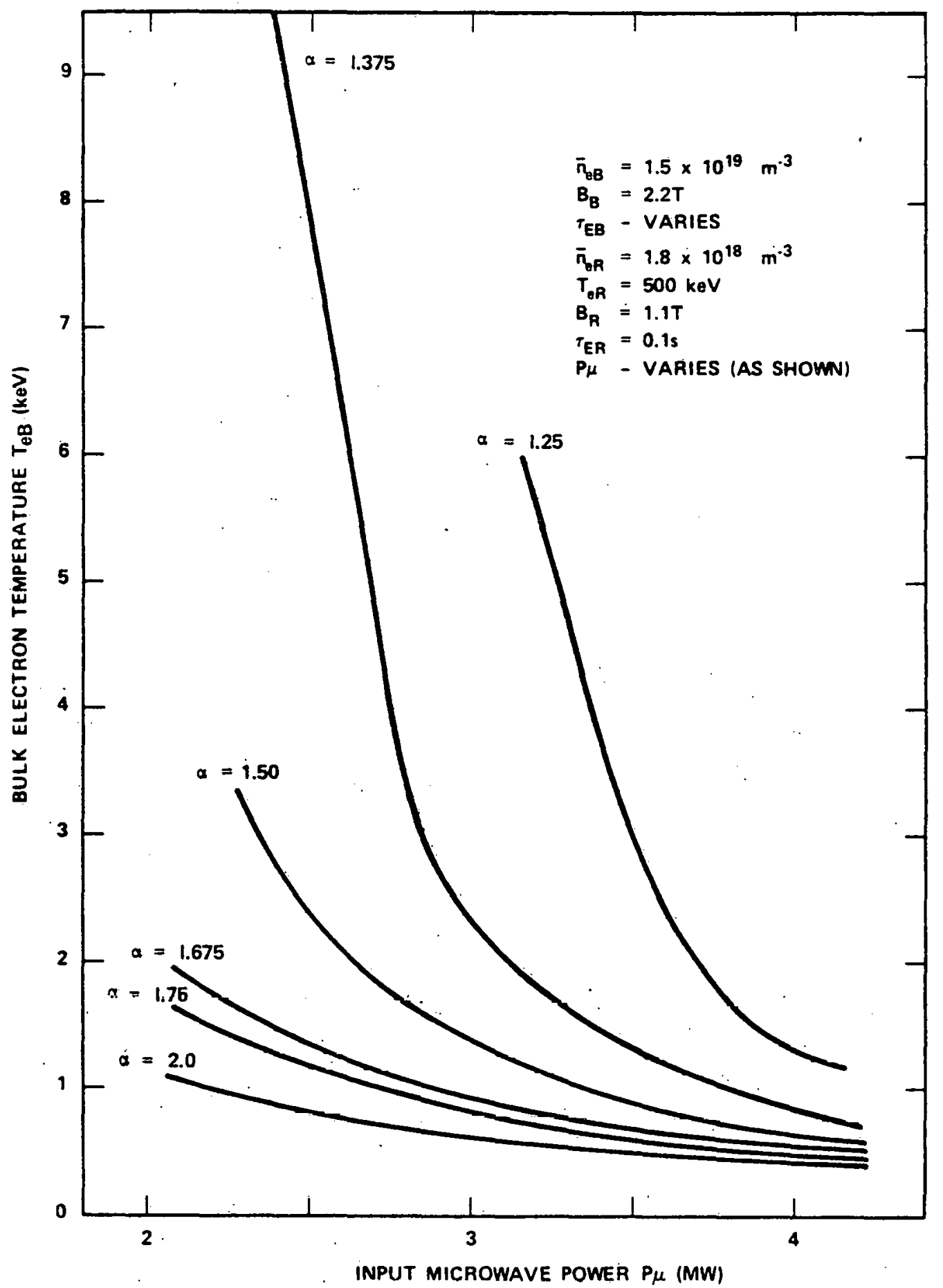

Figure 8-7. Scaled Bulk Electron Temperature $\left(n \tau \propto A_{C}{ }^{2} T_{e B}{ }^{\alpha}\right)$ as a Function of Input Microwave Power for Fixed Density and Scaling Exponent $\alpha$. 


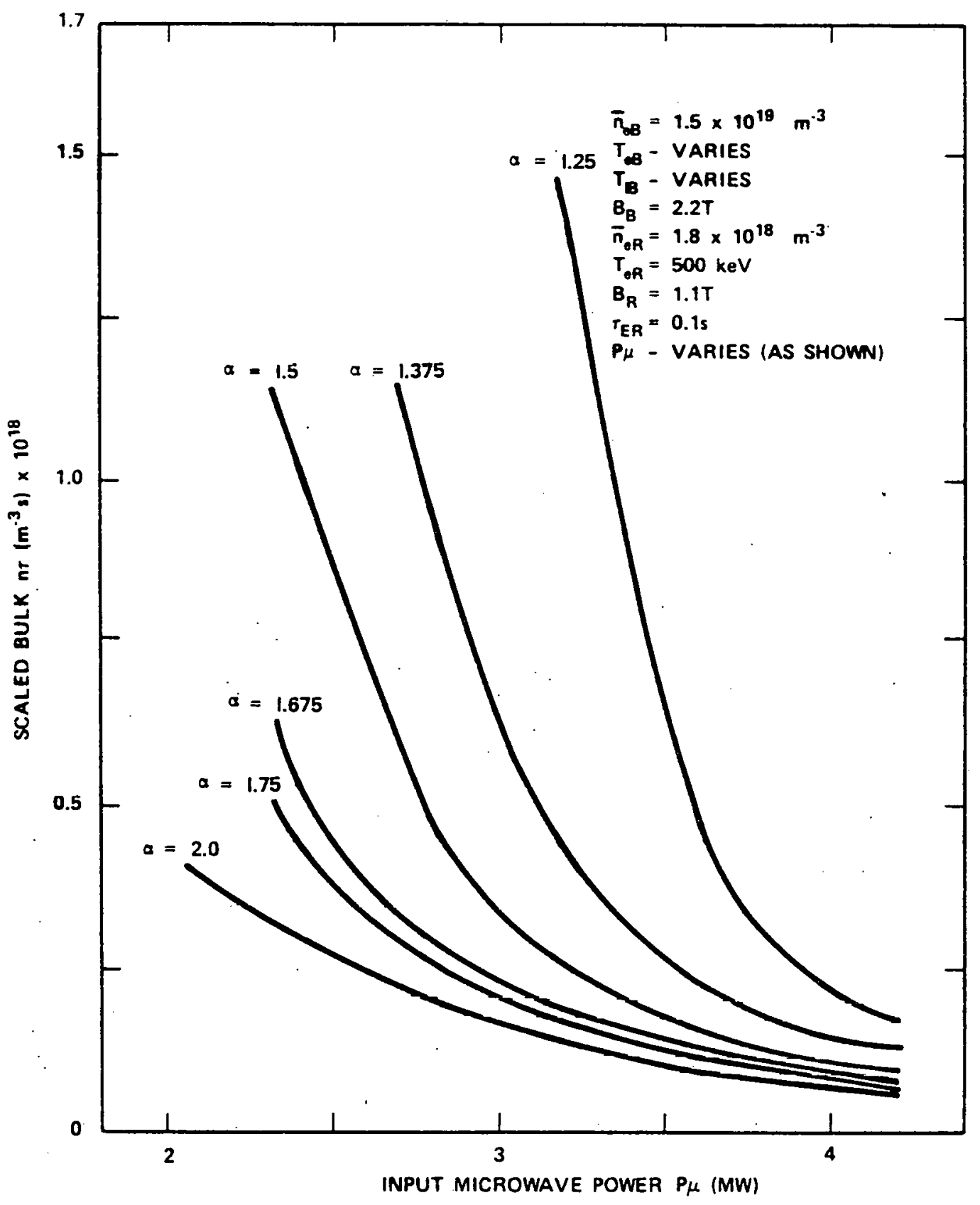

Figure 8-8. Scaled Bulk $n \tau\left(n \tau \propto A c^{2} T_{e} B^{\alpha}\right)$ as a Function of Input Microwave Power for Fixed Density and Scaled Exponent $\alpha$. 


\subsection{CONCLUSIONS}

This report presents a description of the OASIS computer code for the Operational Analysis of EBT Support and Ignition Systems, and summarizes results of preliminary EBT trade studies performed using OASIS. The code is operational in its present form but many necessary updates and improvements are apparent after the trade studies. The trade studies are not exhaustive but represent examples of the types of studies possible using OASIS and represent a starting point for further investigation.

\subsection{EBT PHYSICS AND OASIS MODELING}

The OASIS code model.s EBT ring and bulk plasmas separately and calculates a self-consistent two component plasma description: The coding provides for interaction between the ring and bulk plasma models through the relativistic drag term in the ring radiative power loss model. The physics of EBT plasma particle and energy balance is incorporated in the coding including relativistic effects in the ring plasma model and neutral beam and alpha particle effects in the bulk plasma model.

Results of theoretical analyses of EBT plasmas are incorporated in the code including:

- the criterion for stability of the bulk plasma, viz, bulk beta $\lesssim$ ring beta;

- the cutoff density for microwave penetration into an EBT plasma at a given frequency, viz, $\left.\begin{array}{l}\text { bulk electron density } \\ \text { ring electron density. }\end{array}\right\}$ < cutoff density in the region

- slowing=down theory for neutral beam and alpha particles, viz,

$$
\begin{array}{ll}
\tau_{\text {slowing }} \lesssim & \begin{array}{l}
\tau_{\text {particle }} \\
\text { down }
\end{array} \\
\text { confinement }
\end{array}
$$


In addition, the technological limits of current microwave systems are incorporated in the coding in the form of a check on the condition that the required input microwave frequency for ECRH be less than $120 \mathrm{GHz}$. Finally, in evaluating the results of the trade studies the conditions for the symbiotic relationship between the ring and bulk plasmas for the stability of both components were applied;
1) $15 \% \preccurlyeq$ ring $\beta \leqslant 50 \%$ for bulk stability, and

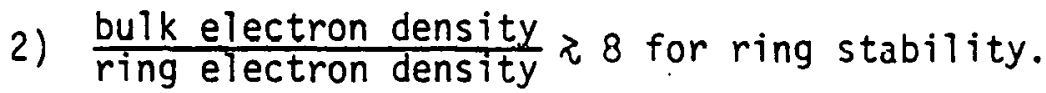

\subsection{STRENGTHS AND WEAKNESSES OF OASIS}

Section 3.0 of this report describes the problem solved by the OASIS code, the method of solution and the input/output characteristics of the code. The code calculations can model EBT devices with ECRH plasma heating in non-beam driven, beam driven, or ignition modes. Experimental devices with a single ion species (e.g., H, D) and reactor-like devices with two ion species (i.e., D-T mixture) can be described. For ignition devices operated with a D-T mixture, alpha particle effects including "hot" and "cold" particle populations, slowing-down theory and alpha power are incorporated in the bulk plasma model. A generalized $n_{\tau}$ scaling law is available in both the ring and bulk plasma models. The method of solution in OASIS incorporates iterative bisection : methods and a self-checking algorithm to achieve high flexibility. Grossly inconsistent input data can normally be handled without termination of the code run. A single plasma description can be obtained using OASIS as well as multiple plasma cases (maximum of ten) in a single code run. The quantity of output data, controlled by the user, ranges from summary tables of key plasma and plasma support systems parameters to complete descriptions of these parameters at each stage of the convergence process.

Code updates, which could improve the plasma and plasma support systems models, include the addition of profile effects, the generalization of the two ion species model to mixtures other than deuterium and tritium, and the addition of a model for the energy exchange between the ring and bulk plasmas through the relativistic electron drag term. Other code improvements which could be made 
when physics models become available include electron-ion energy exchange in the bulk plasma, models for the electron and ion particle confinement times in both the ring and bulk plasmas, and a model for checking the self-consistency of the EBT geometry and magnetic field data (input by the user) with EBT physics.

\subsection{RESULTS OF THE TRADE. STUDIES}

\subsubsection{DEVICE SIZE}

The trade study for EBT machines of various sizes has shown that large changes in required input power and key plasma parameter values result when the size of the device changes. For the baseline set of plasma parameters the total required input power increased by a factor of 2.2 for increases in device major radius from 4.0 to $5.5 \mathrm{~m}$. In addition, for fixed input power the ring electron temperature decreased significantly as the device size increased. Since the stabilizing effect of the ring plasma on the bulk plasma depends sensitively on the ring $B$, increases in device size can produce rings of insufficient $B$ to stabilize the bulk plasma. Also, for fixed input power the bulk density decreased significantly as the device size increased. The stability of the rings is sensitive to the ratio of cold (bulk) electrons to hot (ring) electrons in the ring region. Increases in device size can produce electron density ratios below the criteria for stability. Finally, if $n_{\tau}$ in the bulk plasma scales as $A^{2} \cdot T_{e B} 3 / 2$, then for fixed input power large increases in $T_{e B}$ and scaled $n_{\tau}$ are required for balance as the device size increases. Larger size devices will require better energy confinement for plasma energy balance at fixed input power.

\subsubsection{MODE OF OPERATION - INPUT MICROWAVE FREQUENCY}

The trade study examining several modes of operation for one EBT device has shown that small changes in required input power and key plasma parameters result when the operating ECRH frequency changes. For constant plasma parameters except the balance parameter, changes in required input power of $17 \%$, ring and bulk plasma temperatures of less than $22 \%$ and ring bulk particle densities of less than $21 \%$ were calculated when the magnetic field strength (proportional to the ECRH frequency) changed by a factor of six. However, for operation modes significantiy different than the baseline case $\left(\left|\vec{B}_{C T}\right|=3.16 T\right.$ with $f_{\mu}=55 / 28$ 
$\mathrm{GHz}$ ) the ring $\mathrm{plasma}$ beta was outside the range $15 \%\{$ ring $\mathrm{B} \leqslant 50 \%$. In addition, the bulk and ring electron. densities calculated for energy balance exceeded the cutoff density for microwave propagation in the low field/low frequency cases considered. Since the ring $\beta$ condition for bulk plasma stability and the limit on electron densities for ECRH at a given frequency must be satisfied simultaneously for EBT operation, significantly lower input power levels are required when low field/low frequericy operation is used. High field/ high frequency operation may require high input power to achieve the ring $\beta$ needed to stabilize the bulk plasma. The trade studies presented show trends which represent a first step toward calculating the optimum plasma and plasma support systems conditions for various modes of EBT operation.

\subsubsection{D-T PROOF-OF-PRINCIPLE DEVICE}

The results from the trade studies on device size and mode of operation have been used to estimate the parameter values for a D-T operated EBT with proofof-principle characteristics. Operating conditions for the device presented include: 1) bulk density $\bar{n}_{e B}=1.5 \times 10^{20} \mathrm{~m}^{-3}$; 2) bulk plasma $n_{\tau}=2.25 \times$ $10^{19} \mathrm{~m}^{-3} \mathrm{~s}$; 3) bulk plasma temperature $T_{e B}=15 \mathrm{keV}$; and 4) alpha power $P_{\alpha} \approx 10 \% P_{\text {input }}$. The study showed that energy breakeven in an EBT machine may be difficult since high input microwave power is required (with the absorption coefficients used) to sustain the plasmas at operating conditions which produce comparatively low fusion power. The study also-indicated that significant code improvements may be required to assure convergence in $D-T$ operated proof-of-principle and reactor studies.

\subsection{SENSITIVITY STUDIES}

The effects of changes in microwave power sharing fractions and the bulk electron temperature scaling exponent $\alpha$ (for $n \tau \propto A_{C}{ }^{2} T_{e B}{ }^{\alpha}$ ) on required input power and key plasma parameters have been examined. For variations of $\pm 40 \%$ in the microwave power sharing fractions, with energy conduction losses in each plasma scaled as the input power density, the required total input power decreases by $26 \%$ for $40 \%$ increase in the power sharing fractions and increases by $50 \%$ for $40 \%$ decrease in the power sharing fractions. The effects of increases. in power sharing fractions are different from the effects when the 
fractions decrease due to the scaling assumption on the energy conduction loss term and the changes in its significance relative to other terms in the energy balance equation over the range of power sharing fractions (i.e., energy balance solutions) considered. The bulk plasma temperature and particle densities at balance showed a linear response to changes in power sharing fractions. Ring electron temperature and density obtained at balance showed non linear dependence on power sharing fraction changes when the ring and bulk fractions were changed simultaneously (wi.th the effect most evident in the density balances) due to the coupling of the ring energy balance with the bulk plasma parameters in the relativistic drag loss term. As an example of this coupling, ring electron density decreased by $19 \%$ when bulk power sharing fraction alone increased by $40 \%$ and decreases in bulk power sharing fraction of $40 \%$ produced ring electron density increases of $14 \%$.

Changes in the electron temperature scaling exponent for scaled bulk $n_{\tau}$ a $A_{C}{ }^{2} T_{e B}^{\alpha}$ produce large changes in the bulk electron temperature and scaled $n \tau$ value at energy balance. At constant input power the electron temperature and bulk $n_{\tau}$ at balance decrease as $\alpha$ increases. For constant scaling exponent the balance temperature and $n \tau$ decrease as the input power increases. This trend is consistent with the scaling of the kinetic energy term in the bulk energy balance as $T^{-\beta}$ where $\beta>0$ whenever $\alpha>1.0$. The results of the study show sharp rises in electron temperature and bulk ni required for balance as a approaches 1.0 .

\subsection{FURTHER WORK REQUIRED}

The work summarized in this report represents the beginning of OASIS code development and application for the study of EBT device and plasma performance. The report contains documentation of the code and presentation of results from preliminary trade studies of EBT's using OASIS. Further work of this type is suggested by the results of this study in three areas: 1) continued OASIS code development and update; 2) continued and expanded trade studies of EBT plasmas and plasma support systems performance; and 3) the incorporation of OASIS in a systems code for sizing and costing EBT devices and facilities. 
Work areas for OASIS coding include:

- Modeling the energy coupling between the ring and bulk plasmas through the relativistic drag loss term;

- Profile effects for temperature and particle density in both plasma models;

- Iterative bisection method algorithms in the bulk plasma temperature and particle density balance loops;

- Internal calculation of parameters now required as input (e.g., ring and bulk plasma magnetic field strengths calculated from the fields in the coil throat and midway between the coils);

Areas for OASIS code updates when theoretical models become available include:

- Scaling of energy conduction and particle diffusion losses in EBT plasmas;

- Bulk plasma electron-ion energy exchange;

- Absorbed microwave power sharing in the ring and bulk plasmas;

- Alpha and neutral beam particle slowing-down in EBT plasmas and bumpy torus magnetic fields.

Further trade study work would necessarily include development of procedures for iteration of hand calculations and OASIS code calculations to assure that converged balance solutions are obtained consistent with optimum operating conditions of the device for each case considered. Present theoretical analyses indicate that this means satisfying the criteria for bulk plasma stability, bulk $\beta \leqslant$ ring $\beta$ and $15 \% \leqslant$ ring $\beta \leqslant 50 \%$, and ring plasma stability $\bar{n}_{e B} / \bar{n}_{e R} \approx 8.0$ consistent with an energy and particle balance solution. Additional sensitivity studies would focus on key issues of EBT physics and engineering which effect the power balance such as the assumptions made in calculating the ring and bulk plasma volumes. Finally, the results of this study suggest that significant trade study work is needed to examine whether a positive energy balance can be obtained in an ignited EBT device of reactor size and characteristics. An answer to this question will help to determine the future of EBT as a viable fusion reactor concept. 


\subsection{REFERENCES}

1. D. A. Sink and E. M. Iwinski, "User's Manual for COAST 4, A Code for Costing and Sizing Tokamaks," Westinghouse Electric Corporation, Report WFPS:TME-79-023, September 1979.

2. R. A. Dandl, et al., "Research Program for Plasma Confinement and Heating in ELMO Bumpy Torus Devices," ORNL/TM-4941, June 1975.

3. R. A. Dandl, et al., "The EBT-II Conceptual Design Study," ORNL/TM-5955, September 1978.

4. T. C. Varljen, G. Gibson, et al., "ELMO Bumpy Torus Proof-of-Principle Project Definition Study," WFPS:TME-79-027, October 1979.

5. S. K. Borowski, N. A. Uckan, E. F. Jaeger, and T. Kammash, "A Simple Annulus Power Balance in EBT-I," ORNL/TM-6910, October 1979.

6. T. Kammash, Fusion Reactor Physics:Principles and Technology, 3rd edition, pp 152-6, Ann Arbor Science Publishers, Inc., Ann Arbor MI.

7. D. L. Jassby, "Neutral Beam Driven Tokamak Fusion Reactors," Nuclear Fusion 17, Pp 309-65 (1977).

8. L. Spitzer, Physics of Fully Ionized Gases, pp 78-9, Interscience Publ ishers, Inc., New York NY. 
APPENDIX A

OASIS COMPUTER CODE ABSTRACT

PROGRAM IDENTIFICATION: OASIS, a code for the Operational Analysis of EBT Support and Ignition Systems.

DESCRIPTION OF PHYSICAL PROBLEM SOLVED: OASIS produces a generalized description of the plasma and plasma support systems for an EBT device. Arbitrary plasmas with one ion species (e.g., hydrogen operation) or two ion species (i.e., mixtures of deuterium and tritium) can be described. Both ignition mode and neutral-beam-driven mode of plasma operation are modeled. The plasma engineering calculations involve time independent, zero-dimensional models which account for energy balance in the bulk and electron ring plasma regions, particle balance in the bulk and ring, alpha particle effects in the bulk plasma, slowing-down theory, plasma-plasma and beam plasma fusion reaction rates, impurity effects in the bulk plasma, and $n_{e} \tau_{E}$ scaling. The bulk and electron ring plasma calculations are coupled and the code logic yields a selfconsistent two-component EBT plasma description. The output data may be simply summary tables of important plasma and plasma support systems parameters or complete sets of parameters for the rings and the bulk at intermediate stages of the calculation. The output data are clearly labeled with descriptive titles and appropriate units. The input data can contain up to 200 card images. The input is lengthy since all of the numerical data (except for physical constants) must be supplied by the user, and it was desired to achieve high flexibility for multiple cases in trade-off studies at low cost using a single computer run.

METHOD OF SOLUTION: The OASIS code begins with a complete description of the plasma and plasma support systems parameters supplied as input. This description need not be self-consistent but the specifications of the plasma support systems should be consistent with the EBT device being modeled. Input controls are set to determine the type of calculation performed. The most frequently changed input controls for trade studies are: 1) the controls on the parameter 
to be balanced in the ring and bulk regions (e.g., density, temperature, nt or power requirements); 2) the control on the number of bulk plasma ion species; 3 ) the control on the model of radiation losses from the ring plasma region (five models are provided); and 4) the controls on the generalized scaling law used in the ni calculations for the ring and bulk plasma regions. Messages are printed when ground rules or assumptions are violated and depending on the type of violation the calculation continues or is terminated. In some cases continuation of the calculation may cause fatal errors from the operating system, and the run is terminated in this way.

In several of the OASIS balance loops it was found that the results were so sensitive to changes in the balancing parameters that iterative bisection methods were required for convergence. The bisection algorithm developed includes a self-checking procedure to assure that the iteration is proceeding toward a converged solution. This algorithm provides the capability of handling grossly inconsistent plasma input parameters in a converged calculation.

RESTRICTIONS: The code calculations are limited to specification of plasma and plasma support systems physics and engineering data for steady state EBT devices with one or two ion species. The two ion species option is limited to mixtures of deuterium and tritium. Other plasma and plasma support systems modeling limitations include: 1) RF heating methods are not modeled in detai1; 2) no limiter or divertor parameters are modeled; 3 ) modeling for pellet fueling is not included; 4) radiation losses from the electron rings are not modeled in detai1; 5) transport losses due to energy conduction and particle diffusion are not modeled in detai1;6) electron-ion energy and charge exchange are not mode1ed; 7) profile effects in plasma temperature and density are not modeled. The modeling of D-T operation needs improvement, especially in the area of alpha slowing-down and energy exchange with EBT bulk.plasmas. The modeling of the energy exchange between the ring and bulk plasma regions requires an update incorporating existing theoretical models. In general, the coupling of the ring plasma and bulk plasma calculation will require many updates as better theoretical models become available. Finally, care must be taken when studies involving the size of the device are performed. OASIS models do not include the capability of detecting whether or not the geometry and magnetic field data are consistent 
with EBT physics. When the size of the device is changed the consistency of the size and magnetic field data with EBT physics must be assured with calculations outside of OASIS.

COMPUTER: CDC-7600 at Westinghouse Power Systems Computer Center, Westinghouse Electric Corporation, Pittsburgh, Pennsylvania.

RUNNING TIME: Up to 0.4 seconds of CDC-7600 time is required for a single OASIS run to describe the ring and bulk plasmas in a single EBT device. For' multiple device descriptions or multiple balance parameters on a single device this time is significantiy reduced, e.g., ten device descriptions in a single run will require approximately 2.5 seconds run time. Compilation requires between five and eight seconds of CDC-7600 time.

PROGRAMMING LANGUAGES: OASIS is written in Fortran IV and requires no special computer features.

OPERATING SYSTEM: The code runs under SCOPE' 2.1.5, Level 285.76 with the FTN 4.6 Compiler, Level 452.06 at the Westinghouse Power Systems Computer Center using a COC-7600. A Fortran card image file and an executable binary file are available on the PSCC system.

MACHINE REQUIREMENTS: The standard input/output files used with Fortran compilers are required for OASIS runs. No special files are defined or required.

ACKNOWLEDGEMENT: This work was sponsored by the U.S. Department of Energy, Westinghouse Electric Corporation, and the University of Michigan. 
APPENDIX B

OASIS INPUT DECK

VARIABLE DESCRIPTIONS 
TABLE B-1

OASIS INPUT DECK

Only two formats are used for OASIS input data. An I is entered in the format column of the table for (1016) while an $E$ is entered for (5E12.5). The number of cases in a code run (JSETS) will commonly be a multiple of five.

\section{CARD}

TYPE FORMAT VARIABLE DESCRIPTION/COMMENTS

01 I

$\begin{array}{ll}1-6 & \text { JSETS } \\ 7-12 & \text { JMIN } \\ 13-18 & \text { JMAX }\end{array}$

INDEX $J$ RUNS FROM I TO JSETS

\begin{tabular}{|c|c|c|c|}
\hline 02 & I & $\operatorname{ISCLRO}(j)$ & Ring $n_{\tau}$ Control: $\begin{aligned} 0 & =\text { not scaled } \\
1 & =\text { scaled }\end{aligned}$ \\
\hline 02 & I & $\operatorname{IPLAO}(\mathrm{J})$ & Plasma Type Control: $\begin{aligned} 1 & =\text { single ion } \\
2 & =D-T \text { ions }\end{aligned}$ \\
\hline 02 & I & $\operatorname{IPROO}(\mathrm{J})$ & Profile Control: 1 = flat profiles \\
\hline 02 & $I$ & $\operatorname{IRBALO}(\mathrm{J})$ & Ring Balance Control: $\begin{aligned} 0 & =\text { temperature } \\
1 & =\text { input power } \\
2 & =\text { density } \\
3 & =\text { confinement time }\end{aligned}$ \\
\hline 02 & I & $\operatorname{IONEO}(\mathrm{J})$ & Calculation Control: $0=$ standard \\
\hline 02 & I & $\operatorname{IEDITO}(\mathrm{J})$ & Edit Control: $\begin{aligned} 0 & =\text { full l edit } \\
1 & =\text { summary edit only }\end{aligned}$ \\
\hline 02 & I & $\operatorname{IZERRO}(\mathrm{J})$ & $\begin{aligned} \text { ZEFF Control: } & 0=\text { global calculation } \\
1 & =\text { bul.k plasma } \\
2 & =\text { ring plasma }\end{aligned}$ \\
\hline 02 & $I$ & $\operatorname{IMUO}(\mathrm{J})$ & Power Fraction Control: $\begin{aligned} 0 & =\text { calculated } \\
1 & =\text { input directly }\end{aligned}$ \\
\hline 02 & I & $\operatorname{ILOSSO}(\mathrm{J})$ & Radiation Loss Control (see Table 4-1) \\
\hline 02 & I & $\operatorname{IBBALO}(J)$ & 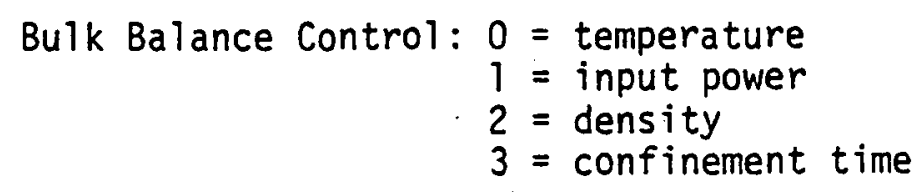 \\
\hline 02 & I & $\operatorname{ISCLBO}(J)$ & Bulk Scaling Control: $\begin{aligned} 0 & =\text { not scaled } \\
1 & =\text { scaled }\end{aligned}$ \\
\hline 02 & I & $N(J)$ & Number of Device Sectors \\
\hline
\end{tabular}




\begin{tabular}{|c|c|c|c|}
\hline $\begin{array}{l}\text { CARD } \\
\text { TYPE }\end{array}$ & FORMAT & VARIABLE & DESCRIPTION/COMMENTS \\
\hline \multirow[t]{5}{*}{03} & I & & \\
\hline & $1-6$ & IIMAX & Maximum Number of Steps \\
\hline & $7-12$ & I2MAXX & Maximum Number of Iterations \\
\hline & $13-18$ & I 3 MAX & $\begin{array}{l}\text { Maximum Number of Passes Through Scaled } \\
\text { nt Loop }\end{array}$ \\
\hline & $19-24$ & LMAX & $\begin{array}{l}\text { Maximum Number of Ring/Bulk Self-Consistency } \\
\text { Iteration }\end{array}$ \\
\hline 04 & E & $\operatorname{NERO}(\mathrm{J})$ & Ring Electron Density \\
\hline 04 & $E$ & $\operatorname{NEBO}(J)$ & Bulk Electron Density \\
\hline 04 & E & $\operatorname{PMUO}(J)$ & Input Microwave Power \\
\hline 04 & E & $\operatorname{WLER}(\mathrm{J})$ & Ring Particle Diffusion Power Density Loss \\
\hline 04 & E & WENER(J) & Ring Energy Conduction Power Density Loss \\
\hline 04 & E & $\operatorname{ERTMPO}(\mathrm{J})$ & Ring Electron Temperature \\
\hline 04 & E. & $\operatorname{BRING(J)}$ & Ring Magnetic Field \\
\hline 04 & $E$ & BBULK(J) & Bulk Magnetic Field \\
\hline 04. & E & EBTMPO(J) & Bulk Electron Temperature \\
\hline 04 & $E$ & $\operatorname{TEERO}(J)$ & Ring Energy Confinement Time \\
\hline 04 & E & $\operatorname{NEC}(\mathrm{J})$ & Mean Surface Plasma Density \\
\hline 04 & $E$ & $\operatorname{ESCT}(J)$ & Aspect Ratio Scaling Exponent \\
\hline 04 & $E$ & $\operatorname{ESC} 2(\mathrm{~J})$ & Electron Temperature Scaling Exponent \\
\hline 04 & E & $\operatorname{ESC} 3(\mathrm{~J})$ & Magnetic Field Scaling Exponent \\
\hline 04 & E & $\operatorname{ESC} 4(J)$ & Plasma Beta Scaling Exponent \\
\hline 04 & E & $\operatorname{ESC5}(J)$ & ZEFF Scaling Exponent \\
\hline 04 & E & $\operatorname{CNTAU}(J)$ & $\mathrm{n \tau}_{\tau}$ Proportionality Constant \\
\hline 04 & $E$ & $\operatorname{RITMPO}(\mathrm{J})$ & Ring Ion Temperature \\
\hline 04 & E & BTMIO(J) & Bulk Temperature of MI Particles \\
\hline 04 & E & $\operatorname{TEEBO}(\mathrm{J})$ & Bulk Energy Confinement Time \\
\hline 04 & $E$ & $\operatorname{PNBO}(\mathrm{J})$ & Neutral Beam Power \\
\hline 04 & $E$ & $\operatorname{PRFO}(\mathrm{J})$ & RF Auxiliary Heating Power \\
\hline 04 & E & WLEB (J) & Bulk Electron Diffusion Power Density Loss \\
\hline 04 & $\dot{E}$ & WLIB $(J)$ & Bulk Ion Diffusion Power Density Loss \\
\hline 04 & $E$ & $\operatorname{WENEB}(\mathrm{J})$ & $\begin{array}{l}\text { Bulk Electron Energy Conduction Power } \\
\text { Density Loss }\end{array}$ \\
\hline
\end{tabular}




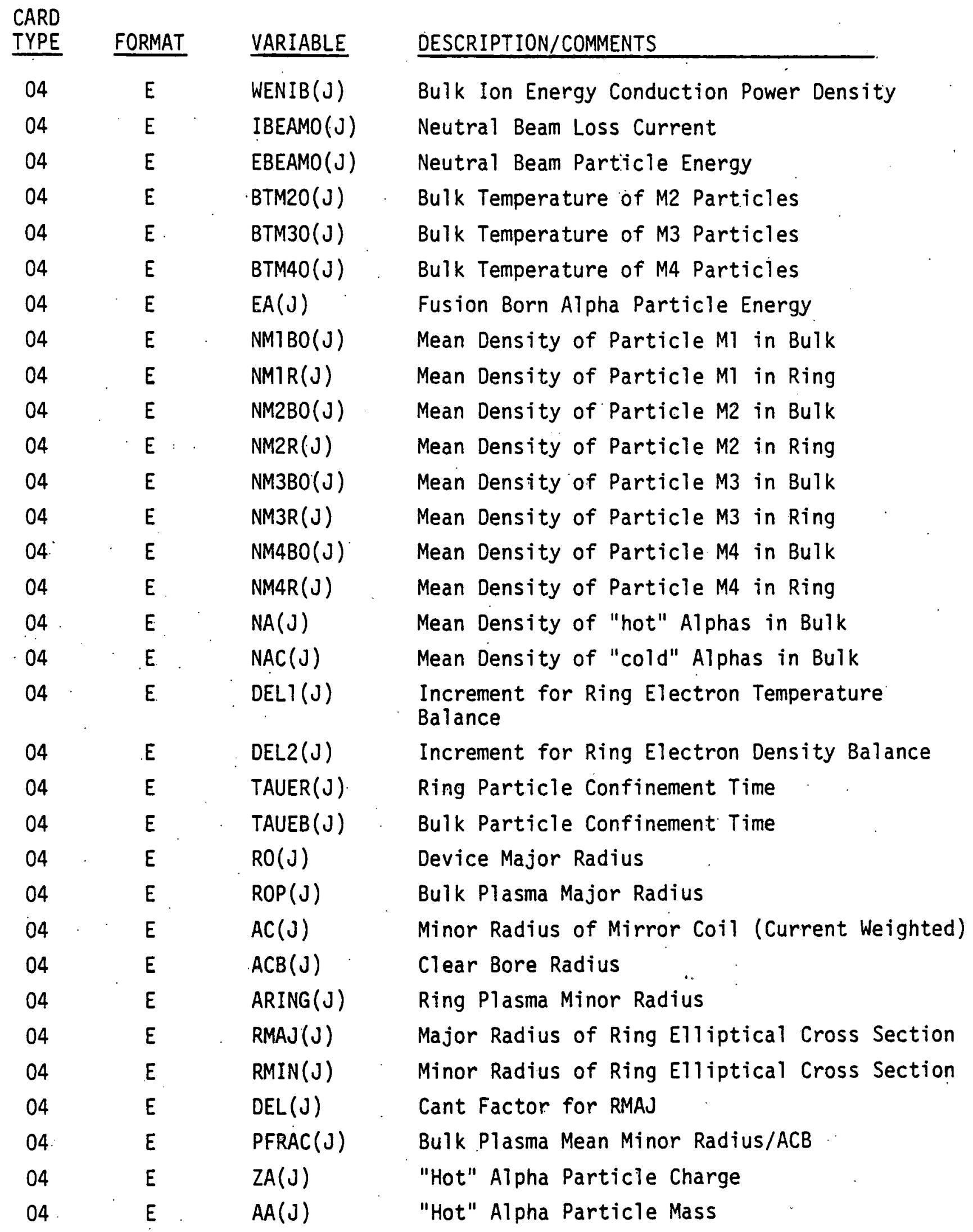




\begin{tabular}{|c|c|c|c|}
\hline $\begin{array}{l}\text { CARD } \\
\text { TYPE } \\
\end{array}$ & FORMAT & VARIABLE & DESCRIPTION/COMMENTS \\
\hline 04 & $E$ & $Z A C(\mathrm{~J})$ & "Cold" Alpha Particle Charge \\
\hline 04 & $E$ & $\operatorname{AAC}(\mathrm{J})$ & "Cold" Alpha Particle Mass \\
\hline 04 & $E$ & $\mathrm{ZMT}(\mathrm{J})$ & Particle MI Charge \\
\hline 04 & $E$ & $\operatorname{AM} 1(J)$ & Particle Ml Mass \\
\hline 04 & E & $\mathrm{ZM} 2(\mathrm{~J})$ & Particle M2 Charge \\
\hline 04 & $E$ & $\operatorname{AM2}(J)$ & Particle M2 Mass \\
\hline 04 & $E$ & $2 M 3(J)$ & Particle M3 Charge \\
\hline 04 & $E$ & $\operatorname{AM} 3(\mathrm{~J})$ & Particle M3 Mass \\
\hline 04 & E & $2 M 4(J)$ & Particle M4 Charge \\
\hline 04 & $E$ & $\operatorname{AM4}(\mathrm{J})$ & Particle M4 Mass \\
\hline 04 & E & $Z I(J)$ & Impurity Ion Charge \\
\hline 04 & $E$ & $A I(J)$ & Impurity Ion Mass \\
\hline .04 & $E$ & $\operatorname{ZNB}(\mathrm{J})$ & Neutral Beam Ion Charge \\
\hline 04 & E & $\operatorname{ANB}(\mathrm{J})$ & Neutral Beam Ion Mass \\
\hline 04 & E & $\operatorname{RFRACO}(\mathrm{J})$ & $\begin{array}{l}\text { Fraction of Input Microwave Power Absorbed } \\
\text { by Rings }\end{array}$ \\
\hline 04 & $E$ & $\operatorname{BFRACO}(\mathrm{J})$ & $\begin{array}{l}\text { Fraction of Input Microwave Power Absorbed - } \\
\text { by Bulk }\end{array}$ \\
\hline 04 & $E$ & $\operatorname{RCPL}(J)$ & Ring Microwave Power Coupling Coefficient \\
\hline 04 & E & $\mathrm{BCPL}(\mathrm{J})$ & Bulk Microwave Power Coupling Coefficient \\
\hline 04 & E & $\operatorname{RDIV}(J)$ & Ring Microwave Power Division Coefficient \\
\hline 04 & E & $\operatorname{BDIV}(J)$ & Bulk Microwave Power Division Coefficient \\
\hline 04 & E & $\operatorname{RBTAUE}(1)$ & $\begin{array}{l}\text { Ratio of Bulk Electron to Ion Particle } \\
\text { Confinement Times }\end{array}$ \\
\hline 04 & E & $\operatorname{RBTEMP}(\mathrm{J})$ & Ratio of Bulk Ion to Electron Temperature \\
\hline 04 & $E$ & FBEAMI (J) & $\begin{array}{l}\text { Fraction of Neutral Beam Energy Deposited } \\
\text { in Bulk }\end{array}$ \\
\hline 04 & E & $\operatorname{FBEAM2}(\mathrm{J})$ & $\begin{array}{l}\text { Fraction of Neutral Beam Particles Retained } \\
\text { in Bulk }\end{array}$ \\
\hline 04 & $\mathrm{E}$ & FRCYC(J) & Fraction of Particles Recycled at the Wall. \\
\hline 04 & E. & $\operatorname{NNBO}(\mathrm{J})$ & Mean "hot" Neutral Beam Particle Density \\
\hline 04 & E & $\operatorname{RLCFF}(J)$ & Radiation Loss Correction Factor \\
\hline 04 & E & $\mathrm{NIO}(\mathrm{J})$ & Mean": "global" Impurity Ion Density \\
\hline 04 & E & $\operatorname{NIIBO}(\mathrm{J})$ & Mean Bulk Impurity Ion Density \\
\hline
\end{tabular}




\begin{tabular}{|c|c|c|c|}
\hline $\begin{array}{l}\text { CARD } \\
\text { TYPE }\end{array}$ & FORMAT. & VARIABLE & DESCRIPTION/COMMENTS \\
\hline 04 & $E$ & $\operatorname{NIIRO}(\mathrm{J})$ & Mean Ring Impurity Ion Density \\
\hline 04 & $E$ & $\operatorname{BMID}(J)$ & $\begin{array}{l}\text { Magnetic Field on the Ring Axis Midway } \\
\text { Between Mirror Coils }\end{array}$ \\
\hline 04 & $E$ & $\operatorname{BCT}(J)$ & $\begin{array}{l}\text { Magnetic Field on the Ring Axis in a Mirror } \\
\text { Coil Throat }\end{array}$ \\
\hline 04 & $E$ & $\operatorname{CCOLL}(\mathrm{J})$ & Collisionality Scaling Constant \\
\hline 04 & E & $\operatorname{RTAUS}(\mathrm{J})$ & $\begin{array}{l}\text { Ratio of Slowing-Down Time to Particle } \\
\text { Confinement Time }\end{array}$ \\
\hline 04 & $E$ & $Q(J)$ & $\begin{array}{l}\text { Background Plasma Correction Factor for } \\
\text { Beam-Plasma Fusions }\end{array}$ \\
\hline $04^{\circ}$ & E & $\operatorname{RNDT}(J)$ & Ratio $N M 2 B /(N M 2 B+N M 3 B)$ \\
\hline 04 & $E$ & FALPHAI (J) & $\begin{array}{l}\text { Fraction of Fusion Alpha Power Absorbed } \\
\text { in Bulk }\end{array}$ \\
\hline 04 & $E$ & FALPHA2 (J) & $\begin{array}{l}\text { Fraction of Fusion Alpha Particles Retained } \\
\text { in Bulk }\end{array}$ \\
\hline 04 & $E$ & $E F(J)$ & Surface Area Correction Factor \\
\hline 04 & $E$ & $\operatorname{AT}(J)$ & Minor Radius of Vacuum Vessel \\
\hline 04 & $E$ & $S C(J)$ & Mirror Coil Width \\
\hline
\end{tabular}

